FACULDADE DE FILOSOFIA, CIÊNCIAS E LETRAS DE RIBEIRÃO PRETO DEPARTAMENTO DE PSICOLOGIA E EDUCAÇÃO PROGRAMA DE PÓS-GRADUAÇÃ̃ EM PSICOBIOLOGIA

\title{
Atratividade Facial e Cirurgia Ortognática: Aspectos Físicos e Emocionais
}

Luciana Maria da Silva

Tese apresentada à Faculdade de Filosofia, Ciências e Letras de Ribeirão Preto da Universidade de São Paulo, como parte das exigências para obtenção do título de Doutor em Ciências, Área de Concentração: Psicobiologia.

Ribeirão Preto - SP

2009 
UNIVERSIDADE DE SÃO PAULO

FACULDADE DE FILOSOFIA, CIÊNCIAS E LETRAS DE RIBEIRÃO PRETO DEPARTAMENTO DE PSICOLOGIA E EDUCAÇÃO PROGRAMA DE PÓS-GRADUAÇÃO EM PSICOBIOLOGIA

\title{
Atratividade Facial e Cirurgia Ortognática: Aspectos Físicos e Emocionais
}

\author{
Luciana Maria da Silva \\ Orientador: Prof. Dr. Sérgio Sheiji Fukusima \\ Tese apresentada à Faculdade de Filosofia, \\ Ciências e Letras de Ribeirão Preto da \\ Universidade de São Paulo, como parte \\ das exigências para obtenção do título de \\ Doutor em Ciências, Área de \\ Concentração: Psicobiologia.
}

Ribeirão Preto - SP 
AUTORIZO A REPRODUÇÃO E DIVULGAÇÃO TOTAL OU PARCIAL DESTE TRABALHO, POR

QUALQUER MEIO CONVENCIONAL OU ELETRÔNICO, PARA FINS DE ESTUDO E PESQUISA, DESDE QUE CITADA A FONTE.

\section{FICHA CATALOGRÁFICA}

Faculdade de Filosofia, Ciência e Letras de Ribeirão Preto da Universidade de São Paulo

Silva, Luciana Maria da

Atratividade Facial e Cirurgia Ortognática: Aspectos Físicos e Emocionais. Ribeirão Preto, 2009.

125 p.: fig. $30 \mathrm{~cm}$.

Tese apresentada à Faculdade de Filosofia, Ciências e Letras de Ribeirão Preto, Universidade de São Paulo, Departamento de Psicologia e Educação.

Área de concentração: Psicobiologia

Orientador: Prof. Dr. Sérgio Sheiji Fukusima.

1. Atratividade Facial

2. Cirurgia Ortognática

3. Percepção de Faces 
À Minha MÃE, que me ensinou a serforte $e$ ao DÁRIo, que divide sua força comigo. 


\section{AGRADECIMENTOS}

Agradeço a Deus por abençoar minha vida, me conduzir nos seus braços e me proporcionar conquistas como esta.

Aos meus queridos pais, Ana Maria, minha mãe que me fortalece a cada dia, ensinando que a luta é grande, mas Deus é sempre maior e em memória de meu pai, Geraldo, que dedicou sua vida a me ensinar que as maiores virtudes de uma pessoa de bem são humildade, respeito e muito trabalho. Esta conquista também é de vocês!

Ao Dário, meu amado, companheiro de todas as horas, que me dá forças de superar cada obstáculo e seguir em frente. Obrigada por compartilhar sua vida comigo e me proporcionar crescimento a cada dia.

Ao Prof. Dr. Sérgio S. Fukusima pela atenção, paciência e orientação nestes quase dez anos de trabalho conjunto.

Aos meus queridos sobrinhos, Gabi, que me socorre sempre nos assuntos da informática e Léo, que me alegra com seu sorriso meigo, lindo e sua risada gostosa.

As minhas irmãs queridas, Bel, Fer e Drica, quase mães e que se dedicam em cuidar de mim mesmo de longe.

Aos meus sogros, Sr. Edson e Vastir, pelo carinho, cuidado e amor de pais. Também a extensão da família: Anne, Fabiano, Fabiola, Fabrizio, Fernando, Juninho e Carol, obrigada pela força e carinho.

Ao CEDEFACE (Centro de Pesquisa e Tratamento das Deformidades Buco-Faciais), principalmente ao psicólogo Ocimar Eiras e ao presidente Dr. Roberto Della Coleta, que autorizaram o contato e a coleta de dados nesta séria e respeitável clínica da cidade de Araraquara, SP. 
As amigas e secretárias do CEDEFACE Bel, Denise e Graça. Vocês foram fundamentais neste trabalho. Obrigada pelo carinho e dedicação.

Aos pacientes que, no seu anonimato e boa vontade, possibilitaram a realização deste estudo e a todos aqueles que participaram como voluntários nos Experimentos.

A minha querida amiga Fabiola, que mesmo na distância não cansa de dizer que sua amizade é sincera e leal. Esta irmã é do coração e pra sempre.

A Renata, secretária da psicobio, sobretudo pelo carinho, amizade, atenção e dedicação em todos os momentos desta dura caminhada.

Ao pessoal do laboratório, os 'antigos': Ana Irene, Adriana Bacci, Adriana Panico, Nelson, Kátia, Silvia e os 'novatos': Bruno, Léo, Lina e Cíntia. Agradeço a todos vocês por dividir esta árdua tarefa de ser um pós-graduando, em todas as traduções que esta palavra possa ter. Um abraço especial para Maria Amélia e Patrícia pelo carinho e amizade.

Aos amigos da Psicobio: Junior, Joseane, Kátia Maria, Claudinha, Milena, Maria Cecília, Raquel, Júlia, Karina, Milene, Veridiana, Marcelo, Carlo, Lucas, Mikael, todos os amigos que nunca vão sair da minha memória, pelos longos anos passados juntos. Um beijo especial à Joseane, que 'me carregou no colo' no momento mais difícil da coleta de dados.

Ao Igor, técnico do laboratório, pela disponibilidade e boa vontade de sempre ajudar.

Ao Prof. Dr. Alexandre Elias Trivellato, Prof. Dr. Cássio Edvard Sverzut pelas preciosas contribuições durante o exame de qualificação.

Ao Prof. Dr. Sebastião de Sousa Almeida, pelas contribuições durante estes quatro anos de assessoria e também no exame de qualificação.

Aos professores que compõem esta banca de defesa de doutorado, pelos valiosos aportes para meu crescimento pessoal e profissional.

Ao Conselho Nacional de Desenvolvimento Científico e Tecnológico (CNPq) pela concessão da bolsa de doutorado e pelo auxílio financeiro para realização desta pesquisa. 
A perfeição é feita de pequenos detalhes

- não é apenas um detalhe.

(Michelangelo) 


\section{RESUMO}

\section{Silva, L. M. da. Atratividade Facial e Cirurgia Ortognática: Aspectos Físicos e}

Emocionais. 2009. 126f. Tese (Doutorado) - Faculdade de Filosofia Ciências e Letras de Ribeirão Preto, Universidade de São Paulo, Ribeirão Preto. 2009.

Pessoas que apresentam grandes deformidades dentofaciais podem ter prejuízos sociais, pessoais e emocionais. A cirurgia ortognática é utilizada para correções dessas deformidades, que consequentemente afeta as aparências das faces dos pacientes. Este estudo teve como objetivos: 1) Avaliar amostras de faces da população de Ribeirão Preto, SP e as faces prototípicas provenientes delas, consideradas sem deformidades; 2) Analisar a atratividade facial de dez pacientes submetidos a cirurgias ortognáticas nas fases pré e pós-cirúrgicas; ao relacionar suas atratividades aos parâmetros físicos alterados pela cirurgia; e também avaliar as consequências na qualidade de vida, ansiedade e auto-estima destes pacientes. As análises faciais foram frontais e obedeceram aos critérios preconizados na literatura de meios, terços e quintos faciais. A coleta de dados com os pacientes foi feita no CEDEFACE (Centro de Pesquisa e Tratamento das Deformidades Buco-Faciais). Foram obtidas fotografias nas fases pré e pós-cirúrgicas; momentos em que também foram aplicadas escalas de qualidade de vida (WHOQOL bref), de ansiedade (IDATE e Escala Analógica de Humor) e autoestima (Escala de Autoestima de Rosenberg). Dois experimentos foram realizados. Um com as fotos das faces pré e pós-cirúrgicas a fim de avaliar a atratividade facial dos pacientes antes e depois das cirurgias e outro para comparar a atratividade facial dos pacientes com a atratividade de faces prototípicas relativas ao sexo e etnia correspondentes. Nesses experimentos os julgamentos de atratividade foram provenientes de uma amostra de 40 participantes leigos. Os resultados apontaram que: 1) As análises do banco de faces e protótipos apresentaram parâmetros físicos faciais diferentes daqueles apontados na literatura, principalmente na 
análise dos terços e quintos; 2) A cirurgia ortognática contribuiu para o aumento da atratividade dos pacientes, embora estes ainda considerados menos atrativos que as faces prototípicas. Também foram notadas melhoria na condição psicológica por meio do Whoqol bref e diminuição da ansiedade por meio da Escala Analógica de Humor. Tais resultados apontam para a importância de estudos sobre parâmetros físicos faciais relacionados à melhoria de sua estética e que a cirurgia ortognática para o tratamento de deformidades dentofaciais pode trazer benefícios estéticos e emocionais àqueles que a procuram.

Palavras-chave: Percepção de Faces, Atratividade Facial, Cirurgia Ortognática. 


\begin{abstract}
Silva, L. M. da. Facial Attractiveness and Orthognatic Surgery: Emotional and Physical Aspects. 2009. 126f. Thesis (Doctoral) - Faculdade de Filosofia Ciências e Letras de Ribeirão Preto, Universidade de São Paulo, Ribeirão Preto. 2009.
\end{abstract}

People with salient dentofacial deformities can have social, personal and emotional injury. The orthognathic surgery is used to correct these deformities, and consequently, it affects the facial appearances of the patients. The general aims of this study were: 1) Evaluate samples of faces from a population of Ribeirão Preto, SP and their prototypical faces considered as without deformities; 2) Analyze the facial attractiveness of ten patients before and after being submitted to orthognathic surgery; searching the relationship between the attractiveness and physical parameters modified on the faces by the surgery; and also assessing the effects of this surgery on the quality of life, the anxiety and the self-esteem of these patients. The facial analyses were frontal and from the halves, the thirds and the fifths of the faces. The pictures of faces before and after the orthognathic surgery were from voluntary patients from CEDEFACE (Centro de Pesquisa e Tratamento das Deformidades Buco-Faciais) at Araraquara, SP. Before and after the surgery, these patients also had their quality of life (by WHOQOL bref scale), the anxiety (by IDATE and Escala Analógica de Humor) and the selfesteem (by Escala de Auto-Estima de Rosenberg) evaluated. There were two experiments. From an experiment, forty volunteers judged the attractiveness of the faces pictured before and after the surgery. From the other experiment, the volunteers compared the attractiveness of the patient faces with the attractiveness of the prototypical faces, respectively to their sex and race. The results showed that: 1) The facial analyses of the faces from population sample of Ribeirão Preto, SP, and their prototypical faces indicated physical parameters that differ from the literature, mainly for the facial analyses of the thirds and the fifths 2) The orthognathic surgery contributed to increase the facial attractiveness of the patients, although 
they were still considered less attractive than the prototypical faces. Improvement in psychological condition, assessed by the Whoqol bref, and anxiety decrement, assessed by the Escala Analógica de Humor, were noticed. These results pointed out the importance to study facial analyses related to the aesthetic improvement, and that the orthognathic surgery to treat dentofacial deformities can bring aesthetic and emotional benefits to the patients.

Key-words: Face Perception, Facial Attractiveness, Orthognatic Surgery. 


\section{SUMÁRIO}

1. INTRODUÇÃO 12

2. OBJETIVOS GERAIS DO TRABALHO 29

3. MÉTODO 31

3.1) Análise Facial do Banco de Faces e Protótipos 31

Resultados 34

Faces Brancas $\quad 34$

Faces Pretas $\quad 42$

$\begin{array}{ll}\text { Faces Pardas } & 48\end{array}$

Discussão $\quad 54$

3.2) Análise Facial dos Pacientes Submetidos à Cirurgia Ortognática e Investigação da Atratividade dos Mesmos 62

3.2.1) Análise Facial 62

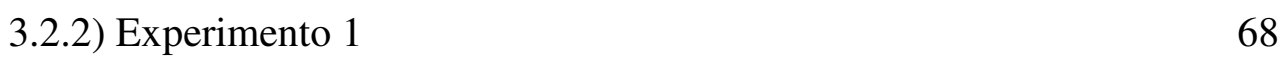

$\begin{array}{ll}\text { Resultados } & 69\end{array}$

$\begin{array}{ll}\text { Discussão } & 75\end{array}$

3.2.3) Experimento 2 79

$\begin{array}{ll}\text { Resultados } & 81\end{array}$

$\begin{array}{ll}\text { Discussão } & 84\end{array}$

3.3) Investigação da Qualidade de Vida, Ansiedade e Autoestima dos Pacientes Submetidos à Cirurgia Ortognática. $\quad 88$

Resultados $\quad 93$

$\begin{array}{ll}\text { Discussão } & 99\end{array}$

4. DISCUSSÃO GERAL 103

5. REFERÊNCIAS 106

$\begin{array}{ll}\text { 6. ANEXOS } & 114\end{array}$ 


\section{1) Introdução}

A aparência física de um indivíduo é uma característica importante a considerar tanto no contexto de relações interpessoais quanto no contexto evolutivo. A atratividade física sinaliza boa saúde, qualidade genética e outros fatores que influenciam na evolução das espécies, uma vez que aparência física 'agradável’, harmoniosa indica que o organismo teve um bom desenvolvimento fisiológico e orgânico, sendo sinal de saúde do mesmo (MILLER, 2000; FINK; PENTON-VOAK, 2002; PENTON-VOAK; PERRETT, 2000; SCAVONE JUNIOR et al., 2006).

Traços físicos podem servir de indícios sobre a saúde, a qualidade genética, o estado do sistema imunológico e outros fatores que influenciam na busca de parceiros saudáveis, com fins de procriação e disseminação genética, nas mais diferentes espécies animais (MILLER, 2000).

No campo cultural e social, principalmente no contexto de relações interpessoais, o conceito de atratividade e de senso estético varia muito entre regiões e épocas distintas e tem um cunho bastante subjetivo, fortemente influenciado pela sociedade, cultura e autoimagem (BRUCE; YOUNG, 1998; ENLOW, 1993; HABBEMA, 2004; KERR; DORTH; O’DONNELL, 1990; MILLER, 2000; ONG, 2004; PHILLIPS; PROFFIT, 2005).

Diante de diversos outros atributos físicos observáveis no corpo humano, a face destaca-se por desempenhar um papel de 'cartão de visita' de quem se olha, sendo também um importante canal de comunicação, tanto pela fala como também por sua expressividade (OMOTE, 1994).

A noção de identidade está intimamente relacionada às características físicas faciais, e a partir das diferentes variações entre os elementos faciais comuns (dois olhos, nariz, boca, bochechas, testa, orelhas, formato do rosto), há a produção das mais diversas formas de rostos que caracterizam cada ser humano como único (ENLOW, 1993). 
A atratividade facial é um amplo campo de estudo dentro deste contexto, e as diferentes combinações e harmonizações físicas dentro deste estímulo padrão produzem faces medianas, agradáveis ou desagradáveis. Como consequência a percepção destas pequenas e sutis diferenças individuais afetam o modo como as pessoas são julgadas, bem como os relacionamentos interpessoais (FAURE; RIEFLE; MALTHA, 2002; OMOTE, 1994).

Muitas são as consequências sociais envolvidas na estética pessoal e facial. Pessoas com alta atratividade tendem a serem percebidas como mais adequadas e competentes e serem mais favorecidas que as de baixa atratividade (OMOTE, 1991). Pessoas com faces atraentes são julgadas como mais inteligentes e com maior probabilidade de obterem sucesso do que as não atrativas (FAURE; RIEFLE; MALTHA, 2002), além de serem mais preferidas em escolhas sexuais (HENDERSON; ANGLIN, 2003; PERRETT et al., 1999). Chen, German e Zaidel (1996) relataram que indivíduos atrativos normalmente recebem mais reações positivas de outras pessoas que as menos atrativas.

No contexto evolutivo, a evolução sexual da espécie humana privilegiou traços físicos faciais que mostram características potencialmente importantes para os indivíduos, como o sucesso da reprodução e sobrevivência dos descendentes (ENQUIST et al., 2002; MEALEY; BRIGSTOCK; TOWSEND, 1999). Estudos sobre psicologia evolutiva mostram que faces atraentes são preferidas em escolhas sexuais a faces não atraentes (HENDERSON; ANGLIN, 2003; PERRETT et al., 1999).

Segundo Thornhill e Gangestad (1999) existem três grandes áreas de estudo sobre atratividade facial: simetria (RHODES et al., 1998, 2001; SILVA, 2005; SWADDLE; CUTHILL, 1995), proporções e harmonizações entre os elementos (FRIEDENBERG, 2001; SUGUINO et al., 1996) e características sexuais secundárias, como textura e cor da pele (JONES et al., 2004). 
Alguns destes estudos dão indícios que tais atributos podem ser considerados como possíveis indicadores de um 'padrão' de atratividade para a face humana, mas com algumas restrições. Em estudos prévios foi verificado que a simetria isoladamente não pode ser considerada como um fator preponderante na atratividade facial (SILVA; ALVES; FUKUSIMA, 2004; SILVA, 2005). Foi demonstrado que a simetria deve ser considerada em conjunto com manipulação de outros elementos faciais, como tonalidade e luminância da pele e elementos faciais externos, para que uma face possa se tornar mais atrativa (KERR; DORTH; O’DONNELL, 1990; SILVA; ALVES; FUKUSIMA, 2004; SILVA, 2005; PROFFIT; SARVER, 2005).

Em outra teoria sobre atratividade facial relata-se que faces atrativas possuem aparência próxima à média matemática das faces da população estudada, que seria uma face prototípica (RHODES; TREMEWAN, 1996; RHODES; SUMICH; BYATT, 1999; RHODES; SIMMONS; PETERS, 2005). Uma face será julgada como mais atraente quanto mais ela tiver aparência próxima do protótipo de sua raça (LANGLOIS; ROGGMAN, 1990; RHODES; TREMEWAN, 1996; RHODES; SUMICH; BYATT, 1999; O’TOOLE et al., 1999).

Faces prototípicas são imagens faciais que representam a aparência típica de um grupo de pessoas, podem ser representativas de categorias como sexo, raça ou idade. Por ser o protótipo a média matemática dos valores dos traços de uma população, obtida pela sobreposição de diferentes faces de uma mesma categoria, as análises faciais de protótipos indicam a tendência de características físicas faciais daquela população (RHODES; TREMEWAN, 1996; RHODES; SIMMONS; PETERS, 2005; RHODES; SUMICH; BYATT, 1999; RHODES, 2006; O’TOOLE et al., 1999).

Contudo, o conceito de atratividade e de senso estético vai além das características físicas, é muito pessoal, subjetivo, com múltiplas influências no cotidiano. Da mesma maneira 
que uma face atrativa pode 'abrir portas' a um indivíduo, o contrário pode se tornar um empecilho na vida de alguém. Pessoas com grandes distorções faciais - e por isso, pouco atrativas - são, até certo ponto, prejudicadas por sua aparência 'fora do padrão', no contexto de relacionamentos interpessoais (NEWELL; MARKS, 2000; PROFFIT; WHITE JUNIOR, 2005; OMOTE, 1994).

Estudos sugerem que os efeitos da atratividade facial estão presentes desde muito cedo no estágio do desenvolvimento infantil. Bebês de dois meses já demonstram preferências para faces consideradas atrativas por adultos (SAMUELS et al., 1994; LANGLOIS et al., 1997 apud RHODES et al., 1998). O comportamento de crianças pré-escolares (entre 3 a 6 anos) parece ser também bastante influenciado pelos efeitos de uma face bela.

O desenvolvimento da interação social parece acontecer de maneira mais tranquila em crianças que não apresentam nenhuma disfunção ou alteração em suas formas e funções faciais (RUMSEY, 1983 apud NEWELL; MARKS, 2000). Crianças com algum problema ortopédico ou ortodôntico, aliado a algum tipo de deformidade dentofacial, não costumam ser tão populares, estimadas e benquistas por amigos, colegas quanto aquelas sem problemas desta natureza.

Nesta perspectiva, pessoas que apresentam deformidades dentofaciais, seja em nível estético ou estético/funcional, podem se defrontar com empecilhos no convívio e na interação social; além de dificuldades em relação consigo mesma (NEWELL; MARKS, 2000; PHILLIPS; PROFFIT, 2005). As deformidades dentofaciais são desvios nas proporções faciais normais e relações dentárias que afetam em graus variáveis a função e/ou de aceitabilidade social. Tais discrepâncias entre maxila e mandíbula não podem ser tratadas apenas ortodonticamente, havendo necessidade de intervenções cirúrgicas (PROFFIT; WHITE JUNIOR, 2005), denominadas cirurgias ortognáticas. 
Os indivíduos que apresentam tais deformidades são afetados de dois modos: comprometimento nas funções maxilomandibulares, o que gera dificuldades principalmente na mastigação, dicção, respiração e comprometimento nas aparências dentária e facial, com consequentes discriminações no âmbito social (PROFFIT; WHITE JUNIOR, 2005).

Procedimentos cirúrgicos nestes casos podem variar de pequenas movimentações de grupos dentários até a movimentação completa da mandíbula e/ou maxila. Estas movimentações vão depender do tipo de problema apresentado pelo paciente e do tipo de planejamento traçado para melhorias estéticas e funcionais no mesmo (PROFFIT; TURVEY, 2005).

Como dito anteriormente cada ser humano é dotado de características únicas que lhe conferem identidade e exclusividade facial. Contudo existem características semelhantes que configuram as diferentes faces humanas, que servem para categorização e estudo das mesmas (ENLOW, 1993). Mesmo com suas diferentes peculiaridades, os formatos da cabeça e da face dependem crucialmente do tamanho e posição do cérebro bem como da maneira que o homem evoluiu para andar, tornando-se ereto e bípede (BRUCE; YOUNG, 1998; ENLOW, 1993). Por se um animal predominantemente visual, a configuração facial reflete adaptações sensoriais, alimentares, linguísticas e sociais que a espécie humana sofreu ao longo do tempo (BRUCE; YOUNG, 1998).

As diferenças de formatos e características faciais também dependem dos hormônios masculinos e femininos, que configuram características marcantes nos homens e mulheres, diferenciando-os. De uma maneira geral homens têm os narizes mais proeminentes que tendem a voltar-se para baixo se comparados aos das mulheres; que por sua vez possuem narizes arredondados, menos protrusivos e voltados para cima. A testa masculina tende a ser mais inclinada e os olhos mais profundos, em contraste com a testa vertical da mulher e seus olhos mais salientados. As bochechas femininas são aparentemente mais proeminentes do que 
as dos homens devido aos formatos da testa e do nariz e o queixo é mais arredondado. A face feminina tem características próximas a de um bebê, mais arredondada e curta no geral (BRUCE; YOUNG, 1998; ENLOW, 1993).

Existem diferentes classificações a partir de estudos sobre a forma da cabeça e os tipos faciais e oclusais. Na literatura relata-se que existem três tipos básicos de formas da cabeça: 1) Dolicocéfalo - de forma ovalada, horizontalmente longa e relativamente estreita; 2) Braquicéfalo - forma arredondada, com características mais curtas e mais alargadas no sentindo horizontal e 3) Mesocéfalo - tipo médio que se encontra entre estas duas classificações (ENLOW, 1993). Os diferentes tipos faciais e oclusais estão diretamente relacionados com estas formas de cabeça.

As classificações segundo os perfis faciais são também três e são orientadas pelo traçado de uma linha vertical que passe pela boca e queixo, perpendicular a uma linha horizontal que se estende do centro da órbita: 1) Ortognata - denominado 'queixo quadrado' é considerado um bom perfil, pois o ângulo facial é quase reto e a linha vertical toca o lábio superior e o queixo; 2) Retrognata - perfil de aparência convexa em que a linha vertical fica na frente do queixo e o lábio superior é retrusivo (para trás) e 3) Prognata - perfil de aparência côncava em que a ponta do queixo é para frente da linha vertical e o lábio inferior está à frente do superior (ENLOW, 1993).

Com relação aos padrões oclusais existem as categorias, segundo Angle (1907, apud ENLOW, 1998): Classe I (oclusão normal), Classe II (mandíbula retruída e/ou maxila protruída), Classe III (maxila retruída e/ou mandíbula protruída). Estes problemas podem ser piorados com assimetrias de mandíbula e/ou maxila, advém de padrões de crescimento anormais ou acidentes (ENLOW, 1993; PROFFIT; TURVEY, 2005). Grandes assimetrias faciais, da maxila e mandíbula, são facilmente observadas em exames clínicos e 
frequentemente estão presentes em pacientes com deformidades dentofaciais (PROFFIT; TURVEY, 2005).

Tais problemas, segundo Enlow (1993) podem advir de malformações (defeito morfológico de um órgão, parte dele ou de partes do corpo por consequência de desenvolvimento anormal embrionário - fenda palatina, por exemplo), deformações (forma ou posição anormal de uma região do corpo causada por forças mecânicas no período fetal deformações da mandíbula, por exemplo) ou disrupções (defeito morfológico que resulta de uma ruptura ou interferência no desenvolvimento fetal normal - ocorrência esporádica).

Estudos nas áreas de ortodontia e cirurgia bucomaxilofacial (ortognática) buscam trazer contribuições e soluções para se obter um maior equilíbrio estético e funcional na face, ao corrigir problemas oclusais, de malformações e/ou deformações. As consequências destas intervenções podem gerar melhorias na qualidade de vida e na qualidade das relações interpessoais de quem sofre com tais problemas (LAUREANO FILHO et al., 2003). A harmonia entre os diferentes elementos faciais é um dos pontos principais neste tipo de cirurgia (SUGUINO et al., 1996) e, na grande maioria das vezes, são usadas relações matemáticas para atingir objetivos de melhoria na estética facial.

O conceito de Beleza, segundo Eco (2004), remonta à percepção do que é bom e nos agrada; aquilo que atrai o olhar e estimula o desejo. Na Grécia antiga ela estava associada a outras qualidades como justiça e conveniência. A arte grega destacava a visão subjetiva na avaliação da beleza e suas esculturas, baseadas em cânones de proporções de corpos e faces, traduziam ideais da beleza psicofísica, com harmonização do corpo e da alma: a beleza das formas e a bondade da alma.

Estas concepções de beleza clássica ainda hoje subjazem o imaginário coletivo e influenciam os julgamentos em todo momento, relacionando o que é belo ao que é bom, inclusive entre os seres humanos. 
Com Pitágoras, uma visão estético-matemática do universo relaciona a beleza, a harmonia e a simetria. Contudo foi percebido que a simetria sozinha não dava conta dos fascínios que uma bela escultura poderia provocar. Dois séculos mais tarde, Policleto enfatizou as proporções entre os elementos corpóreos ao produzir uma estátua chamada de 'Cânone', onde se colocaram todas as regras de uma justa proporção e não mais no equilíbrio dos elementos iguais como na simetria (ECO, 2004).

Policleto é considerado o formulador da antropometria clássica grega. Ele determinou proporções 'objetivas’ e ‘orgânicas’ no corpo humano normal que levavam em consideração a sua flexibilidade; sem predeterminar dimensões tecnicamente estabelecidas como na arte estática dos egípcios, dominada por um código mecânico e estático (PANOFSKY, 1976).

As palavras de Cláudio Galeno (século II apud ECO, 2004, p. 75) traduzem o ideal de beleza da época:

\footnotetext{
“(...) Beleza não reside nos elementos singulares, mas na harmoniosa proporção das partes, na proporção de um dedo em relação ao outro, de todos os dedos em relação à mão, do resto da mão em relação ao pulso, deste em relação ao antebraço, do antebraço em relação a todo o braço. Enfim, de todas as partes em relação a todas as outras, como está escrito no cânone de Policleto."
}

Neste sentido, ainda hoje, as proporções entre os atributos físicos da face humana também são utilizadas como parâmetro 'ideal' de beleza. Vários métodos, baseados em tais relações matemáticas e em cânones neoclássicos, são utilizados para analisar faces no campo ortodôntico e cirúrgico. Com a finalidade de planejar intervenções em pacientes com problemas faciais estéticas ou funcionais as análises cefalométricas são um dos instrumentos mais populares. Tais procedimentos padronizados têm a finalidade de coletar dados e obter informações referentes à situação dos tecidos ósseos do paciente (LAUREANO FILHO et al., 2003).

Villela (1998) relata que as análises de radiografias cefalométricas de perfil foram as primeiras a serem utilizadas pelos ortodontistas neste campo, e foram consideradas suficientes 
para estabelecer normas clínicas; no final da década de 1960, com o desenvolvimento de programas computadorizados para cefalometria e maior compreensão das mesmas, a análise frontal - com o diagnóstico das assimetrias faciais - começou a ser valorizada.

Suguino et al. (1996) fizeram uma revisão dos métodos analisando aqueles destinados à avaliação do tecido duro (radiografias cefalométricas) e do tecido mole, tanto de vista frontal quanto lateral. Estes pesquisadores enfatizam que, na visão frontal, a face deve ser examinada na avaliação da simetria bilateral, proporções de tamanho da linha mediana às estruturas laterais e proporcionalidade vertical. O plano estético de Ricketts é um dos métodos mais utilizados neste tipo de análise frontal e baseia-se, na medida de proporção áurea e descreve uma estética facial excelente (SUGUINO et al., 1996).

A análise cefalométrica no plano frontal apresentada por Ricketts é capaz de estabelecer padrões esqueléticos e dentários do paciente, através de distâncias lineares, leva em conta a idade do mesmo e complementa a análise de perfil do paciente (VILLELA, 1998). Na análise de Ricketts a face é analisada segundo padrões normativos em cinco campos diferentes: Problema Dentário, Problema Esquelético, Dentoesquelético, Relação Craniofacial e Estrutural Interno.

Outro método utilizado neste campo de exame facial frontal é a análise dos tecidos moles da face. Gregoret et al. (1999) recomendam que este tipo de estudo seja feito com fotografias que deverão estar em perfeita orientação da cabeça, com paralelismo ao solo. Como na análise cefalométrica também são estudadas as simetrias da face, contudo em função da configuração da face total e não somente em sua configuração óssea.

O estudo frontal fornece informações sobre as dimensões verticais, a linha média, níveis faciais e contorno da face. Nesta análise, no sentido horizontal são considerados os terços: superior, médio e inferior da face; e no sentido vertical é importante dividi-la em quintos 
faciais, sendo estes importantes para o aprofundamento do estudo das assimetrias (GREGORET et al., 1999). Estas relações são mostradas na Figura 1 (I a III).

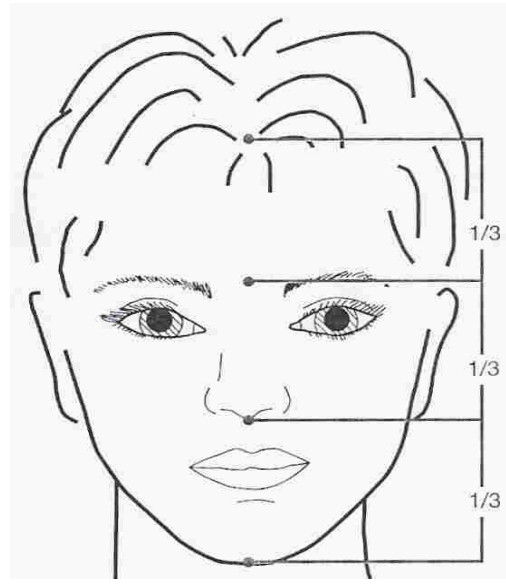

I

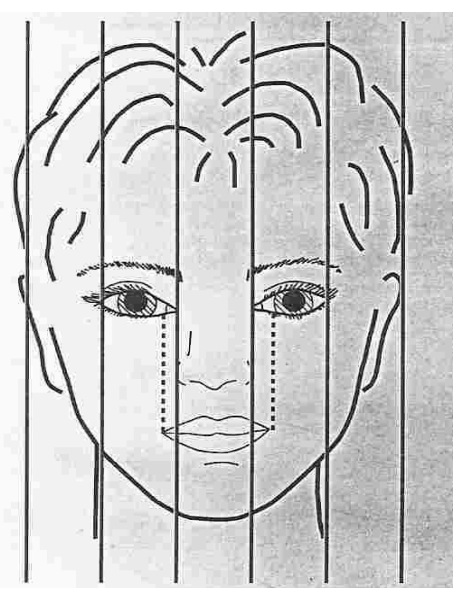

II

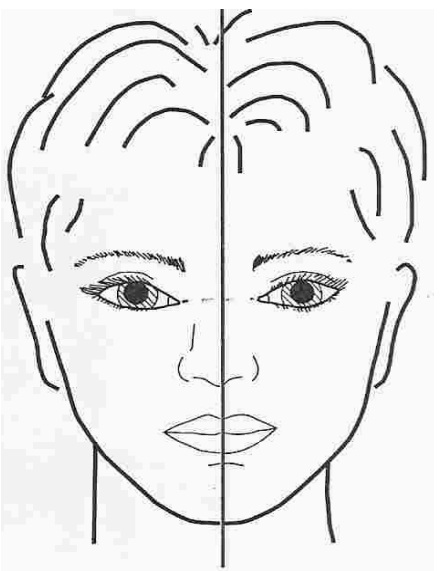

III

Figura 1. Análises Faciais: I) Análise dos terços faciais, II) Análise dos quintos faciais, III) Linha média facial, base para o estudo dos meios faciais (GREGORET et al., 1999)

Pacientes que passam por cirurgias ortognáticas têm seus traços e configurações faciais modificadas, o que faz com que alterações na percepção desta 'nova' face sejam observadas tanto o próprio paciente quanto para terceiros (SUGUINO et al., 1996). A análise facial é útil, então, para poder verificar a situação atual e poder predizer as possíveis alterações faciais que ocorrerão após cirurgia e visa a um correto plano de tratamento para o procedimento cirúrgico (LAUREANO FILHO et al., 2003). Na Figura 2 mostra-se a face de uma paciente antes e depois da cirurgia.

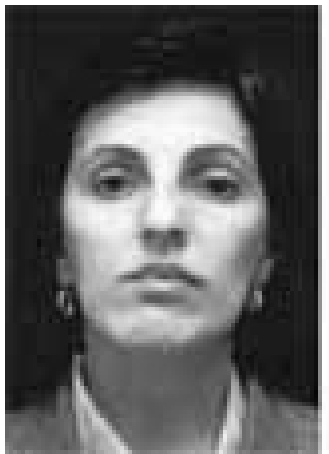

A

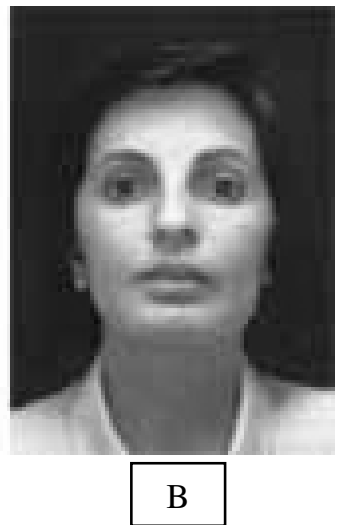

Figura 2. Exemplo de uma face de paciente antes (A) e depois (B) da cirurgia ortognática. Neste caso, na cirurgia foi feito um avanço maxilar com melhora em sua oclusão e obtenção de ganhos estéticos consideráveis (SUGUINO et al., 1996) 
As diferenças entre o 'antes' e o 'depois' da cirurgia parece ter significado marcante na vida do paciente, além de dar subsídios para uma análise funcional e estética desta modificação. Neste sentido, faz-se importante analisar faces de pacientes antes e após o procedimento cirúrgico, a fim de conhecer quais as alterações importantes feitas durante a cirurgia.

Procedimentos cirúrgicos desta natureza, dependendo da magnitude da discrepância facial, podem variar desde pequenas movimentações de grupos dentários até a movimentação completa da mandíbula e/ou maxila. Laureano Filho et al. ( 2003) discutem que, ao se tratar de pacientes com disfunções dentoesqueléticas, são necessárias equipes multidisciplinares, coordenadas por ortodontistas e cirurgiões (bucomaxilofaciais e de cabeça e pescoço), além de acompanhamentos psicológicos, fonoaudiológicos, de otorrinolaringologistas, etc., devido à complexidade dos casos. O tratamento deste tipo de deformidades é constituído pela ortodontia pré-cirúrgica, procedimento cirúrgico em si e ortodontia pós-cirúrgica.

O CEDEFACE (Centro de Pesquisa e Tratamento das Deformidades Buco-Faciais), criado há treze anos, é um centro localizado na cidade de Araraquara que visa estudar, diagnosticar e tratar pacientes portadores de deformidades dentofaciais, em uma abordagem multidisciplinar. Este centro é constituído por uma equipe multiprofissional, que integra dentistas, cirurgiões bucomaxilofaciais, psicólogos, fonoaudiólogos, fisioterapeutas, otorrinolaringologistas, dentre outros profissionais. Estes profissionais realizam avaliações dos pacientes em três fases do atendimento: inicial, no pré-operatório e pós-operatório. As análises faciais são realizadas nestas três fases do tratamento: inicial para diagnóstico e planejamento de intervenção, na fase pré-operatória com a análise de traçados cefalométricos e predictivos e na fase pós-operatória com a análise final da face.

Além das análises faciais o julgamento estético também tem se mostrado muito válido no planejamento de tratamento em cirurgia ortognática (SUGUINO et al., 1996). Alguns 
estudos, como o de Kerr, Dorth e O’Donnell (1990), mostram que julgamentos de atratividade de faces, antes e depois do tratamento ortodôntico, foram diferentes entre quatro diferentes grupos: ortodontistas, estudantes de odontologia, estudantes de artes e parentes de crianças que estavam em tratamento ortodôntico. Estudantes de artes e os parentes das crianças foram menos críticos com relação à atratividade e menos sensíveis às mudanças ortodônticas ocorridas na face do que os ortodontistas e os estudantes de odontologia.

Outro aspecto importante a ser estudado nesta área é como o paciente avalia o resultado do tratamento, tanto em dimensões físicas e funcionais quanto em avaliações psicológicas, com combinação de testes e/ou escalas psicológicas a entrevistas sobre satisfação e percepção de resultados (FINLAY; ATKINSON; MOOS, 1995; PHILLIPS; PROFFIT, 2005).

Tais avaliações são importantes principalmente para verificar o quanto este tipo de cirurgia afeta o cotidiano destes pacientes. Estudos norteamericanos mostram que até metade dos pacientes com deformidades maxilomandibulares apresentam nível elevado de angústia, o que pode predizer problemas de relacionamento interpessoal que afetam a qualidade de vida (PHILLIPS; BENNETT; BRODER, 1998). Cirurgias deste tipo podem, então, ser enquadradas no paradigma da qualidade de vida, para um melhor o dia-a-dia destes indivíduos. Estudos mostram que a grande maioria dos pacientes norteamericanos (82\%) está feliz com os resultados do tratamento entre 4 e 6 semanas após a cirurgia e este número sobe para 90\% após dois anos (PHILLIPS; BENNETT, 2000, apud PHILLIPS; PROFFIT, 2005).

A literatura aponta que, não somente curar e prevenir doenças, mas também melhorar e manter aspectos de saúde são objetivos na busca da qualidade de vida. O alto nível de satisfação dos pacientes submetidos a cirurgias ortognáticas pode ser interpretado como uma melhoria na qualidade de vida, com obtenção de ganhos na saúde geral, no comportamento emocional e nas dimensões psicossociais (BENNETT; PHILLIP, 1999). 
Parece ser muito importante ter um amplo entendimento sobre os efeitos do tratamento das deformidades dentofaciais na qualidade de vida e estados emocionais dos pacientes. Isto pode permitir espaços de mudanças nas políticas públicas (e também privadas, com coberturas nos planos de saúde) para possibilitar que os benefícios sejam estendidos à população, não como um tratamento supérfluo, mas sim como uma questão de saúde pública.

Os instrumentos de avaliação são artefatos de grande valia nestes tipos de avaliações que envolvem quadros clínicos complexos, em situações de julgamento do estado emocional diante de cirurgias e/ou extensos tratamentos.

Sabe-se que todos os campos do saber científico são dependentes, em grande parte, dos instrumentos de medidas. A evolução e aperfeiçoamento destes instrumentos possibilitam avanços na ciência (DA SILVA; RIBEIRO-FILHO, 2006). Os estudos na área de psicologia tiveram um grande avanço com a evolução e aprimoramento das técnicas e instrumentos de medidas.

Descobriu-se que o homem era um precioso e fidedigno instrumento de medida, e que ele conseguia mensurar variáveis métricas e também as não métricas. Com desenvolvimento dos testes psicológicos, com os primeiros de na área da inteligência, não somente o estudo das diferentes habilidades cognitivas humanas foi possibilitado, mas também o entendimento de variáveis que podem explicar comportamentos humanos e, até mesmo, prevê-los.

Os diferentes usos e aplicações de métodos de medidas nas ciências humanas são necessários para a mensuração dos aspectos subjetivos, que antes não podiam ser expressos a não ser com palavras. Este avanço permite uma melhoria nos cuidados de saúde em geral e possibilita mais avanços científicos no campo da saúde em geral.

A psicometria é o campo de estudo da psicologia que possibilita a estruturação, avanço e aprimoramento das técnicas utilizadas para o estudo das inúmeras características humanas. Com o uso de escalas, questionários, testes, inventários, há possibilidades de uma abordagem 
científica para o estudo de fatores como: atitudes, interesses, traços de personalidade, diversas experiências sensoriais, estados mentais, dentre diversos outros constructos subjetivos.

Por conta disto, por serem do campo da psicofísica, e apresentarem respostas subjetivas, são observadas grande variabilidade, o que faz necessário a atenção na elaboração, construção e aplicação de instrumentos para que tenham bons coeficientes de fidedignidade e validade, ao medir exatamente aquilo que foi proposto em sua elaboração (PASQUALI, 2003).

Outras características importantes como: ser considerado fácil tanto na aplicação, na pontuação e na interpretação, ser aplicado em um menor tempo possível, ser relevante e apropriado para a amostra de interesse, etc. Tais qualidades devem ser levadas em conta para que um instrumento possa ser considerado bom (DA SILVA; RIBEIRO-FILHO, 2006).

Muitos e diversificados são os instrumentos de medida em psicologia utilizados na atualidade. Desde a obtenção de números que expressam a intensidade sonora de um ruído ou o comprimento de uma simples linha até a avaliação de estados de dor, ansiedade, qualidade de vida; o uso de escalas, questionários e testes padronizados possibilitam o inferir sobre o mundo subjetivo.

Diferentes são as formas de aplicação destes instrumentos, como os preenchidos pelo observador/pesquisador (que, de certo modo, podem esbarrar na falta de experiência do observador e prejudicar os dados) ou os preenchidos pelo próprio sujeito, as de autoaplicação. Estes últimos são fáceis de administrar; eficientes e econômicos na avaliação de grande número de indivíduos (FREITAS; GORENSTEIN; APPOLINARIO, 2002), contudo Guimarães (2000) aponta que as autoaplicáveis podem apresentar limitações por maior dificuldade de compreensão, falsificação dos dados e maior necessidade de cooperação do avaliado. 
No uso ampliado dos instrumentos de avaliação de estados subjetivos podem ser encontradas escalas de natureza discreta, em que os sujeitos devem assinalar 'categorias' intervalares ou não (pouco, mais ou menos, intensamente) ou analógica, as quais são apresentadas em uma linha reta contínua que representa, supostamente, toda a gama daquela situação a ser avaliada (GUIMARÃES, 2000).

Um exemplo dessa última, a Visual Analogue Scale (VAS) possui em suas extremidades de sua linha, os limites, mínimo e máximo identificados por categorias verbais, para avaliar a experiência subjetiva. A tarefa do examinado ou participante é marcar na linha um ponto correspondente daquele continuum que represente sua experiência subjetiva. A distância marcada é medida por uma régua milimetrada e é atribuído um valor numérico correspondente (HUSKISSON, 1983).

A escala analógica visual (EVA ou VAS) é empregada na avaliação de humor, dor, ansiedade, além de servir para mensuração da atratividade, como no presente estudo. A literatura alerta que as instruções e o treinamento prévio no preenchimento são fatores importantes no emprego deste tipo de escalas, ademais alguns cuidados extras, como a análise fatorial de respostas, podem torná-las mais sensíveis na detecção de experiências subjetivas do que as de natureza discreta (GUIMARÃES 2000).

Huskinsson (1983) também apresenta algumas falhas que podem atrapalhar a aplicação da VAS, como falhas no entendimento dos conceitos utilizados nas extremidades e pequenas variações em reproduzir a experiência subjetiva ao longo da linha. Contudo ele afirma que esta escala pode ser utilizada com confiança uma vez que é simples, confiável, reproduzível e sensível; e por ter uma maior capacidade de transformar em resposta uma experiência subjetiva do que uma escala verbal puramente descritiva ou categórica.

Nos estudos sobre ansiedade as escalas tentam garantir todos os diferentes aspectos de sensações e sentimentos que envolvem o quadro, contudo a maioria enfatiza apenas um ou 
outro (ANDRADE; GORENSTEIN, 2000). Além de sua utilização no contexto científico e clínico, o uso de escalas no estudo da ansiedade também é útil para a distinção entre ansiedade-traço e ansiedade-estado, tanto em pessoas normais quanto em pacientes. $\mathrm{O}$ "IDATE - Inventário de Ansiedade Traço-Estado" foi construído para tal distinção (ANDRADE; GORENSTEIN, 2000).

Pesquisas com pacientes com deformidades dentofaciais apontam para o uso de escalas no enfrentamento do problema e na avaliação dos resultados. Tais avaliações são importantes principalmente para verificar o quanto este tipo de cirurgia afeta o cotidiano emocional destes pacientes, sua qualidade de vida (BENNETT; PHILLIPS, 1999; NARDI et al., 2003) e outras variáveis como autoestima (CUNNINGHAM; HUNT; FEINMANN, 1996; LAZARIDOU-TERZOUDI et al., 2003; NICODEMO; PEREIRA; FERREIRA, 2008), imagem corporal (LAZARIDOU-TERZOUDI et al., 2003), ansiedade (PHILLIPS; BENNETT; BRODER, 1998), depressão (NICODEMO; PEREIRA; FERREIRA, 2008), dificuldades sociais (NEWELL; MARKS, 2000; PHILLIPS; BENNET; BRODER, 1998), dentre outras.

A área de estudo que abrange os indivíduos que sofrem com as deformidades dentofaciais e suas implicações físicas e emocionais é bastante ampla. No entanto para que se possibilite estudar faces com deformidades físicas tem-se que, primeiramente, estudar faces sem grandes deformidades. E, além disto, verificar o quanto estas faces, sem grandes distorções aparentes, são consideradas atrativas ou não. Também outro parâmetro comparativo que serve de base tanto física quanto perceptiva (para julgamentos) é análise de faces prototípicas.

Faces prototípicas sendo então imagens faciais que representam a aparência típica de um grupo de pessoas, com o cômputo da média matemática dos valores dos traços de uma população, indicam a tendência de características físicas faciais daquela população 
(RHODES, 2006). Portanto, protótipos faciais têm sido utilizados para testar hipóteses em reconhecimento de faces e também para elucidação de alguns tópicos em percepção de faces, como atratividade.

Como visto na teoria sobre atratividade dos protótipos, faces atrativas possuem aparência próxima aos protótipos de sua raça (RHODES; TREMEWAN, 1996; RHODES; SIMMONS; PETERS, 2005; RHODES; SUMICH; BYATT, 1999; O’TOOLE et al., 1999).

O julgamento de atratividade de uma face prototípica tende a ser mediano, independentemente da atratividade das faces da amostra que o compõe (LANGLOIS; ROGGMAN, 1990). Assim, um protótipo construído por faces não atrativas terá níveis de atratividade superior a elas; já um protótipo gerado por faces muito atrativas, terá um nível inferior de atratividade.

Além de estudos sobre atratividade, o protótipo, como representante da forma facial de um determinado grupo, pode também ser utilizado como parâmetros físicos em cirurgias de correção e reconstruções faciais.

No Brasil estudos sobre atratividade de faces humanas utilizaram fotografias provenientes de banco de faces de outras culturas, outras etnias (SILVA, 2005). Neste estudo, (em que foram utilizadas faces do banco pertence à Universidade de Stirling, na Escócia), os baixos escores de atratividade evidenciaram uma má aceitação das faces-estímulos, e por consequência, a maioria dos participantes considerou as faces estímulo como 'feias'. Considera-se que o viés cultural ou étnico possa ter influencia e/ou prejudicado os julgamentos das faces.

Estudos mostram que as diferenças étnicas devem ser levadas em consideração neste tipo de análise (CHOE et al., 2004; ENLOW, 1993; REIS et al., 2006a, 2006b; SCAVONE JUNIOR et al., 2006). Muitos outros estudos transculturais devem ser realizados a fim de ampliar as possibilidades de análises faciais em diferentes grupos étnicos e raciais. 
Ao tentar diminuir este viés, e com o interesse em estudar as características da população brasileira em seus aspectos físicos e perceptivos, este estudo propõe a análise de uma amostra de faces de voluntários provenientes da cidade de Ribeirão Preto, SP. Essa amostra de faces pertence a um banco de imagens faciais do laboratório de Psicofísica e Percepção do DPE-FFCLRP-USP, sob responsabilidade do Prof. Dr. Sérgio S. Fukusima, e que fora construído pela Dra. Ana Irene Fonseca Mendes e Kátia Cruvinel Arrais.

As possibilidades de pesquisas em percepção facial na população brasileira cresceram significativamente com a criação deste banco de faces e, também a partir dele, com a confecção de protótipos da população por ele composta (Figuras 3 a 8). Têm-se, então, faces das três etnias mais frequentes em nossa região, segundo o Censo do IBGE de 2000: brancos (77\%), pardos $(16 \%)$ e pretos $(6 \%)$. Os critérios para o enquadre das pessoas em uma destas etnias consistiu na autodeclaração dentro das categorias definidas pelo IBGE (2000): branco, preto, pardo, indígena e amarelo.

\section{2) Objetivos Gerais do Trabalho:}

Com base nestas informações, três objetivos gerais foram traçados para este estudo: 1) Avaliar faces sem deformidades através da análise do banco de faces da população de Ribeirão Preto, SP e seus respectivos protótipos a fim de que pudessem servir como parâmetros físicos e perceptivos para análises de faces de pessoas com deformidades dentofaciais que sofreram cirurgia ortognática; 2) Analisar a atratividade facial dos pacientes submetidos a cirurgias ortognáticas, nas fases pré e pós-cirúrgicas, relacionando a atratividade aos parâmetros físicos faciais alterados pela cirurgia e também avaliar as consequências emocionais que abrangem qualidade de vida, ansiedade e autoestima nestes pacientes que sofreram modificações estéticas e funcionais nas faces através da correção ortognática. 


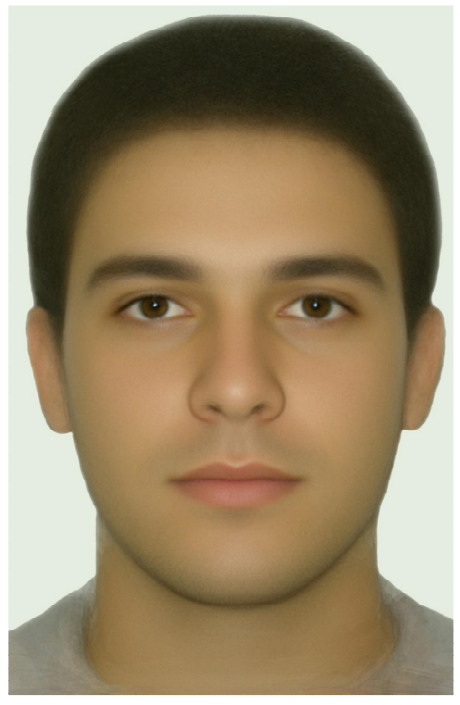

Figura 3. Protótipo da população masculina branca.

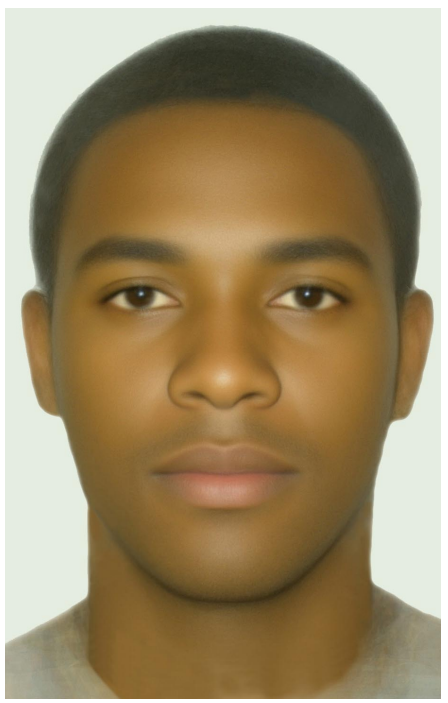

Figura 5. Protótipo da população masculina preta.

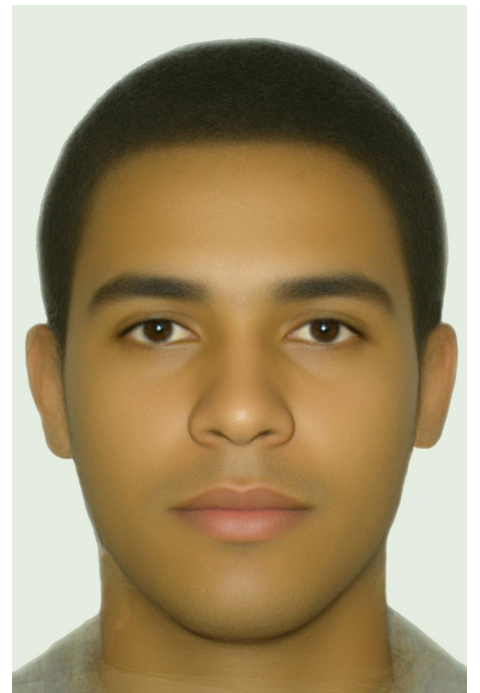

Figura 7. Protótipo da população masculina parda.

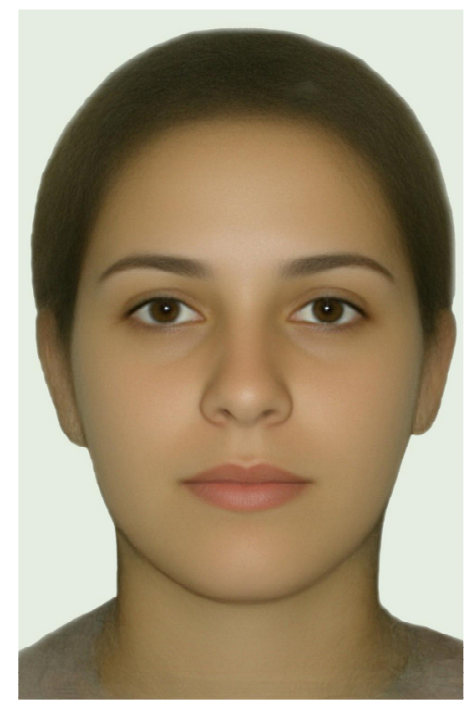

Figura 4. Protótipo da população feminina branca.

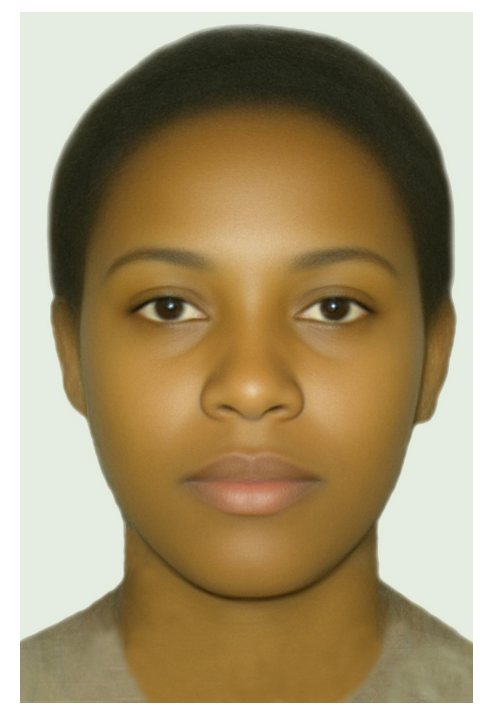

Figura 6. Protótipo da população feminina preta.

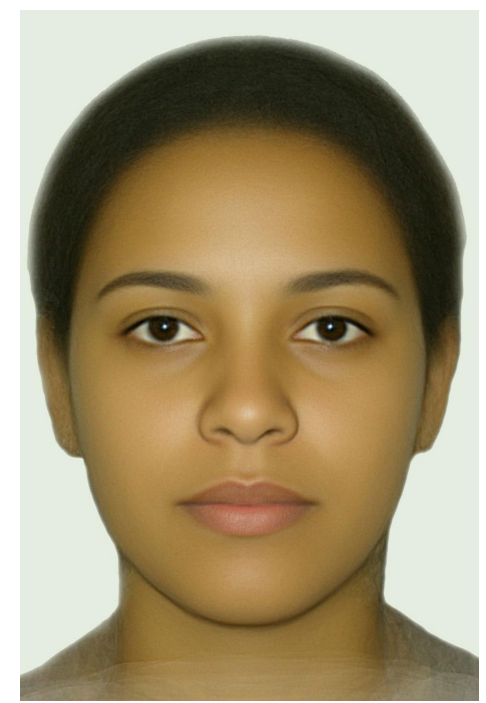

Figura 8. Protótipo da população feminina parda. 
Faz-se importante este tipo de estudo em predizer quais os melhores parâmetros a serem utilizados em tratamentos ortocirúrgicos que podem se correlacionar a melhorias da estética facial e aos aspectos emocionais dos pacientes envolvidos.

\section{3) Método}

O estudo foi dividido em três fases:

1) Análise facial do banco de faces e protótipos;

2) Análise facial dos pacientes submetidos à cirurgia ortognática e investigação da atratividade dos mesmos (Experimentos 1 e 2);

3) Investigação da qualidade de vida, ansiedade e autoestima dos pacientes submetidos à cirurgia ortognática.

\section{1) ANÁlise Facial do Banco de FaCes e Protótipos.}

Foram analisadas 390 imagens de faces frontais de adultos (18 a 30 anos), sendo: 192 fotografias femininas (64 brancas, 64 pretas e 64 pardas) e 192 fotografias masculinas (64 brancas, 64 pretas e 64 pardas) de pessoas provenientes da cidade de Ribeirão Preto, SP, que se auto declararam brancas, pretas ou pardas, mais 6 protótipos faciais, 2 de cada gênero (2 masculinos e 2 femininos) e etnia (brancos, pretos e pardos). Estas faces compõem o 'Banco de imagens faciais’ pertencente ao Laboratório de Psicofísica e Percepção do DPE-FFCLRPUSP, sob responsabilidade do Prof. Dr. Sérgio S. Fukusima.

Os protótipos foram confeccionados pela Dra. Ana Irene Fonseca Mendes e Kátia Cruvinel Arrais, a partir das faces pertencentes ao banco de faces do laboratório de Psicofísica e Percepção. A confecção dos mesmos ocorreu a partir das 64 fotografias analisadas para cada gênero e etnia, por exemplo, o protótipo feminino preto foi confeccionado pelas 64 faces femininas pretas que compõem esta amostra e assim sucessivamente para cada gênero e etnia. 
As médias de idade em anos (e respectivos desvios padrões) de cada protótipo são: Masculino Branco: 21.77 (D.P.: 2.86), Feminino Branco: 22.02 ( D.P.: 3.31), Masculino Preto: 22.95 (D.P.: 3.97), Feminino Preto: 23.03 (D.P.: 3.94), Masculino Pardo: 21.60 (D.P.: 3.24), Feminino Pardo: 22.73 (D.P.: 3.90).

\section{Procedimento:}

Todas as imagens (faces e protótipos) foram editadas e medidas com o auxílio de um editor de imagens. Todas as fotografias, antes de serem analisadas, foram submetidas a um procedimento de padronização, o que permite uma uniformidade dos elementos e características faciais externas (como cabelos, orelhas e pescoço). Para tanto as faces receberam uma máscara correspondente ao protótipo de seu gênero e etnia. Por exemplo, todas as faces brancas masculinas receberam a máscara com os cabelos, orelhas e pescoço do protótipo branco masculino e assim sucessivamente com todas as etnias e gêneros. Posteriormente realizou-se adaptação do tamanho, cores e contrastes da máscara para melhor adequação à imagem facial original.

As análises tiveram seus critérios baseados nas proporções entre os terços, meios e quintos faciais. Na análise dos terços a face é dividida em três partes praticamente iguais (GREGORET et al., 1999): o terço superior (do tríquio à glabela), o terço médio (da glabela a subnasal) e o terço inferior (da subnasal ao mentoniano) como na Figura 1 I.

$\mathrm{Na}$ análise dos meios (simetria facial) divide-se a face em hemiface direita e esquerda, pela linha mediana traçada a partir do centro da glabela, equidistante a ambos os cantos oculares internos (Figura 1 III). Quatro medidas são analisadas para cada hemiface: 1) da mediana à base alar do nariz, 2) da mediana à comissura labial, 3) da mediana aos cantos oculares externos e 4) da mediana às orelhas. A numeração 1, 2, 3 e 4 será utilizada para nomear as medidas correspondentes a cada hemiface direita e esquerda. $\mathrm{O}$ esperado para uma face simétrica é: $1 \mathrm{~d}=1 \mathrm{e} ; 2 \mathrm{~d}=2 \mathrm{e}, 3 \mathrm{~d}=3 \mathrm{e}$ e 4d=4e, segundo Gregoret et al. (1999). 
Existem diferentes tipos de assimetrias, que podem englobar desde assimetria ocular, os desvios nasais e do mento até o hipodesenvolvimento de uma hemiface, dentre outros. Algumas assimetrias são quase imperceptíveis em um primeiro exame do paciente outras, porém, podem ser muito severas, muitas relacionadas a síndromes genéticas ou má formações (GREGORET et al., 1999).

A análise dos quintos faciais aprofunda o estudo da simetria. Ela é realizada ao se dividir a face em cinco partes, ao traçar linhas paralelas à linha mediana. Essas linhas passam pelos cantos externos e internos dos olhos e pelos pontos mais externos à altura dos ossos parietais. A saber: $1^{\circ}$.) medida da orelha direita ao canto ocular externo direito, $2^{\circ}$.) medida do olho direito, $3^{\circ}$.) medida entre os cantos internos dos olhos, $4^{\circ}$.) medida do olho esquerdo, $5^{\circ}$.) medida do canto ocular externo esquerdo a orelha esquerda. Existe uma regra chamada "regra dos quintos" que afirma que a largura total da face seria equivalente a cinco vezes a largura dos olhos, num total de cinco partes praticamente iguais (GREGORET et al., 1999), como visto na Figura 1 II.

Análise dos dados: Todas as imagens (faces e protótipos) foram medidas com o auxílio de um software editor de imagens. As medidas reais em cada análise foram transformadas em proporções para que as imagens pudessem ter uniformidade nas medidas. Os softwares SPSS $^{\odot}$ versão 12.0 e BioEstat 5.0 foram utilizados para as análises estatísticas.

Testes de normalidade (Kolmogorov-Smirnov e Shapiro-Wilk) foram aplicados aos dados e testes não paramétricos utilizados, como Friedman (equivalente à ANOVA paramétrica e compara a soma dos postos entre os diferentes tratamentos, de acordo com DAWSON; TRAPP, 2003) e o teste de Wilcoxon (equivalente ao Teste T, de acordo com DAWSON; TRAPP, 2003), pela característica de não normalidade dos dados analisados. 


\section{Resultados}

Os dados das 390 imagens de faces frontais estão exibidos conforme a etnia das faces: brancas, pretas e pardas, respectivamente.

\section{- Faces Brancas:}

As análises faciais das 130 imagens brancas, sendo 128 fotos de faces (64 femininas e 64 masculinas), mais os protótipos de cada gênero ( 1 masculino e 1 feminino), indicaram alguns resultados diferentes do preconizado pela literatura, tanto para os terços quanto para os quintos faciais.

Ao analisar os terços (superior, médio e inferior), segundo (GREGORET et al., 1999), divide-se a face em três partes praticamente iguais, sendo a proporção esperada para cada uma igual a 0,33 (Figura 1 I).

Para as faces masculinas o teste de normalidade (Kolmogorov-Smirnov) mostrou que os dados dos terços superior e médio não se distribuem normalmente e somente as medidas do terço inferior se distribuem na curva normal. Portanto, optou-se pela utilização de testes não paramétricos nas análises como o Teste de Friedman e o teste de Wilcoxon, (DAWSON; TRAPP, 2003) para comparar os três terços analisados. Verificou-se que as proporções dos três terços diferem entre si $[\mathrm{Q}(2,64)=96,024 ; \mathrm{p}<0,01]$, com medianas de 0,29 para o terço superior, 0,33 para o médio e 0,38 para o inferior (Figura 9). O Teste de Wilcoxon foi aplicado para verificar as diferenças entre as proporções de cada terço e a medida esperada $(0,33)$. O terço médio apresentou proporção igual ao esperado $(p>0,01)$ e os terços superior e inferior apresentaram diferenças estatisticamente significativas $(\mathrm{p}<0,01)$ entre as suas proporções e a esperada.

Para as faces femininas o teste de normalidade (Kolmogorov-Smirnov) mostrou que os dados dos terços superior e médio não se distribuem normalmente e somente as medidas do 
terço inferior se encaixam na curva normal. O Teste de Friedman também foi aplicado para comparações entre a soma dos postos dos três terços analisados. Verificou-se que as proporções dos três terços diferem entre si $[\mathrm{Q}(2,64)=77,200 ; \mathrm{p}<0,01]$, com medianas de 0,30 para o terço superior, 0,34 para o médio e 0,36 para o inferior (Figura 9).

Houve um aumento de proporções de medidas no sentido vertical de cima para baixo como nas faces masculinas. O Teste de Wilcoxon foi aplicado para verificar as diferenças entre as medidas de cada terço e a medida esperada $(0,33)$. Como para as faces masculinas, houve diferenças significativas $(\mathrm{p}<0,01)$ entre as medidas dos terços superior e inferior comparadas à medida esperada, contudo as medidas do terço médio não tiveram diferenças estatisticamente significativas à esperada $(\mathrm{p}>0,01)$.

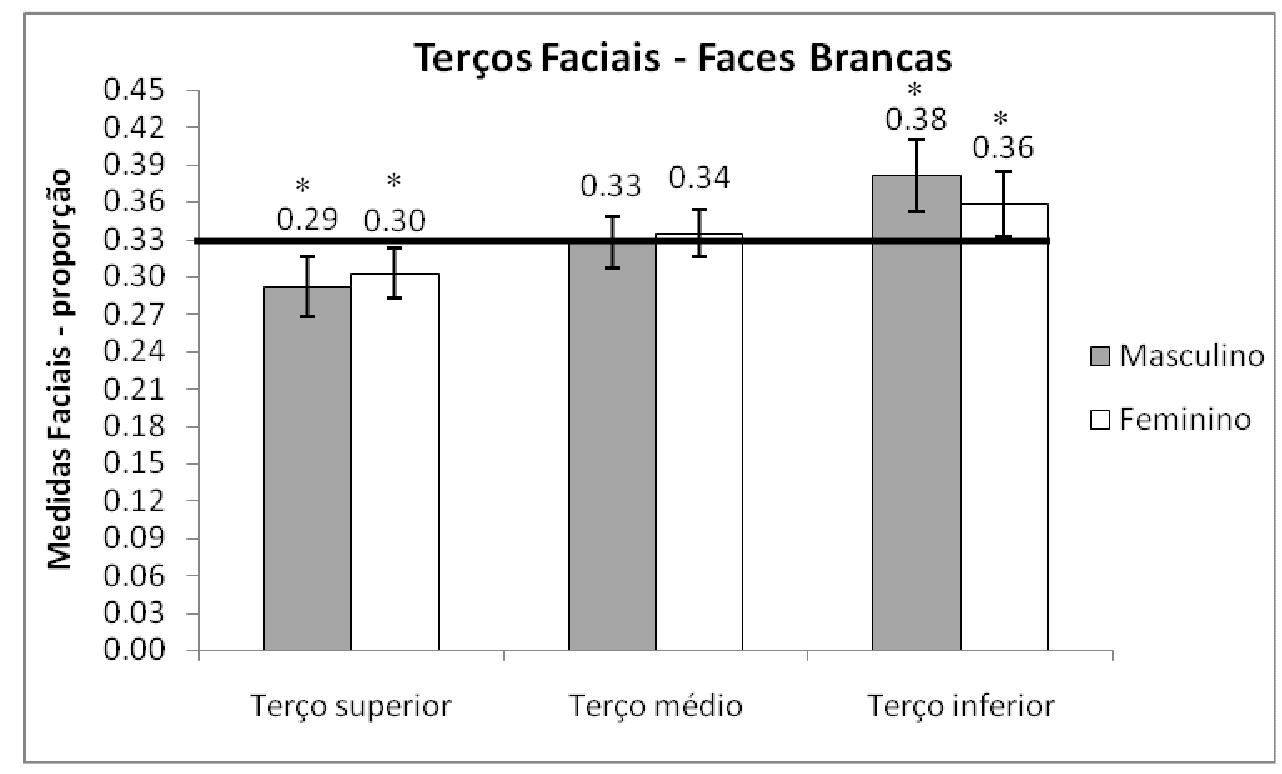

Figura 9. Análise facial dos terços das faces masculinas e femininas brancas (os dados são representados como as proporções dos terços e \pm E.P.M. ; * $\mathrm{p}<0,01$ comparado com o esperado 0,33 destacado pela linha)

Para o protótipo masculino as proporções foram: terço superior 0,28 , terço médio 0,33 e terço inferior 0,39 , o que segue a mesma tendência de medidas das faces que o compuseram. Para o protótipo feminino as medidas foram: terço superior 0,29 , terço médio 0,34 e terço 
inferior 0,36, também seguem a tendência de medidas das faces que o compuseram (Figura $10)$.

Para a análise dos quintos esperava-se a igualdade entre as medidas, pois segundo Gregoret et al. (1999) a regra dos quintos afirma que a largura total da face seria equivalente a cinco vezes a largura dos olhos, com cinco partes praticamente iguais. Ou seja, proporção de 0,20 para cada quinto facial. A saber, os quintos analisados foram: $1^{\circ}$.) medida da orelha direita ao canto ocular externo direito, $2^{\circ}$.) medida do olho direito, $3^{\circ}$.) medida entre os cantos internos dos olhos, $4^{\circ}$.) medida do olho esquerdo, $5^{\circ}$.) medida do canto ocular externo esquerdo a orelha esquerda (Figura 11).

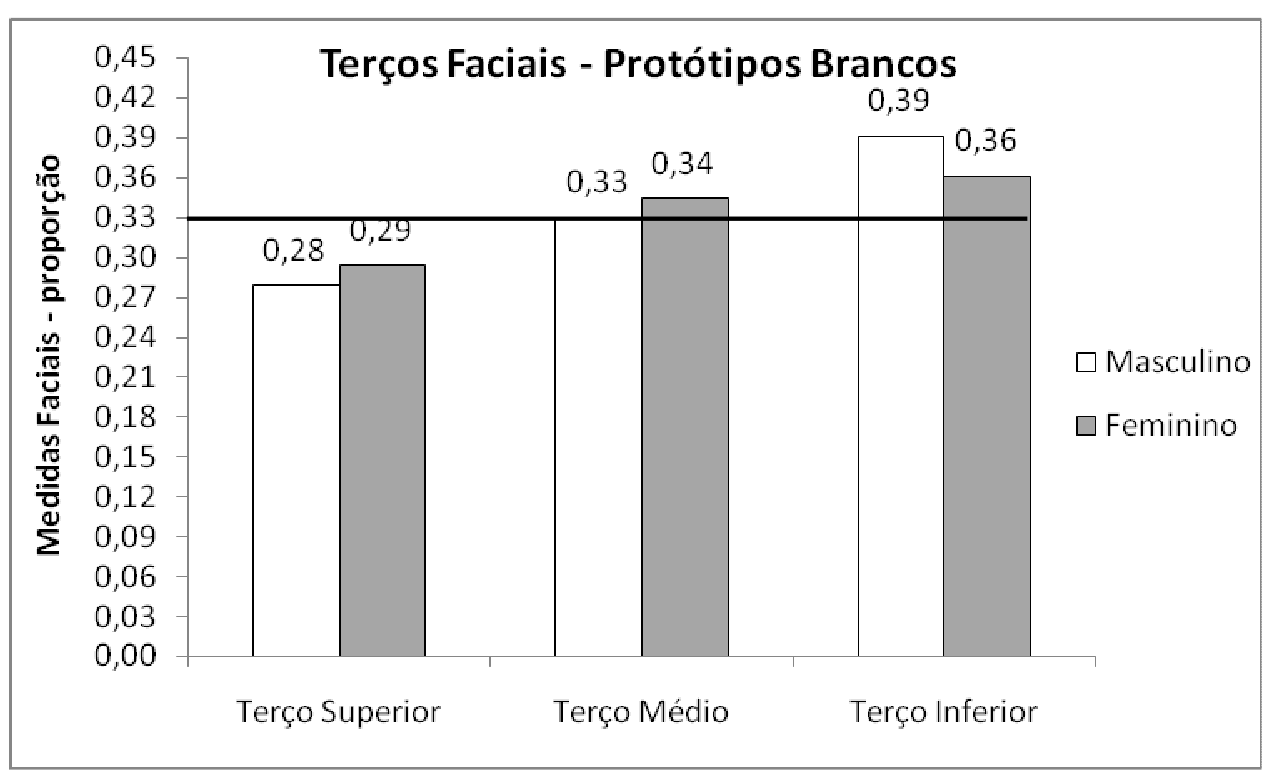

Figura 10. Análise facial dos terços dos protótipos brancos, masculinos e femininos (os dados são representados como as proporções dos terços) 


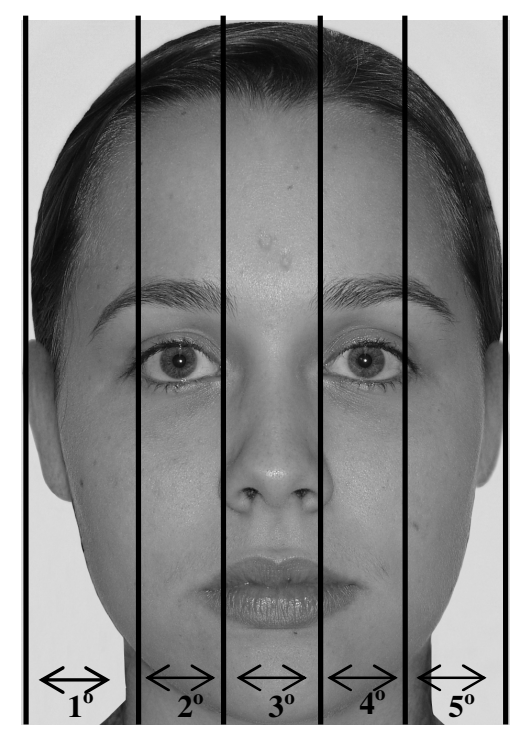

Figura 11. Exemplo de face feminina, com referência às medidas dos quintos

Para as faces masculinas o teste de normalidade indicou que os dados dos cinco quintos não se distribuem normalmente, foi então aplicado o teste de Friedman para comparação entre a soma dos postos das proporções dos quintos. Foram observadas diferenças significativas entre as proporções dos quintos $[\mathrm{Q}(4,64)=198,920 ; \mathrm{p}<0,01]$, sendo que o $1^{\mathrm{o}}$ quinto apresentou mediana de 0,24 , o $2^{\circ}$ quinto 0,17 , o $3^{\circ}$ quinto 0,20 , o $4^{\circ}$ quinto 0,17 e o $5^{\circ}$ quinto 0,23 . Diferenças significativas $(p<0,05)$ foram observadas entre os pares de quintos: $1^{\circ}$ e $2^{o}$, $1^{\mathrm{o}}$ e $3^{\mathrm{o}}, 1^{\mathrm{o}}$ e $4^{\mathrm{o}}, 2^{\mathrm{o}}$ e $3^{\mathrm{o}}, 2^{\mathrm{o}}$ e $5^{\mathrm{o}}, 3^{\mathrm{o}}$ e $4^{\mathrm{o}}, 3^{\mathrm{o}}$ e $5^{\mathrm{o}}, 4^{\mathrm{o}}$ e $5^{\mathrm{o}}$. Entre os quintos $1^{\mathrm{o}}$ e $5^{\mathrm{o}}$ (medida da orelha ao canto ocular externo direito e esquerdo, respectivamente), $2^{\circ}$ e $4^{\circ}$ (medidas do olho esquerdo e direito, respectivamente) não foram verificadas diferenças significativas $(p>0,05)$.

Para as faces femininas o teste de normalidade também indicou que os dados dos cinco quintos não se distribuem normalmente, para tanto foi aplicado o teste não paramétrico de Friedman para comparação entre a soma dos postos das proporções dos quintos. Foram observadas diferenças significativas entre as proporções dos quintos $[\mathrm{Q}(4,64)=219,321$; $\mathrm{p}<0,01]$, com o $1^{\mathrm{o}}$ quinto com mediana de 0,23 , o $2^{\mathrm{o}}$ quinto 0,17 , o $3^{\mathrm{o}}$ quinto 0,20, o $4^{\mathrm{o}}$ quinto 0,17 e o $5^{\circ}$ quinto 0,23 . Diferenças significativas $(\mathrm{p}<0,05)$ foram observadas entre os pares de 


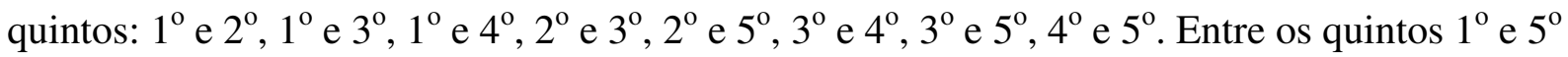
(medidas do canto externo dos olhos à orelha direita e esquerda, respectivamente), $2^{\circ}$ e $4^{\circ}$ (medidas do olho esquerdo e direito respectivamente) não foram verificadas diferenças significativas $(\mathrm{p}>0,05)$.

O teste de Wilcoxon foi aplicado nas medidas dos quintos para faces masculinas e femininas, a fim de comparar à medida esperada $(0,20)$. Foram verificadas diferenças significativas $(p>0,01)$ entre a medida esperada e as medidas $\operatorname{dos} 1^{\circ}, 2^{\circ}, 4^{\circ}$ e $5^{\circ}$ quintos. Para a medida do $3^{\mathrm{o}}$ quinto (distância intercantal) não houve diferença estatística $(\mathrm{p}<0,01)$ com relação à medida esperada (Figura 12)

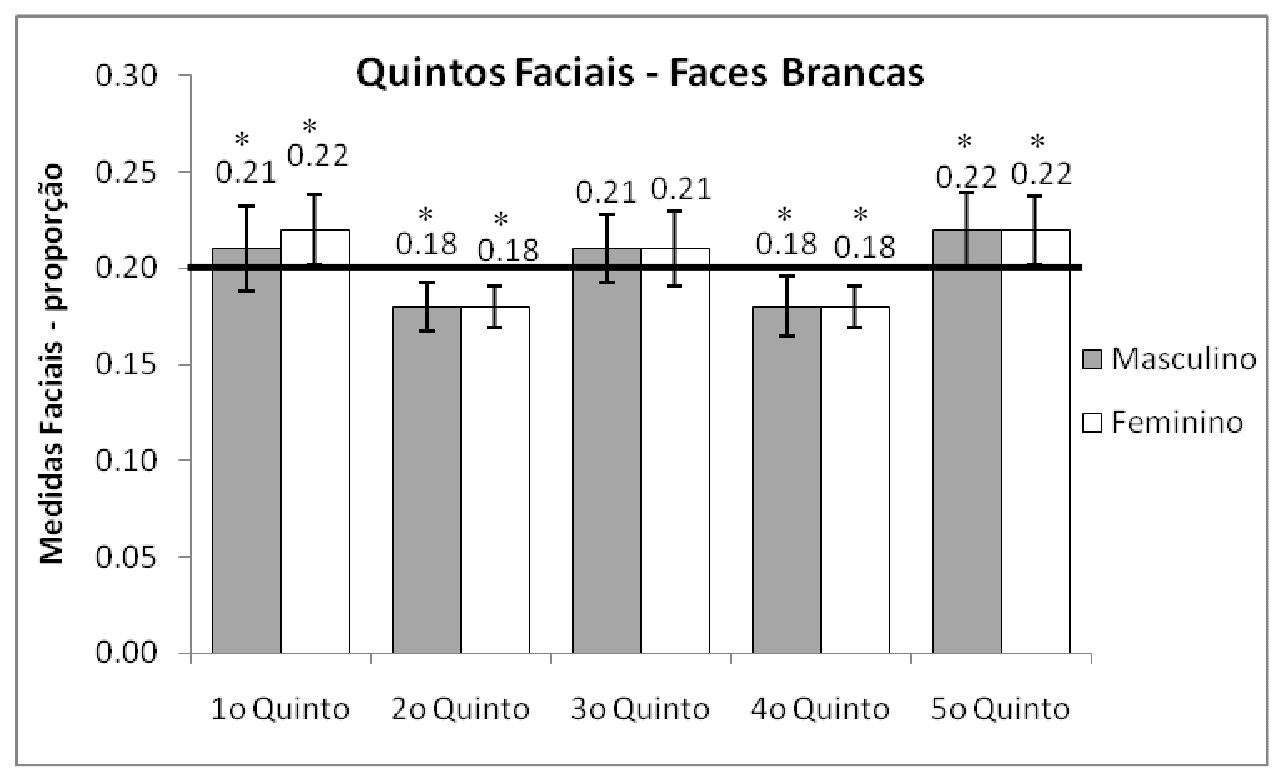

Figura 12. Análise facial dos quintos das faces masculinas e femininas brancas (os dados são representados como as proporções dos quintos e \pm E.P.M; * $\mathrm{p}<0,01$ comparado com $\mathrm{o}$ esperado 0,20 destacado pela linha)

Comparadas à proporção esperada houve um aumento nos $1^{\circ}$ e $5^{\circ}$ quintos e uma diminuição nos $2^{\circ}$ e $4^{\circ}$ quintos, tanto para as faces femininas quanto para as masculinas 
brancas. As proporções dos $3^{\text {os }}$ quintos foram estatisticamente iguais a 0,20 para os dois sexos das faces $(\mathrm{p}<0,01)$.

Para os protótipos, tanto masculino quanto feminino as proporções foram: $1^{\mathrm{o}}$ quinto 0,24 , o $2^{\circ}$ quinto 0,17 , o $3^{\circ}$ quinto 0,19 , o $4^{\circ}$ quinto 0,17 e o $5^{\circ}$ quinto 0,24 . Os aumentos de proporções de medidas observados nos $1^{\circ}$ e $5^{\circ}$ quintos nas faces brancas foram também observados nos protótipos como também as diminuições das proporções nos $2^{\circ}$ e $4^{\circ}$ quintos (Figura 13).

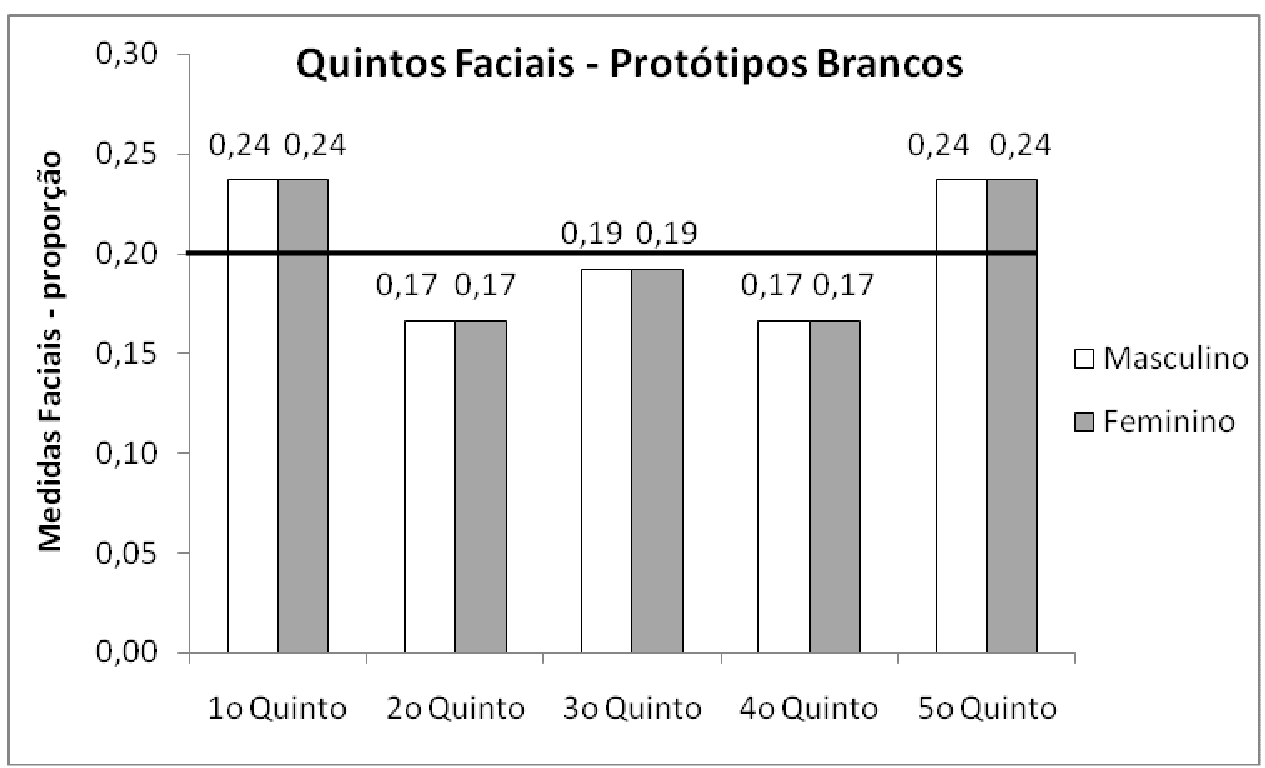

Figura 13. Análise facial dos quintos dos protótipos brancos, masculino e feminino (os dados são representados como as proporções dos quintos)

Para a análise dos meios faciais (simetria bilateral) dividiu-se a face hemiface direita e esquerda, pela linha mediana traçada a partir do centro da glabela, equidistante a ambos os cantos oculares internos. Quatro medidas são analisadas para cada hemiface: 1) da mediana à base alar do nariz, 2) da mediana à comissura labial, 3) da mediana aos cantos oculares externos e 4) da mediana às orelhas. A numeração 1, 2, 3 e 4 será utilizada para nomear as 
medidas correspondentes a cada hemiface direita e esquerda. O esperado para uma face simétrica é: $1 \mathrm{~d}=1 \mathrm{e} ; 2 \mathrm{~d}=2 \mathrm{e}, 3 \mathrm{~d}=3 \mathrm{e}$ e $4 \mathrm{~d}=4 \mathrm{e}$ (Figura 14).

Para as faces masculinas o teste de normalidade indicou que os dados não se distribuem normalmente, para tanto foi aplicado o teste de Wilcoxon (Dawson; Trapp, 2003) para análise entre as proporções das hemifaces direita e esquerda. Os resultados apontaram que as proporções são iguais estatisticamente $(p>0,01)$ entre os dois lados das faces, sendo: 1d e $1 \mathrm{e}=0,11 ; 2 \mathrm{~d}$ e $2 \mathrm{e}=0,15 ; 3 \mathrm{~d}$ e $3 \mathrm{e}=0,26 ; 4 \mathrm{~d}$ e $4 \mathrm{e}=0,48$ (Figura 15$)$

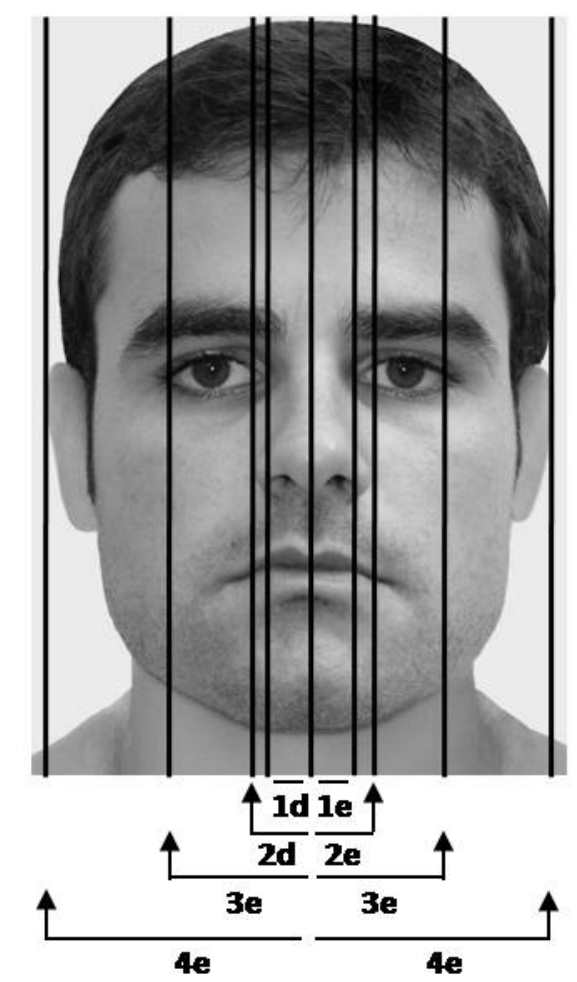

Figura 14. Exemplo de face masculina, com referência às medidas dos meios (simetria)

Também para as faces femininas o teste de normalidade indicou que os dados não se distribuem normalmente, tendo sido aplicado o teste de Wilcoxon para análise entre as proporções das hemifaces direita e esquerda. Os resultados apontaram que as medidas foram estatisticamente iguais ( $p>0,01)$ : $1 \mathrm{~d}$ e $1 \mathrm{e}=0,11 ; 2 \mathrm{~d}$ e $2 \mathrm{e}=0,15 ; 3 \mathrm{~d}$ e $3 \mathrm{e}=0,26 ; 4 \mathrm{~d}$ e $4 \mathrm{e}=0,48$ (Figura 15). Estes dados mostram que tanto as faces masculinas quanto as femininas brancas são simétricas. 
Para o protótipo masculino as medidas foram: $1 \mathrm{~d}$ e $1 \mathrm{e}=0,11 ; 2 \mathrm{~d}$ e $2 \mathrm{e}=0,15 ; 3 \mathrm{~d}=$ 0,26 e $3 \mathrm{e}=0,25 ; 4 \mathrm{~d}$ e $4 \mathrm{e}=0,49$ e para o protótipo feminino: $1 \mathrm{~d}$ e $1 \mathrm{e}=0,11 ; 2 \mathrm{~d}$ e $2 \mathrm{e}=0,15$; $3 \mathrm{~d}$ e $3 \mathrm{e}=0,26 ; 4 \mathrm{~d}$ e $4 \mathrm{e}=0,49$ (Figura 16). Tais medidas acompanham as medidas das faces da amostra estudada, com uma pequena diferença (de 0,01$)$ entre direita e esquerda na medida 3 (da linha mediana à extremidade dos olhos) para o protótipo masculino.

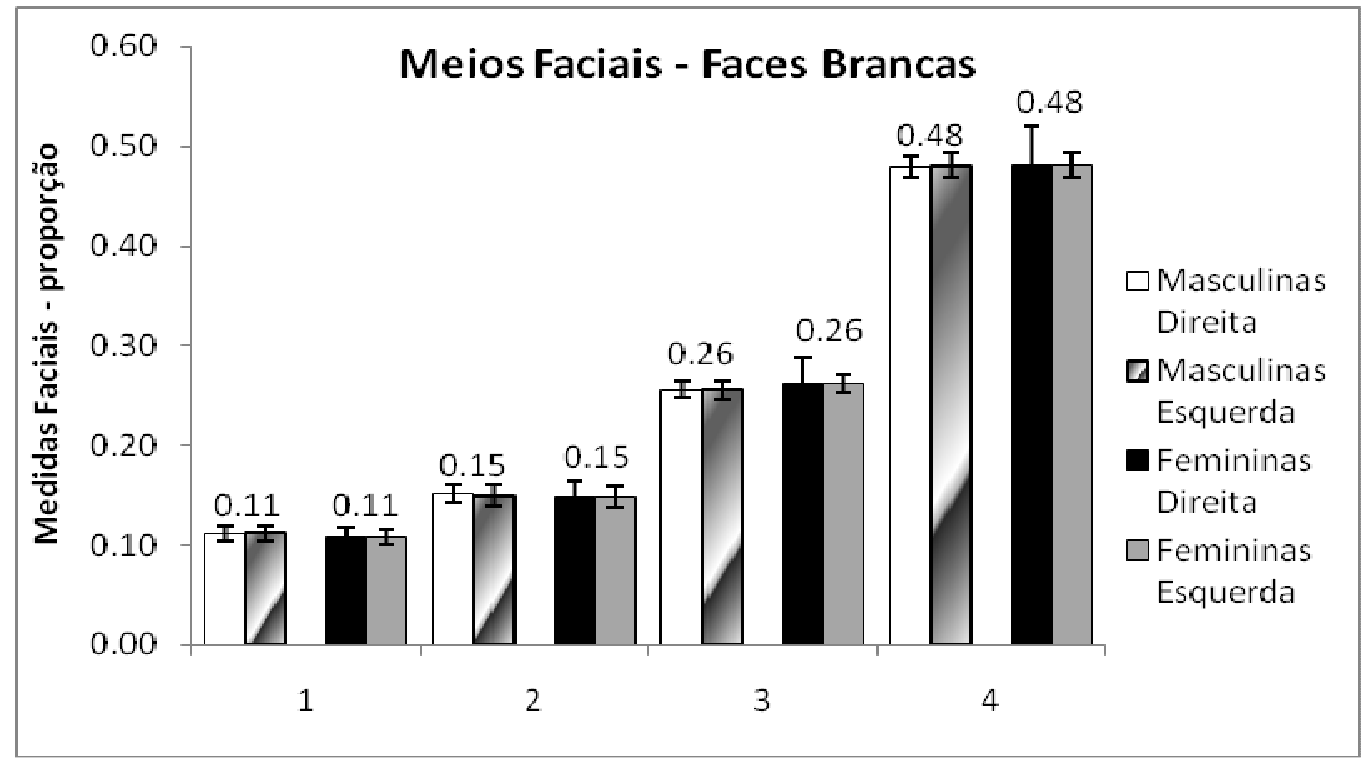

Figura 15. Análise facial dos meios (simetria) das faces masculinas e femininas brancas (os dados são representados como as proporções dos meios e \pm E.P.M)

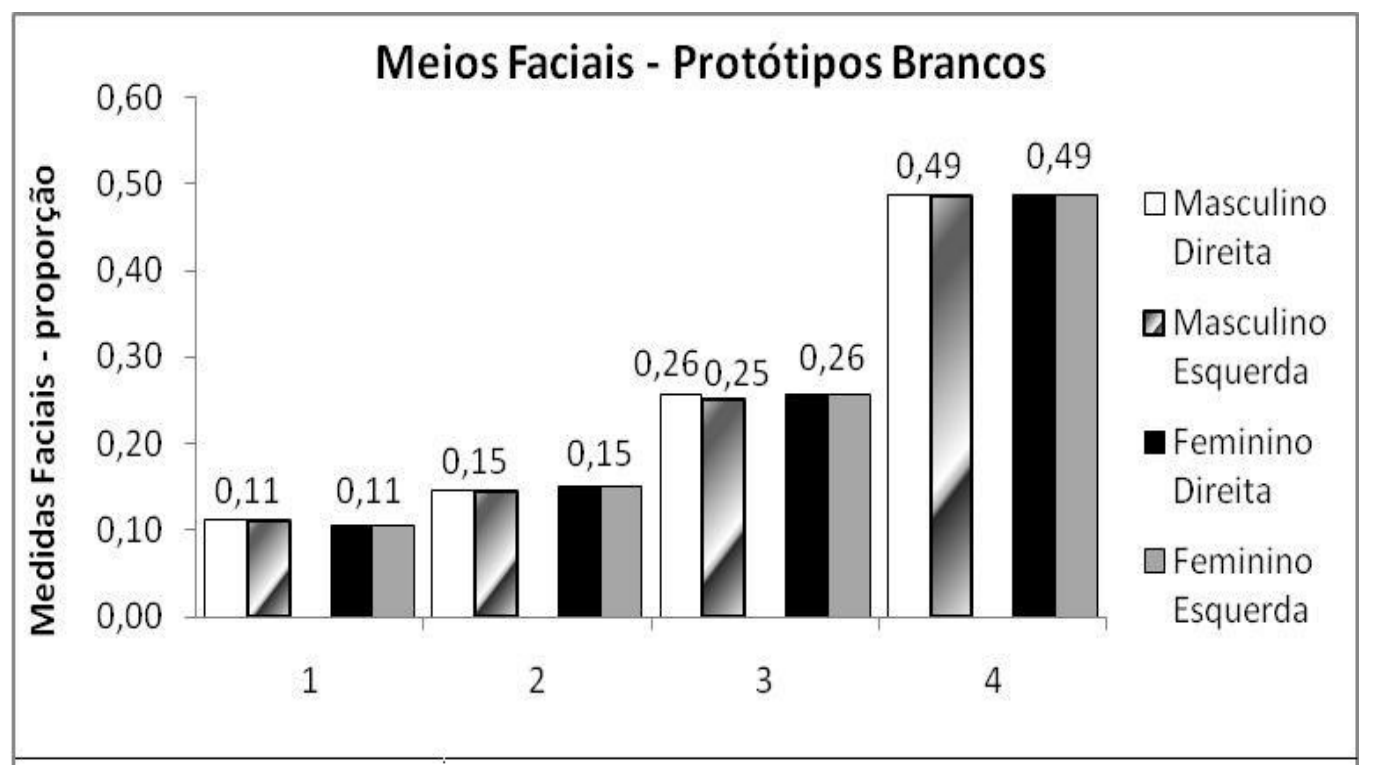

Figura 16. Análise facial dos meios (simetria) dos protótipos brancos, masculino e feminino (os dados são representados como as proporções dos meios) 


\section{- Faces Pretas:}

As análises faciais das 130 imagens pretas, destas 128 fotos eram de faces (64 femininas e 64 masculinas), mais os protótipos de cada gênero (1 masculino e 1 feminino), também indicaram alguns resultados diferentes dos apontados na literatura, tanto para os terços quanto para os quintos faciais.

Para as faces masculinas o teste de normalidade (Kolmogorov-Smirnov) mostrou que os dados dos terços médio e inferior não se distribuem normalmente e somente as medidas do terço superior se distribui na curva normal. O Teste de Friedman foi aplicado para comparações entre a soma dos postos dos três terços analisados. Verificou-se que as proporções dos três terços diferem entre si [Q $(2,64)=113,693 ; \mathrm{p}<0,01]$, com medianas de 0,28 para o terço superior 0,34 para o médio e 0,39 para o inferior (Figura 17). O Teste de Wilcoxon foi aplicado para verificar as diferenças entre as proporções de cada terço e a esperada $(0,33)$. Houve diferenças estatisticamente significativas $(\mathrm{p}<0,01)$ entre as medidas dos terços superior e inferior com relação à esperada. A proporção do terço médio não se diferenciou da esperada $(\mathrm{p}>0,01)$.

Para as faces femininas o teste de normalidade (Kolmogorov-Smirnov) mostrou que os dados dos terços superior e médio não se distribuem normalmente e somente as medidas do terço inferior se encaixam na curva normal. O Teste de Friedman também foi aplicado. Verificou-se que as medidas dos três terços diferem entre si $[Q(2,64)=72,202 ; \mathrm{p}<0,01]$, com medianas de 0,28 para o terço superior, 0,35 para o médio e 0,37 para o inferior. (Figura 17). O Teste de Wilcoxon foi aplicado para verificar as diferenças entre as medidas de cada terço e a medida esperada $(0,33)$. Para os três terços foram verificadas diferenças significativas $(\mathrm{p}<0,01)$ entre as medidas comparadas à medida esperada. 
Houve um aumento de proporções de medidas no sentido vertical de cima para baixo, contudo com diferenças entre as faces masculinas e femininas nas medidas referentes ao terço médio, sendo maior que 0,33 nas faces femininas.

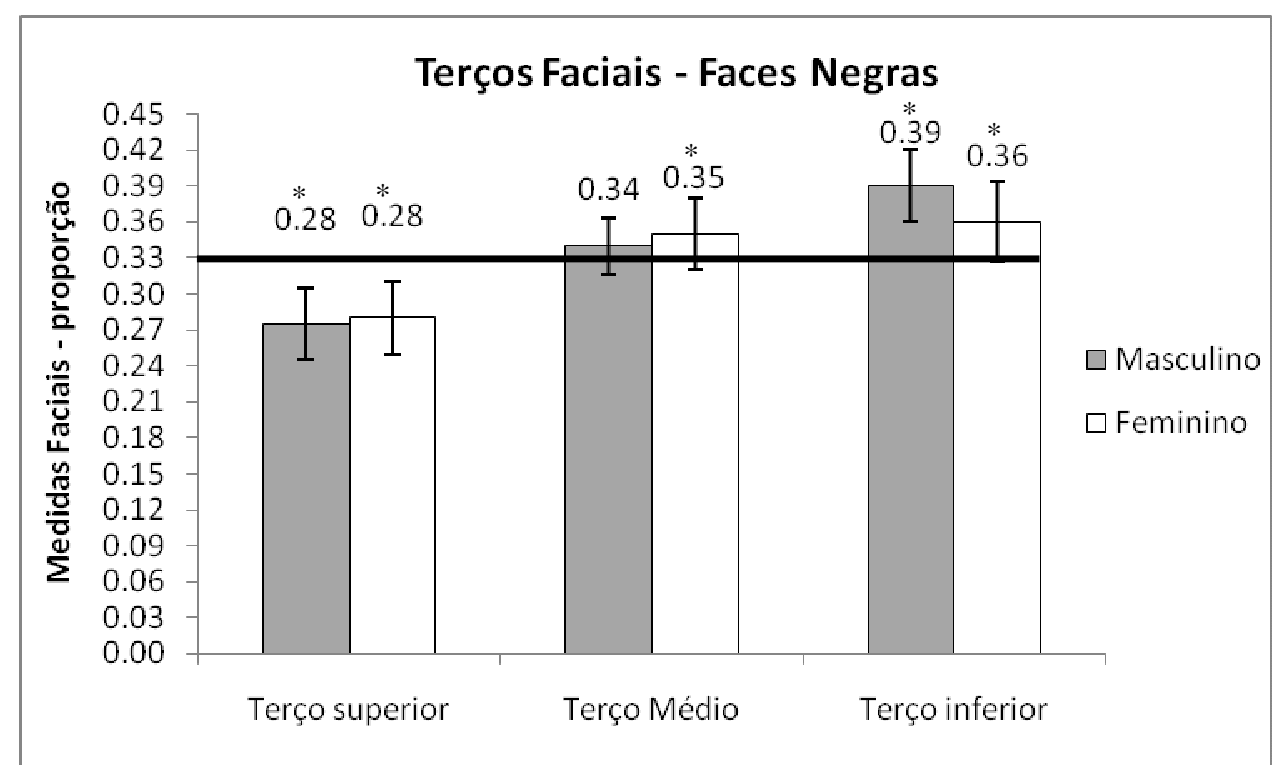

Figura 17. Análise facial dos terços das faces masculinas e femininas pretas (os dados são representados como as proporções dos terços e \pm E.P.M.; * $\mathrm{p}<0,01$ comparado com o esperado, 0,33 destacado pela linha)

Para o protótipo masculino as proporções foram: terço superior 0,27 , terço médio 0,35 e terço inferior 0,38. Para o protótipo feminino as proporções foram: terço superior 0,29, terço médio 0,36 e terço inferior 0,36 , nos dois gêneros seguem a tendência de medidas das faces que o compuseram (Figura 18). 


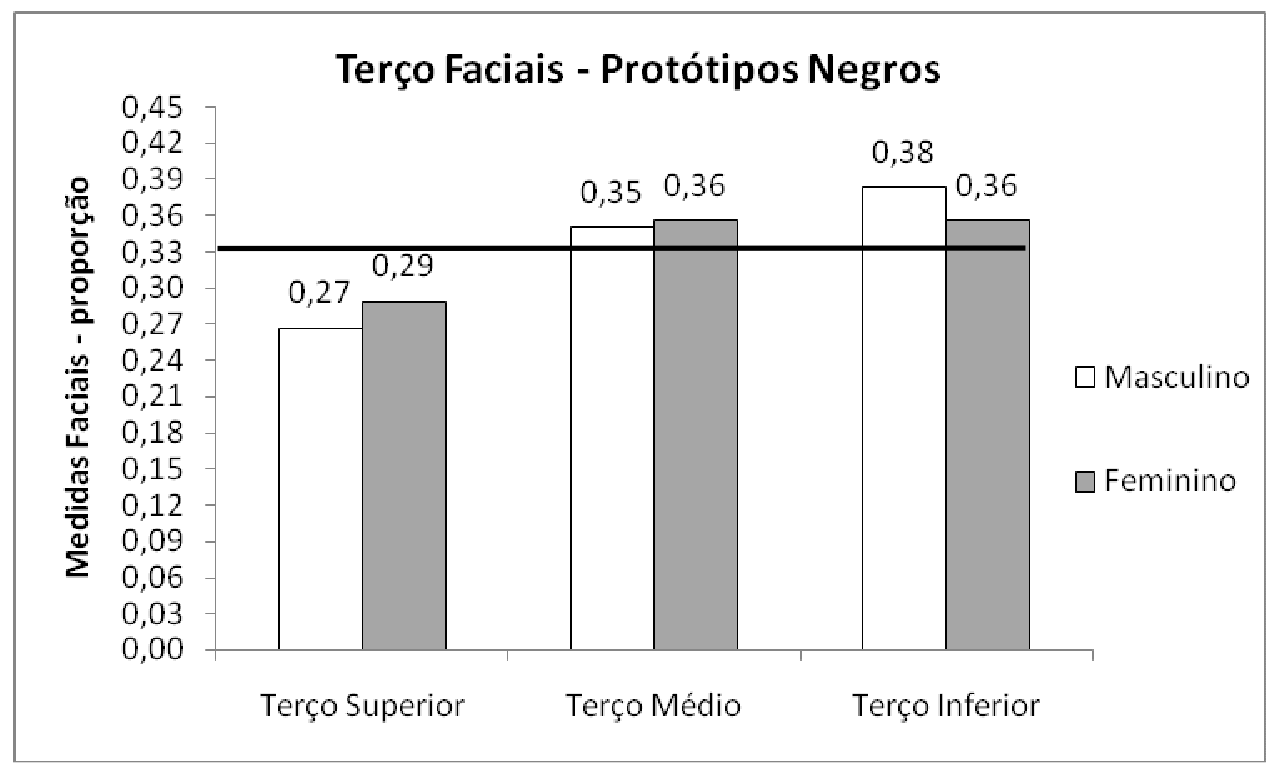

Figura 18. Análise facial dos terços dos protótipos pretos, masculino e feminino (os dados são representados como as proporções dos terços)

$\mathrm{Na}$ análise dos quintos, para as faces masculinas, o teste de normalidade indicou que os dados não se distribuem normalmente, aplicando-se então o teste não paramétrico de Friedman para comparação entre a soma dos postos entre as medidas dos quintos. Foram observadas diferenças significativas entre as proporções dos quintos [Q $(4,64)=159,216$; p<0,01]: o $1^{\circ}$ quinto apresentou mediana de 0,22 , o $2^{\circ}$ de 0,17 , o $3^{\circ}$ de 0,21 , o $4^{\circ}$ de 0,18 e o $5^{\circ}$ de 0,22 . Diferenças significativas $(\mathrm{p}<0,05)$ foram observadas entre os pares de quintos: $1^{\mathrm{o}} \mathrm{e}$ $2^{\circ}, 1^{\circ}$ e $4^{\circ}, 2^{\circ}$ e $3^{\circ}, 2^{\circ}$ e $5^{\circ}, 3^{\circ}$ e $4^{\circ}, 4^{\circ}$ e $5^{\circ}$. Entre os quintos $1^{\circ}$ e $3^{\circ}$ (medida da orelha direita ao canto ocular externo direito e distância intercantal, respectivamente), $1^{\circ}$ e $5^{\circ}$ (medidas da orelha ao canto ocular externo direito e esquerdo, respectivamente), $2^{\circ}$ e $4^{\circ}$ (medidas dos olhos direito e esquerdo respectivamente) e $3^{\circ}$ e $5^{\circ}$ (distância intercantal e medida do canto ocular externo esquerdo a orelha esquerda) não foram verificadas diferenças significativas $(\mathrm{p}>0,05)$.

O teste de Wilcoxon foi aplicado às proporções dos quintos para comparações com a proporção esperada $(0,20)$. Foram verificadas diferenças significativas $(p<0,01)$ entre a medida esperada e as medidas de todos os quintos analisados (Figura 19). 
Para as faces femininas o teste de normalidade também indicou que os dados dos cinco quintos não se distribuem normalmente, tendo sido aplicado o teste não paramétrico de Friedman para comparação entre a soma dos postos das medianas dos quintos. Foram observadas diferenças significativas entre as proporções dos quintos $[\mathrm{Q}(4,64)=166,331$; $\mathrm{p}<0,01$ ] com o $1^{\mathrm{o}}$ quinto com mediana de 0,22 , o $2^{\circ}$ quinto 0,18 , o $3^{\circ}$ quinto 0,21 , o $4^{\circ}$ quinto 0,18 e o $5^{\circ}$ quinto 0,22 . Assim como para as faces masculinas, diferenças significativas $(p<0,05)$ foram observadas entre os pares de quintos: $1^{\circ}$ e $2^{\circ}, 1^{\circ}$ e $4^{\circ}, 2^{o}$ e $3^{\circ}, 2^{\circ}$ e $5^{\circ}, 3^{\circ}$ e $4^{o}$, $4^{\mathrm{o}}$ e $5^{\mathrm{o}}$. Entre os $1^{\mathrm{o}}$ e $3^{\mathrm{o}}$ quintos, $1^{\mathrm{o}}$ e $5^{\mathrm{o}}$ quintos, $2^{\mathrm{o}}$ e $4^{\mathrm{o}}$ quintos e $3^{\circ}$ e $5^{\circ}$ quintos não foram verificadas diferenças significativas $(p>0,05)$.

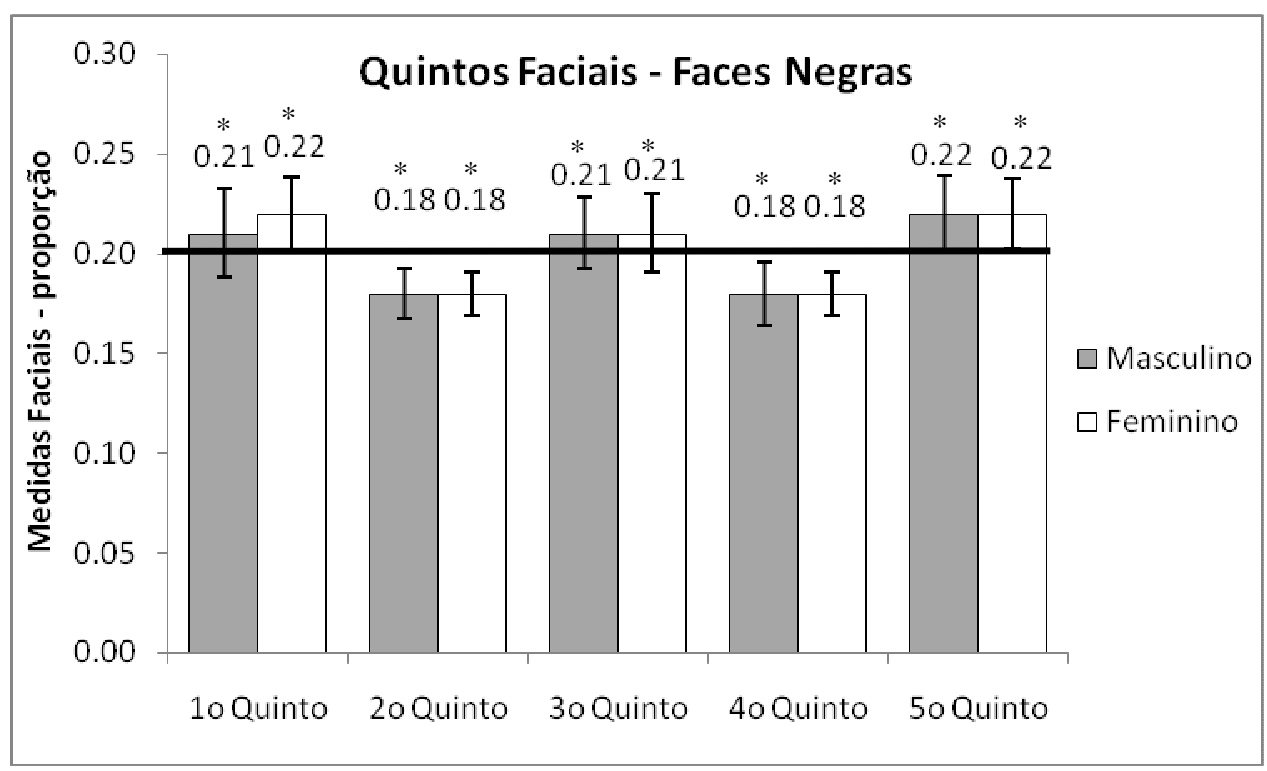

Figura 19. Análise facial dos quintos das faces masculinas e femininas pretas (os dados são representados como as proporções dos terços e \pm E.P.M; ${ }^{*} \mathrm{p}<0,01$ comparado com o esperado 0,20 destacado pela linha)

Tanto as faces masculinas quanto as femininas não tiveram as proporções dos quintos estatisticamente iguais à proporção esperada $(0,20)$, com um aumento de proporções de medidas no $1^{\circ}$ e $3^{\circ}$ e $5^{\circ}$ quintos e uma diminuição das proporções nos $2^{\circ}$ e $4^{\circ}$ quintos. 
Para os protótipos as proporções dos quintos foram iguais nos dois gêneros $\left(1^{\circ}\right.$ quinto $0,22,3^{\circ}$ quinto 0,20, o $4^{\circ}$ quinto $0,18,5^{\circ}$ quinto 0,23 ), exceto no $2^{\circ}$ quinto que apresentou 0,17 para o masculino e 0,18 para o feminino. Os aumentos de proporções de medidas observados nos $1^{\circ}$ e $5^{\circ}$ quintos nas faces pretas foram observados tanto nos protótipos quanto nas faces da amostra, como também as diminuições das proporções nos $2^{\circ}$ e $4^{\circ}$ quintos. Os $3^{\text {os }}$ quintos dos protótipos tiveram proporções iguais à medida esperada $(0,20)$ apenas para os protótipos e não para amostra estudada (Figura 20).

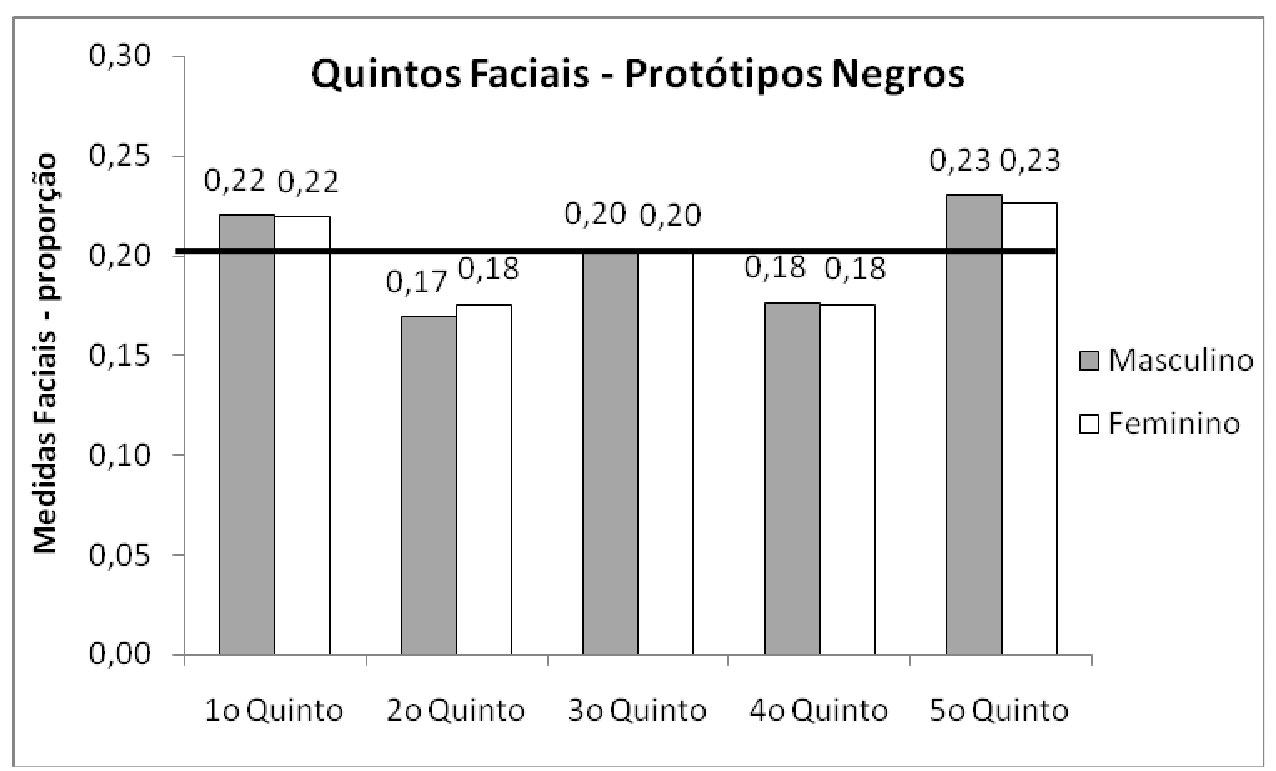

Figura 20. Análise facial dos quintos dos protótipos pretos, masculino e feminino (os dados são representados como as proporções dos quintos)

Ao analisar os meios faciais (simetria) para as faces masculinas pretas masculinas o teste de normalidade indicou que os dados não se distribuem normalmente, para tanto foi aplicado o teste de Wilcoxon para análise entre as proporções das hemifaces direita e esquerda Os resultados apontaram que as medidas não foram estatisticamente diferentes $(p>0,01): 1 d$ e $1 e=0,13 ; 2 d$ e $2 e=0,16 ; 3 d$ e $3 e=0,25 ; 4 d=0,45$ e $4 e=0,46($ Figura 21$)$.

Também para as faces femininas o teste de normalidade indicou que as medidas não se distribuem normalmente, o teste de Wilcoxon foi utilizado então para análise entre as medidas 
das hemifaces direita e esquerda. Os resultados apontaram que as medidas foram estatisticamente iguais $(p>0,01)$ : $1 d$ e $1 e=0,12 ; 2 d$ e $2 e=0,15 ; 3 d$ e $3 e=0,26 ; 4 d=0,46$ e 4 e $=0,47$ (Figura 21). Estes dados mostram que tanto as faces masculinas quanto às femininas pretas são simétricas.

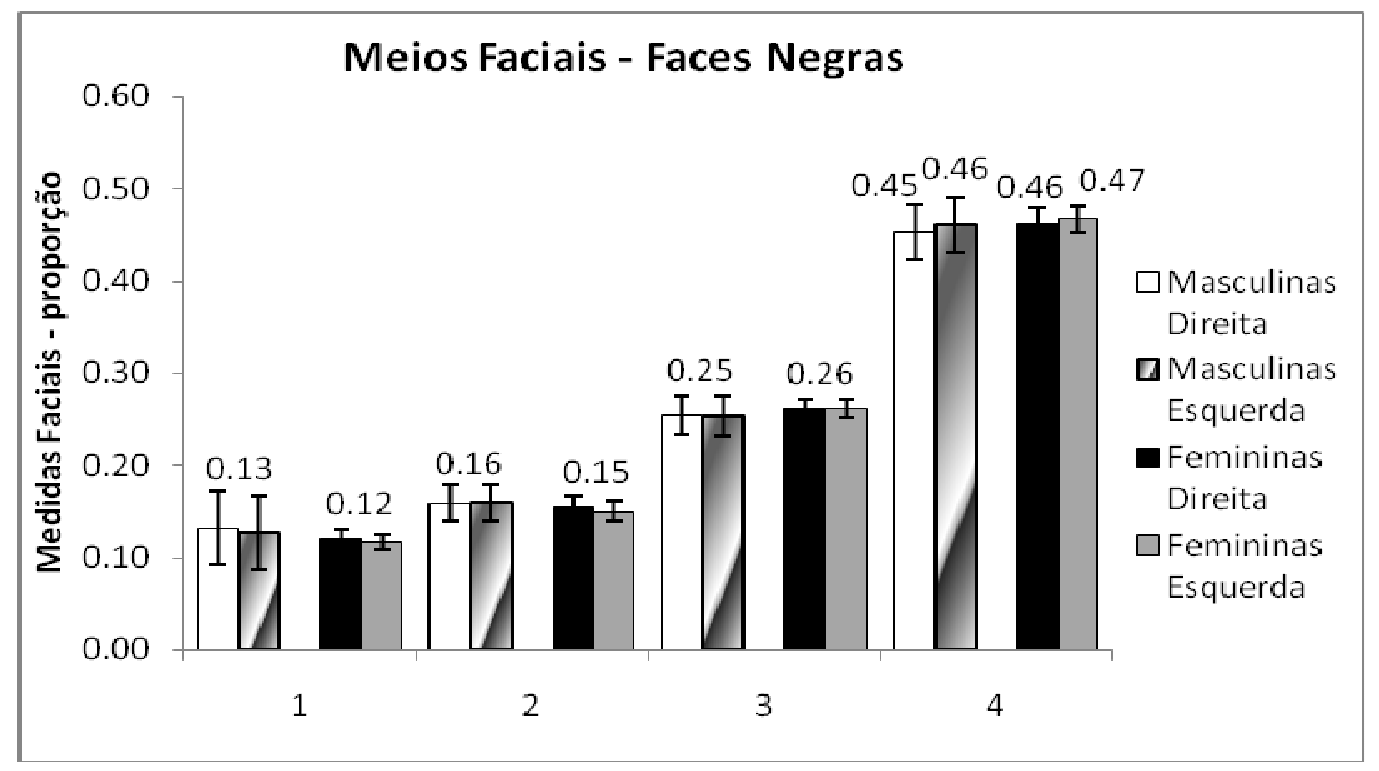

Figura 21. Análise facial dos meios (simetria) das faces masculinas e femininas pretas (os dados são representados como as proporções dos meios faciais e \pm E.P.M.)

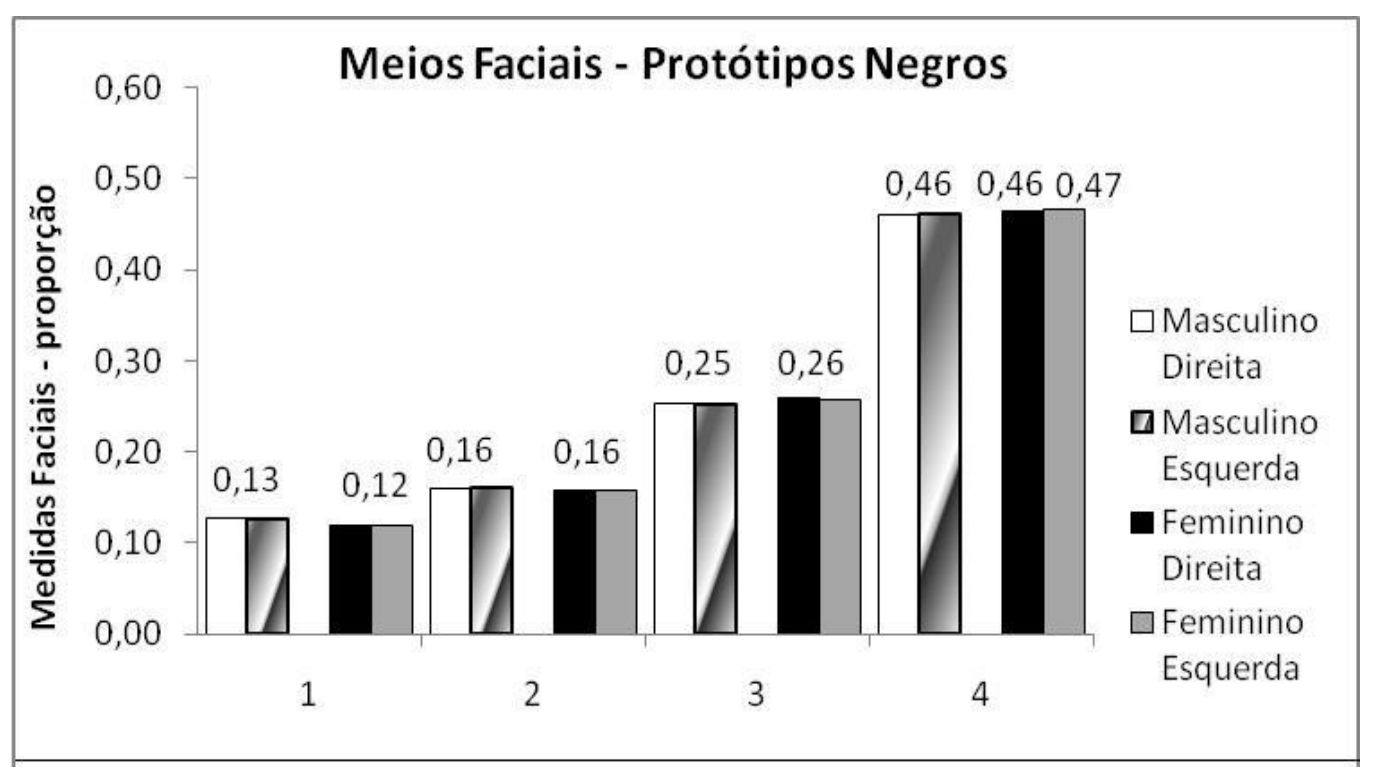

Figura 22. Análise facial dos meios (simetria) dos protótipos pretos, masculino e feminino (os dados são representados como as proporções dos meios faciais) 
Para o protótipo masculino as medidas foram: $1 \mathrm{~d}$ e $1 \mathrm{e}=0,13 ; 2 \mathrm{~d}$ e $2 \mathrm{e}=0,16 ; 3 \mathrm{~d}=3 \mathrm{e}$ $=0,25 ; 4 \mathrm{~d}$ e $4 \mathrm{e}=0,46$ (Figura 22). Para o protótipo feminino houve uma mínima diferença de 0,01 entre as hemifaces esquerda e direita para a medida 4 (da linha mediana à extremidade das orelhas) assim como verificada para a amostra feminina preta: $1 \mathrm{~d}$ e $1 \mathrm{e}=0,12 ; 2 \mathrm{~d}$ e $2 \mathrm{e}=$ 0,$16 ; 3 \mathrm{~d}$ e $3 \mathrm{e}=0,26 ; 4 \mathrm{~d}=0,46$ e $4 \mathrm{e}=0,47$ (Figura 22).

As medidas dos protótipos seguem a tendência das medidas das faces que o compuseram com uma pequena diferença $($ de 0,01$)$ entre direita e esquerda na medida 4 para o protótipo feminino.

\section{- Faces Pardas:}

As análises faciais das 130 imagens pardas, com 128 fotos de faces (64 femininas e 64 masculinas), mais os protótipos de cada gênero (1 masculino e 1 feminino), também indicaram alguns resultados diferentes dos apontados na literatura, tanto para os terços quanto para os quintos faciais.

$\mathrm{Na}$ análise dos terços, para as faces masculinas o teste de normalidade (KolmogorovSmirnov) mostrou que, apesar das medidas dos terços médio e inferior se distribuírem na curva normal, os dados do terço superior não são seguem a normalidade, portanto testes não paramétricos foram utilizados para as análises. O Teste de Friedman, demonstrou que as proporções dos três terços diferem entre si $[Q(2,64)=104,903 ; p<0,01]$, com medianas de 0,28 para o terço superior, 0,34 para o médio e 0,39 para o inferior (Figura 23). Foi verificado com o Teste de Wilcoxon, aplicado as entre as proporções de cada terço e a medida esperada $(0,33)$, que proporção do terço médio foi igual à esperada $(\mathrm{p}>0,01)$ e o terço superior e inferior apresentaram diferenças estatisticamente significativas $(\mathrm{p}<0,01)$ entre as suas proporções e a esperada. 
Para as faces femininas o teste de normalidade mostrou que os dados dos três terços não se distribuem normalmente. O Teste de Friedman também foi aplicado e visto que são diferentes entre si $[\mathrm{Q}(2,64)=86,03 ; \mathrm{p}<0,01]$, com medianas de 0,30 para o terço superior, 0,35 para o médio e 0,36 para o inferior. (Figura 23). O Teste de Wilcoxon aplicado entre as medidas de cada terço e a medida esperada $(0,33)$ demonstrou que houve diferenças significativas $(\mathrm{p}<0,01)$ entre as três medidas dos terços superior e inferior comparadas à medida esperada.

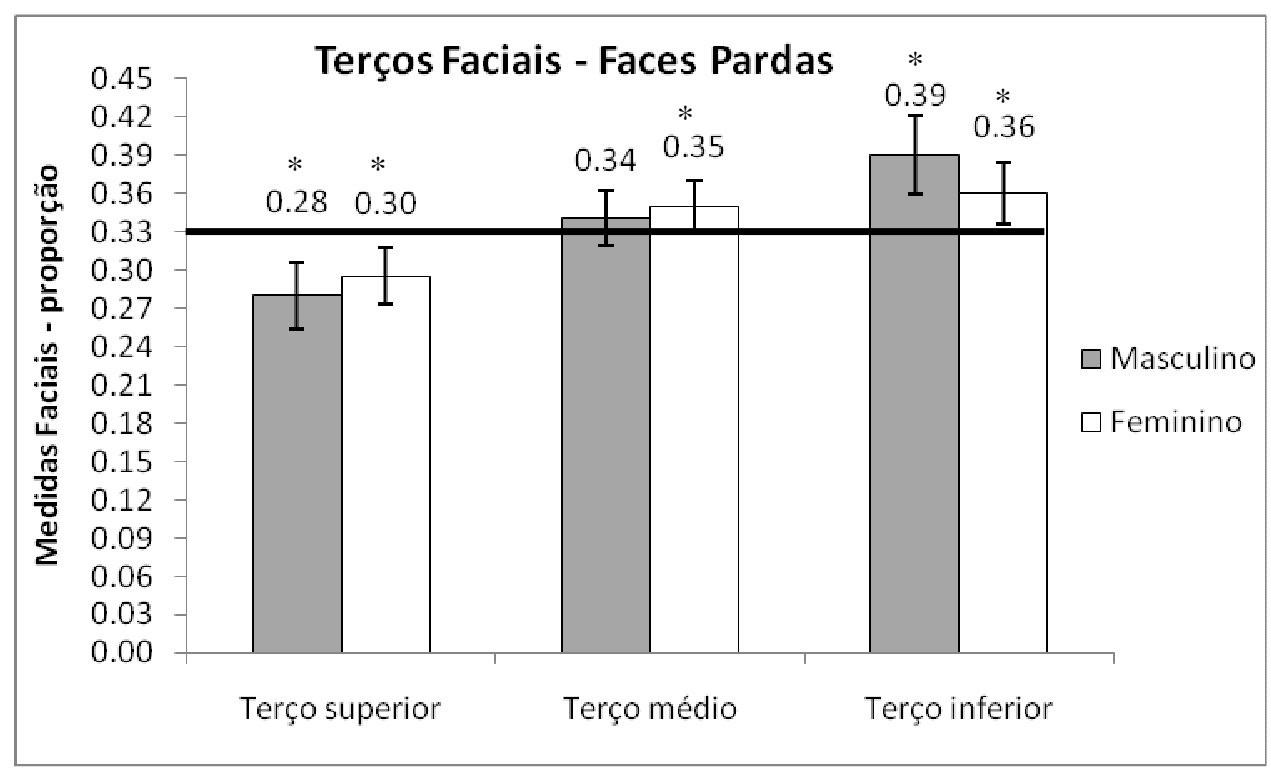

Figura 23. Análise facial dos terços das faces masculinas e femininas pardas (os dados são representados como as proporções dos terços; \pm E.P.M.; * $\mathrm{p}<0,01$ comparado com o esperado 0,33 destacado pela linha)

Para o protótipo masculino pardo as proporções foram: terço superior 0,28 , terço médio 0,33 e terço inferior 0,39 . Para o protótipo feminino as proporções foram: terço superior 0,29, terço médio 0,34 e terço inferior 0,36 (Figura 24). 


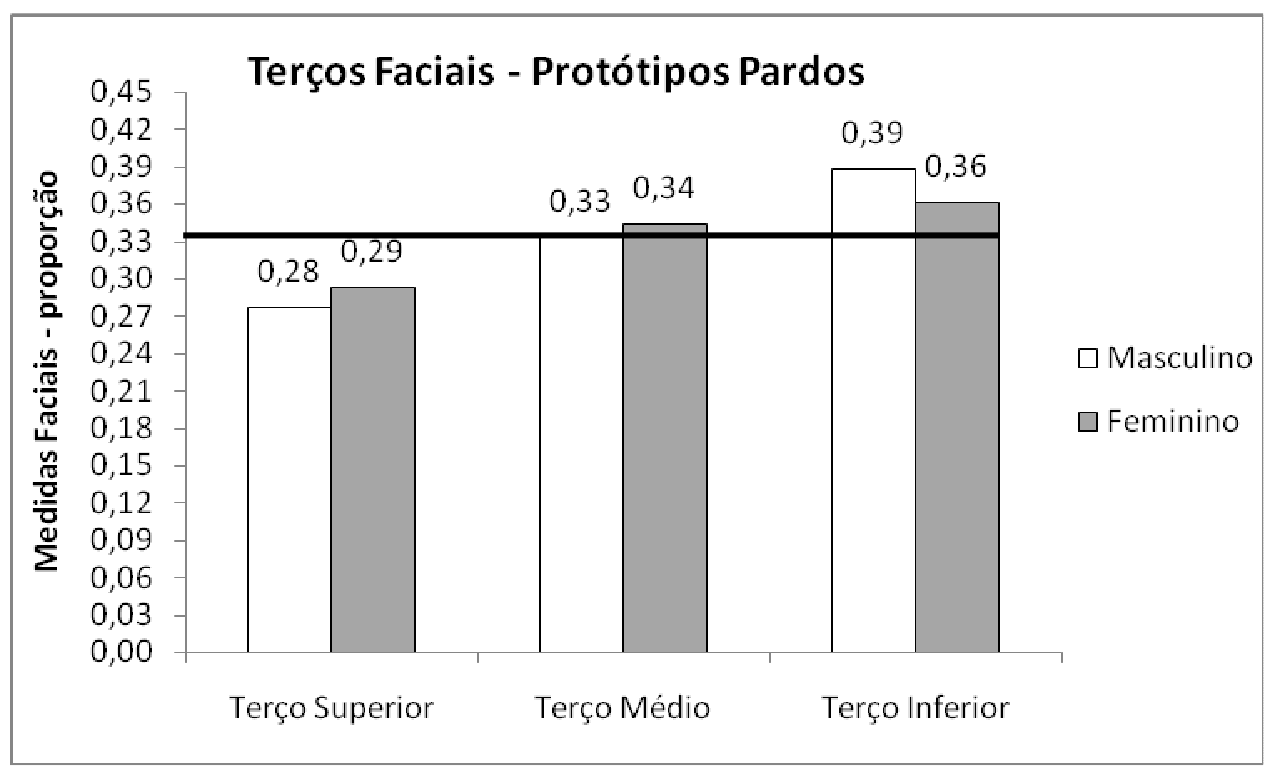

Figura 24. Análise facial dos terços dos protótipos pardos, masculino e feminino (os dados são representados como as proporções dos terços)

$\mathrm{Na}$ análise dos quintos para as faces masculinas o teste de normalidade (KolmogorovSmirnov) indicou que os dados não se distribuem normalmente, aplicando-se então o teste de Friedman para comparação entre a soma dos postos das medidas dos quintos. Foram observadas diferenças significativas entre as proporções dos quintos [Q $(4,64)=201,46$; $\mathrm{p}<0,01]$ : o $1^{\mathrm{o}}$ quinto apresentou mediana de 0,23 , o $2^{\circ}$ de 0,17 , o $3^{\circ}$ de 0,20 , o $4^{\circ}$ de 0,17 e o $5^{\circ}$ de 0,23 . Diferenças significativas $(\mathrm{p}<0,05)$ foram observadas entre os pares de quintos: $1^{\mathrm{o}} \mathrm{e}$ $2^{\circ}, 1^{\circ}$ e $3^{\circ}, 1^{\circ}$ e $4^{\circ}, 2^{\circ}$ e $3^{\circ}, 2^{\circ}$ e $5^{\circ}, 3^{\circ}$ e $4^{\circ}, 3^{\circ}$ e $5^{\circ}, 4^{\circ}$ e $5^{\circ}$ Entre os quintos $1^{\circ}$ e $5^{\circ}$ (medidas da $^{\circ}$ orelha ao canto ocular externo direito e esquerdo, respectivamente) e $2^{\circ}$ e $4^{\circ}$ (medidas dos olhos direito e esquerdo respectivamente) não foram verificadas diferenças significativas $(\mathrm{p}>0,05)$.

$\mathrm{O}$ teste de Wilcoxon demonstrou diferenças significativas $(\mathrm{p}<0,01)$ entre a medida esperada $(0,20)$ e as medidas dos $1^{\circ}, 2^{\circ}, 4^{\circ}$ e $5^{\circ}$ quintos. Já o $3^{\circ}$ quinto teve medida igual à esperada (Figura 25).

Para as faces femininas o teste de normalidade também indicou que os dados dos cinco quintos não se distribuem normalmente, sendo então aplicado o teste de Friedman. Foram 
observadas diferenças significativas entre as proporções dos quintos $[\mathrm{Q}(4,64)=163,91$; $\mathrm{p}<0,01$, com o $1^{\mathrm{o}}$ quinto com mediana de 0,23 , o $2^{\mathrm{o}}$ quinto 0,17 , o $3^{\mathrm{o}}$ quinto 0,21 , o $4^{\mathrm{o}}$ quinto 0,18 e o $5^{\circ}$ quinto 0,22 . Assim como para as faces masculinas, diferenças significativas $(\mathrm{p}<0,05)$ foram observadas entre os pares de quintos: $1^{\circ}$ e $2^{\circ}, 1^{\circ}$ e $4^{\circ}, 2^{\circ}$ e $3^{\circ}, 2^{\circ}$ e $5^{\circ}, 2^{\circ}$ e $4^{\circ}$, $4^{\circ}$ e $5^{\circ}$. Entre os $1^{\circ}$ e $3^{\circ}$ quintos, $1^{\circ}$ e $5^{\circ}$ quintos, $2^{\circ}$ e $4^{\circ}$ quintos e $3^{\circ}$ e $5^{\circ}$ quintos não foram verificadas diferenças significativas $(p>0,05)$. O teste de Wilcoxon foi aplicado nas proporções dos quintos para comparações à proporção esperada $(0,20)$. Foram verificadas diferenças significativas $(\mathrm{p}<0,01)$ entre a medida esperada e as medidas de todos os quintos analisados (Figura 25).

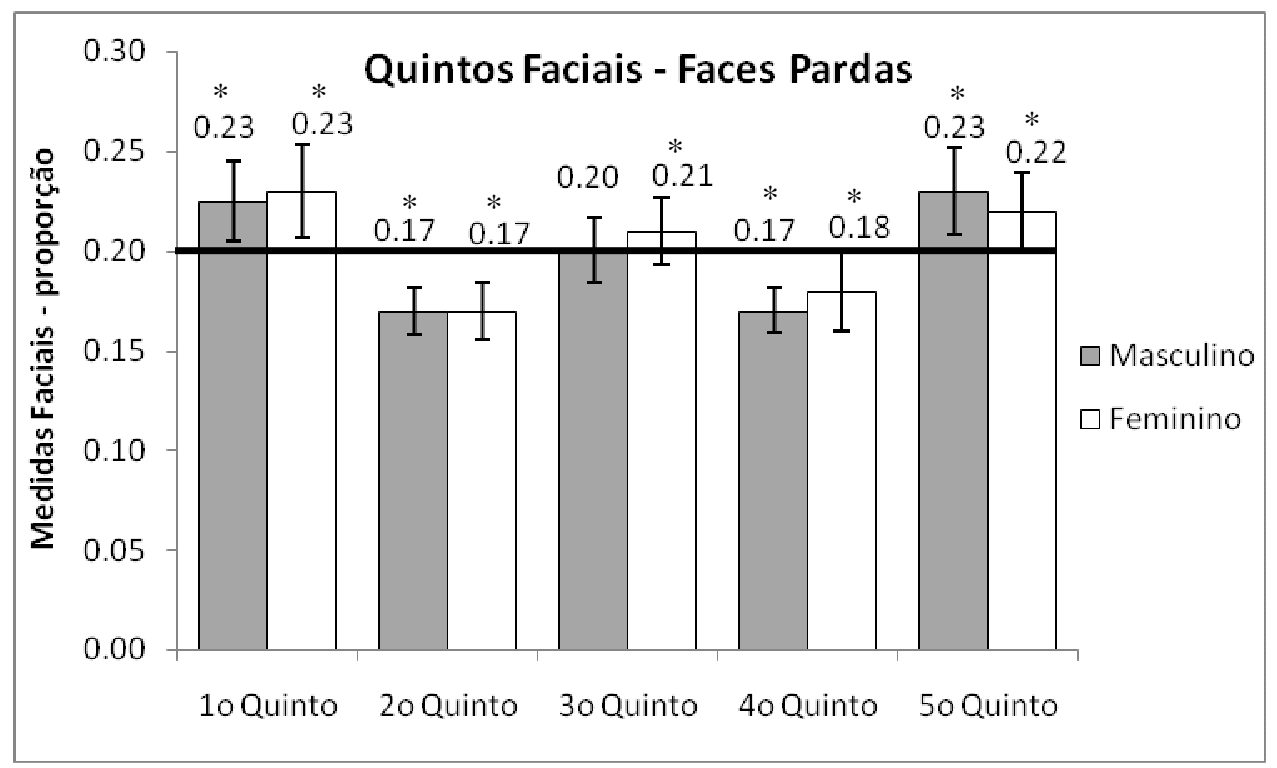

Figura 25. Análise facial dos quintos das faces masculinas e femininas pardas (os dados são representados como as proporções dos terços e \pm E.P.M.; * $\mathrm{p}<0,01$ comparado com $\mathrm{o}$ esperado 0,20 destacado pela linha)

Para as faces pardas houve um aumento de proporções de medidas no $1^{\circ}$ e $3^{\circ}$ e $5^{\circ}$ quintos e uma diminuição das proporções nos $2^{\circ}$ e $4^{\circ}$ quintos. Somente o $3^{\circ}$ quinto apresentou proporção estatisticamente igual à proporção esperada nas faces masculinas $(0,20)$.

Para o protótipo masculino as proporções dos quintos foram: $1^{\circ}$ quinto 0,24, o $2^{\circ}$ quinto 0,16 , o $3^{\circ}$ quinto 0,19, o $4^{\circ}$ quinto 0,18 e o $5^{\circ}$ quinto 0,24 . Para o protótipo feminino as 
proporções foram: $1^{\mathrm{o}}$ quinto 0,22 , o $2^{\circ}$ quinto 0,18 , o $3^{\circ}$ quinto 0,20, o $4^{\circ}$ quinto 0,18 e o $5^{\circ}$ quinto 0,23 (Figura 26). As proporções apresentaram aumentos com relação à esperada $(0,20)$ nos $1^{\circ}$ e $5^{\circ}$ quintos e diminuição dos $3^{\circ}$ e $4^{\circ}$ quintos nos dois sexos de protótipos, sendo o $2^{\circ}$ quinto maior no masculino e igual à esperada no feminino.

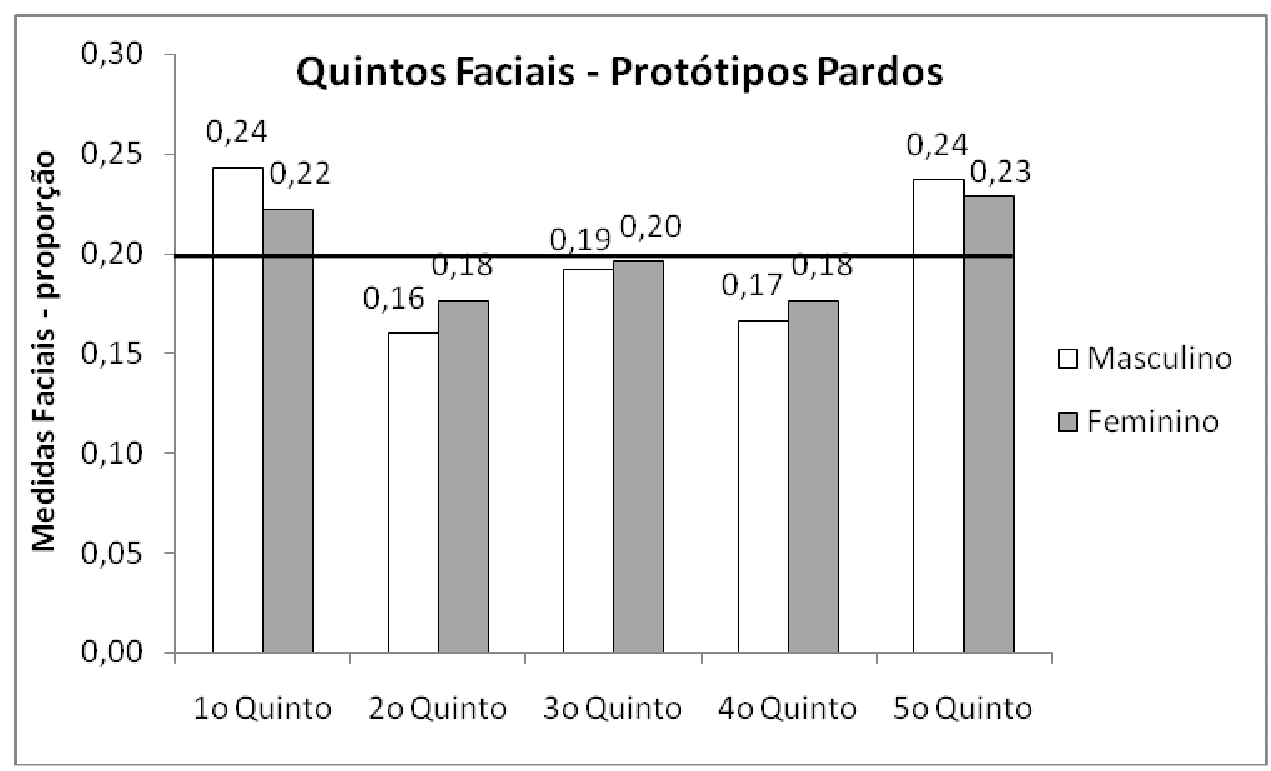

Figura 26. Análise facial dos quintos dos protótipos pardos, masculino e feminino (os dados são representados como as proporções dos quintos)

O teste de normalidade indicou que os dados da análise dos meios (simetria) para as faces masculinas pardas não se distribuem normalmente, então foi aplicado o teste de Wilcoxon para análise entre as proporções das hemifaces direita e esquerda. Os resultados apontaram que as medidas não foram estatisticamente diferentes $(p>0,01)$ : $1 \mathrm{~d}$ e $1 \mathrm{e}=0,12 ; 2 \mathrm{~d}$ e $2 \mathrm{e}=0,15 ; 3 \mathrm{~d}$ e $3 \mathrm{e}=0,25 ; 4 \mathrm{~d}=0,46$ e $4 \mathrm{e}=0,45$ (Figura 27 ). 
Também para as faces femininas o teste de normalidade indicou que as medidas também não se distribuem normalmente, utilizando o teste de Wilcoxon para análise entre as medidas das hemifaces direita e esquerda. Os resultados apontaram que as medidas foram estatisticamente iguais ( $p>0,01)$ : $1 \mathrm{~d}$ e $1 \mathrm{e}=0,12 ; 2 \mathrm{~d}$ e $2 \mathrm{e}=0,15 ; 3 \mathrm{~d}$ e $3 \mathrm{e}=0,26 ; 4 \mathrm{~d}$ e $4 \mathrm{e}=0,47$ (Figura 27). Estes dados mostram que tanto as faces masculinas quanto às femininas pardas são simétricas.

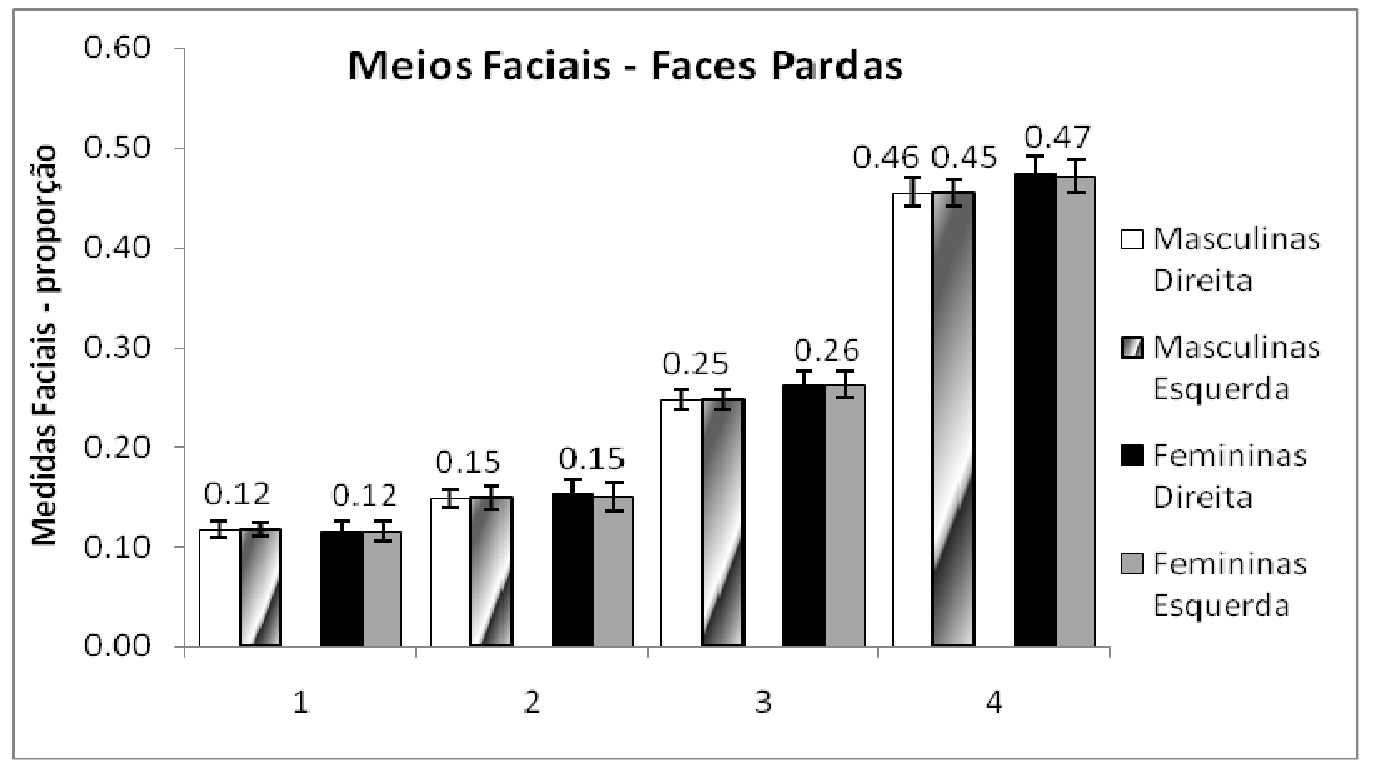

Figura 27. Análise facial dos meios (simetria) das faces masculinas e femininas pardas (os dados são representados como as proporções dos meios faciais e \pm E.P.M.)

Para o protótipo masculino as medidas foram: $1 \mathrm{~d}=0,11$ e $1 \mathrm{e}=0,12 ; 2 \mathrm{~d}=0,16$ e $2 \mathrm{e}=$ 0,$15 ; 3 \mathrm{~d}=0,26$ e $3 \mathrm{e}=0,25 ; 4 \mathrm{~d}$ e $4 \mathrm{e}=0,48$. Para o protótipo feminino foi verificado: $1 \mathrm{~d}=$ 0,12 e $1 \mathrm{e}=0,11 ; 2 \mathrm{~d}$ e $2 \mathrm{e}=0,15 ; 3 \mathrm{~d}=0,25$ e $3 \mathrm{e}=0,26 ; 4 \mathrm{~d}$ e $4 \mathrm{e}=0,48$ (Figura 28). As proporções dos meios nos protótipos apresentaram diferenças de 0,01 entre as medidas 1, 2 e 3 no masculino e nas medidas 1 e 3 no feminino. 


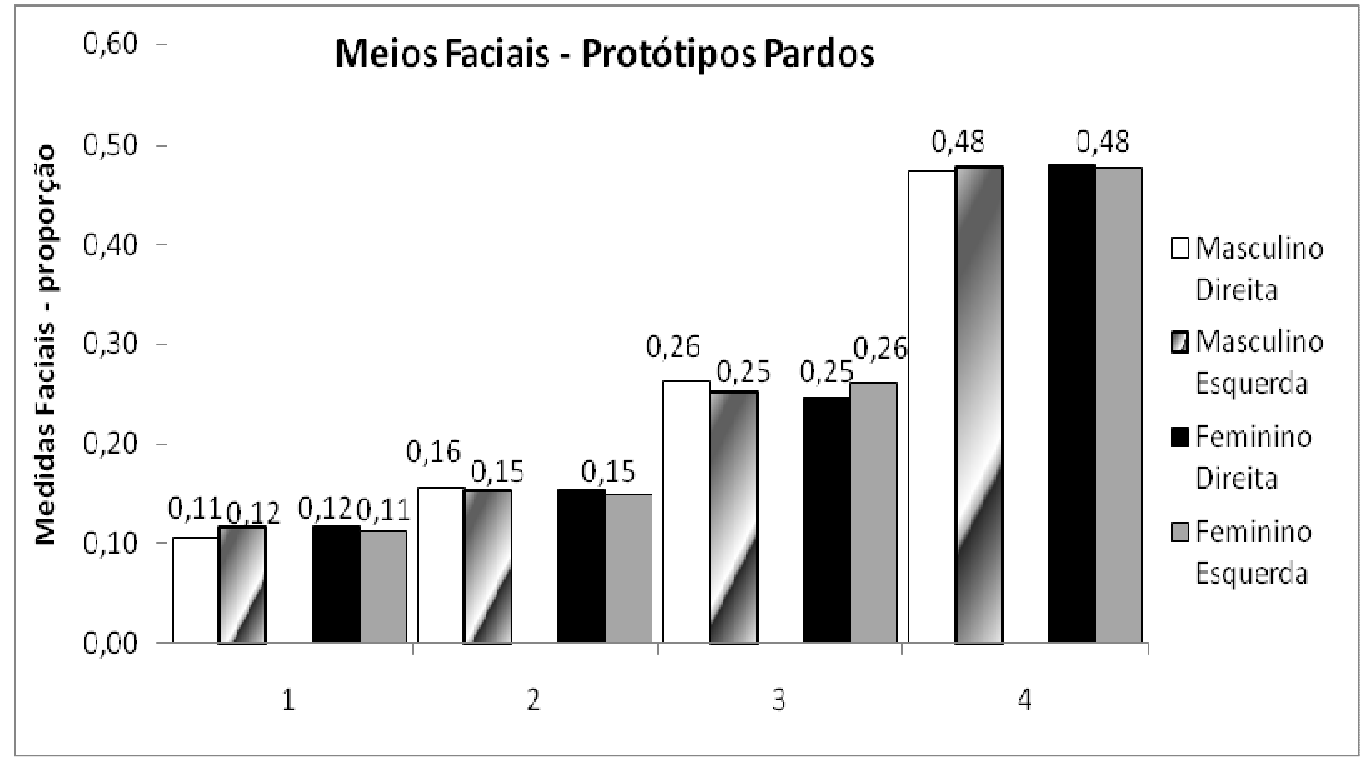

Figura 28. Análise facial dos meios (simetria) dos protótipos pardos, masculino e feminino (os dados são representados como as proporções dos meios faciais)

\section{Discussão}

A análise das faces brancas revelou que, para a população de Ribeirão Preto/SP, as medidas dos terços superior e inferior não correspondem à medida preconizada pela literatura (GREGORET et al., 1999; PROFFIT; WHITE JUNIOR; SARVER, 2005) para faces harmônicas $(0,33)$, em que os três terços faciais teriam medidas proporcionais praticamente iguais. Somente o terço médio, tanto para as faces masculinas quanto para as femininas, apresentou a medida esperada. O aumento das proporções de medidas no sentido vertical, de cima para baixo (terço superior menor que o médio e este menor que o inferior) foi observado tanto para as faces masculinas quanto para as femininas.

Um estudo sobre perfis faciais de brasileiros com faces equilibradas (Classe I de Angle) encontrou que os terços inferiores de faces de indivíduos brancos são ligeiramente maiores que os terços médios (REIS et al., 2006a), sem que isto afete o equilíbrio facial dos mesmos. Também foi demonstrado por Reis et al. (2006a) que os terços inferiores de homens são um pouco maiores que os das mulheres, como observado no presente estudo. Apesar de 
haver diferenças entre análises faciais frontais e de perfil estes dois dados podem ser complementares e indicar um possível padrão facial da população branca brasileira.

Arnett e McLaughlin (2004) discutem que raramente os terços médios e inferiores das faces são iguais e que o mais importante seria analisar as estruturas dentro do terço inferior e não somente as proporções entre ele e o médio. Já Epker, Stella e Fish (1994) descrevem que uma face de um indivíduo atrativo tem as proporções de 0,30 para o terço superior, 0,35 para o médio e 0,35 para o inferior; proporções estas bem próximas às encontradas no presente estudo.

Com relação às medidas dos quintos faciais nas faces brancas masculinas e femininas houve um aumento de proporções de medidas nos $1^{\circ}$ e $5^{\circ}$ quintos e uma diminuição das proporções nos $2^{\circ}$ e $4^{\circ}$ quintos quando comparadas à medida esperada para faces harmônicas $(0,20)$, segundo a literatura da área (GREGORET et al., 1999; PROFFIT; WHITE JUNIOR; SARVER, 2005). Apenas as medidas do $3^{\circ}$ quinto igualaram-se à medida esperada $(0,20)$, para ambos os sexos. Quanto à análise dos meios pode-se perceber que as faces brancas femininas e masculinas são simétricas, ou seja, não apresentam grandes desvios entre as hemifaces direita e esquerda, como visto na literatura em faces equilibradas (EPKER; STELLA; FISH, 1994; GREGORET et al., 1999, PROFFIT; WHITE JUNIOR; SARVER, 2005; SUGUINO et al., 1996).

Para os protótipos brancos, tanto o masculino quanto o feminino, as medidas dos terços seguiram a mesma tendência daquelas das faces que os compuseram, o que revelou para o masculino serem os terços superiores e inferiores diferentes da medida esperada $(0,33)$ e para o feminino os três terços diferentes da medida esperada $(0,33)$. Quanto aos quintos houve aumentos nas medidas observados nos $1^{\circ}$ e $5^{\circ}$ quintos como também as diminuições das proporções nos $2^{\circ}$ e $4^{\circ}$ quintos, como na amostra. Apenas a medida do $3^{\circ}$ quinto no protótipo branco foi diferente da amostra que o compôs $(0,19)$, não se igualando à medida 
0,20 esperada. O protótipo branco feminino mostrou simetria entre as hemifaces direita e esquerda, já o masculino apresentou pequena diferença de 0,01 na medida 3 (da linha mediana aos cantos oculares externos), fato que não prejudica a percepção da simetria do mesmo.

Para as faces pretas também foi verificado o aumento de proporções de medidas dos terços no sentido vertical, de cima para baixo (terço superior menor que o médio e este menor que o inferior), com medidas diferentes daquelas indicadas para faces harmônicas $(0,33$, segundo GREGORET et al., 1999; PROFFIT; WHITE JUNIOR; SARVER, 2005). Houve diferenças entre os gêneros para as medidas referentes ao terço médio, em que foi igual a 0,33 para as faces masculinas, e maior que 0,33 para as femininas. As faces masculinas seguiram a tendência das faces brancas em geral e as faces femininas apresentaram as maiores diferenças nos terços dentro da amostra da população preta da cidade de Ribeirão Preto/SP.

Um estudo feito nos EUA, ao comparar faces de mulheres pretas americanas com faces de mulheres brancas americanas, coma utilização dos parâmetros neoclássicos de análise facial (incluindo a igualdade dos terços faciais), indicou que perfis de faces de mulheres pretas e brancas apresentaram terços superior e inferior com proporções praticamente iguais e terço médio com proporção menor (PORTER; OLSON, 2001). Tais medidas verticais não apresentaram diferenças entre as etnias estudadas, tanto nos EUA quanto no Brasil no presente estudo, com a diferença de que na amostra brasileira os terços superiores e inferiores não se mostraram iguais.

As faces pretas masculinas e femininas não tiveram as medidas dos quintos estatisticamente iguais à medida esperada $(0,20)$, com um aumento de proporções de medidas no $1^{\circ}$ e $3^{\circ}$ e $5^{\circ}$ quintos e uma diminuição das proporções nos $2^{\circ}$ e $4^{\circ}$ quintos. Resultados diferentes do que diz a literatura em que faces equilibradas possuem cinco vezes o tamanho do olho, no sentido horizontal (GREGORET et al, 1999; PROFFIT; WHITE JUNIOR; SARVER, 2005). Todas as faces pretas apresentaram simetria bilateral pela análise dos meios, 
como preconiza a literatura para faces harmônicas (EPKER; STELLA; FISH, 1994; GREGORET et al., 1999; SUGUINO et al., 1996).

As medidas dos protótipos pretos, masculino e feminino, seguiram a mesma tendência de medidas das faces que o compuseram para os terços, e também não apresentaram medidas iguais às preconizadas na literatura. Quanto às medidas dos quintos, os protótipos pretos apresentaram aumento nas proporções dos $1^{\circ}$ e $5^{\circ}$ quintos e diminuição das proporções nos $2^{\circ}$ e $4^{\mathrm{o}}$ quintos. Para os $3^{\text {os }}$ quintos os protótipos tiveram proporções iguais à medida esperada $(0,20)$, medida diferente daquela vista na amostra e igual à preconizada na literatura (GREGORET et al., 1999; POWEL; HUMPHRIES, 1984 apud EDLER; ORTH, 2001). Os protótipos mostraram-se simétricos assim como a amostra que os compuseram.

Estes dados corroboram a literatura que diz serem as faces prototípicas imagens faciais que representam a aparência típica de um grupo de pessoas e podem ser representativas de categorias como sexo, raça ou idade, além de serem compostas pela média matemática dos valores dos traços da amostra que os compuseram, ao suprimir as variações da mesma (RHODES, 2006).

A análise das faces pardas masculinas revelou que, as medidas dos terços superior e inferior não correspondem à medida preconizada (0,33) (GREGORET et al., 1999; PROFFIT; WHITE JUNIOR; SARVER, 2005). Somente o terço médio, tanto para as faces masculinas quanto para as femininas, apresentou a medida esperada. Para as faces femininas nenhum terço correspondeu estatisticamente ao valor 0,33 . Nos dois gêneros o aumento das proporções de medidas foi no sentido vertical, de cima para baixo como visto nos brancos e pretos. Este dado foi uma tendência nas faces brasileiras estudadas, independente da etnia as proporções faciais mostraram o terço superior menor que o médio e este menor que o inferior.

Choe et al. (2004) mostraram, em um estudo comparativo entre faces de mulheres americanas coreanas e brancas, que também para as coreanas os padrões neoclássicos 
estipulados pela literatura não se encaixam nas análises faciais. Além de que há diferenças entre as medidas das faces de mulheres brancas e de coreanas.

Com relação às medidas dos quintos faciais nas faces pardas masculinas e femininas houve um aumento de proporções de medidas nos $1^{\circ}$ e $5^{\circ}$ quintos e uma diminuição das proporções nos $2^{\circ}$ e $4^{\circ}$ quintos quando comparadas à medida esperada $(0,20)$, segundo Gregoret et al. (1999) e Proffit, White Junior e Sarver (2005). As medidas do $3^{\circ}$ quinto igualaram-se à medida esperada $(0,20)$ para as faces masculinas e não para as femininas. Quanto à análise dos meios as faces pardas femininas e masculinas são simétricas, ou seja, não apresentam grandes desvios entre as hemifaces direita e esquerda como visto na literatura (EPKER; STELLA; FISH, 1994; GREGORET et al., 1999; SUGUINO et al., 1996).

As medidas faciais dos terços para protótipos pardos, tanto o masculino quanto o feminino, seguiram a mesma tendência daquelas das faces que os compuseram, ao mostrar que para o masculino serem os terços superiores e inferiores diferentes da medida esperada $(0,33)$ e para o feminino os três terços diferentes da medida esperada $(0,33)$. Quanto aos quintos houve aumentos nas medidas observados nos $1^{\circ}$ e $5^{\circ}$ quintos como também as diminuições das proporções nos $2^{\circ}$ e $4^{\circ}$ quintos, como na amostra. A medida do $3^{\circ}$ quinto no protótipo masculino $(0,19)$ foi diferente da amostra que o compôs. Com relação à medida dos meios os protótipos pardos feminino e masculino mostraram pequenas variações $(0,01)$ nas medidas 1 (da mediana à base alar do nariz), 2 (da mediana à comissura labial) e 3 (da mediana aos cantos oculares externos) entre as hemifaces direita e esquerda. Somente as medidas 4 (da mediana às orelhas) houve igualdade nas medidas. Contudo, tais variações são insignificantes para a percepção da simetria dos mesmos e são normais graus moderados de assimetrias na população em geral (PROFFIT; TURVEY, 2005).

As medidas dos protótipos das três etnias seguiram a tendência das medidas das faces que os compuseram. Pequenas diferenças $(0,01)$ encontradas tanto nas faces da amostra 
quanto nos protótipos não interferiram estatisticamente na análise global. Pequenas assimetrias corpóreas são encontradas em todos os animais e, de alguma maneira, foram selecionados evolutivamente e hoje são vistas como parte do desenvolvimento e das diferenças individuais de cada ser (ENQUIST et al., 2002; EPKER; STELLA; FISH, 1994).

Estes resultados mostraram que no geral, apesar da simetria estar presente em todas as faces do banco de faces da população de Ribeirão Preto/SP, estas facest não apresentaram medidas de terços e quintos iguais às indicadas na literatura como padrões de faces harmônicas (EPKER; STELLA; FISH, 1994; GREGORET et al., 1999, PROFFIT; WHITE JUNIOR; SARVER, 2005; SUGUINO et al., 1996).

Isto demonstra que a amostra estudada possa ter um padrão facial diferente daquele preconizado na literatura, com medidas que seguem normas com padrões estrangeiros (europeus ou norte americanos). Talvez tais normas não possam ser generalizadas para a população brasileira, tão miscigenada e ímpar em suas características físicas. Reis et al. (2006a) discutem tal questão ao proporem normas de medidas nacionais para análises de perfis na população brasileira.

Estudos mostram que as diferenças étnicas devem ser levadas em consideração neste tipo de análise (CHOE et al., 2004; ENLOW, 1993; REIS et al., 2006a, 2006b; SCAVONE JUNIOR et al., 2006), ainda mais quando se fala de população com múltiplas raízes raciais como a brasileira. Muitos outros estudos transculturais devem ser realizados a fim de ampliar as possibilidades de análises faciais em diferentes grupos étnicos e raciais.

Esta é uma importante questão a ser investigada no país, com a possibilidade de abranger outras amostras regionais, a fim de ampliar o estudo facial no Brasil e encontrar parâmetros nacionais de análises a serem adotados em cirurgias faciais estéticas e/ou funcionais tanto em normas frontais quanto de perfis. 
Estudos sobre percepção de faces podem auxiliar nesta investigação da análise facial. Cruzamentos de dados físicos e subjetivos devem trazer luz aos aspectos físicos normativos para a população. Reis et al. (2006b) propuseram a 'Análise Facial Subjetiva' como mais um critério diagnóstico na atividade clínica em pacientes odontológicos. Por meio dessa análise os indivíduos são classificados de acordo com a agradabilidade estética em três níveis: esteticamente agradável, esteticamente aceitável e esteticamente desagradável. Tal nomenclatura foi anteriormente utilizada por Neger e Newark (1959, apud REIS et al., 2006b) que afirmaram ser a maioria da população composta por indivíduos esteticamente aceitáveis.

O estudo (REIS et al., 2006b) avaliou a distribuição dos brasileiros brancos, adultos, normais (face equilibrada), com idades entre 18 a 36 anos, segundo tais critérios de agradabilidade. Os resultados da avaliação de faces perfil mostraram que $89 \%$ dos indivíduos foram classificados como esteticamente aceitáveis, 3\% agradáveis e 8\% desagradáveis, o que comprova a tese de que a maioria da população é esteticamente aceitável (Neger; Newark, 1959, apud REIS et al., 2006b) e salientam a excepcionalidade da face agradável (apenas 3\%). Estes dados mostram a importância de uma análise multifatorial na avaliação facial de um indivíduo, com parâmetros subjetivos e morfológicos envolvidos.

Um primeiro estudo realizado por Arrais (2007) sobre atratividade do banco de faces da população de Ribeirão Preto e seus respectivos protótipos indicou que todas as faces foram consideradas pouco atraentes no geral, com notas baixas. As faces brancas foram consideradas mais atraentes que as faces pardas e não houve diferença significativa entre as faces brancas e pretas e nem entre as faces pretas e pardas.

Neste mesmo estudo a atratividade dos protótipos foi mediana, contudo suas médias de julgamentos foram superiores às das faces da amostra (ARRAIS, 2007). Isto corrobora os dados da literatura que dizem que um protótipo construído por faces não atrativas terá níveis de atratividade superior a elas; já um protótipo gerado por faces muito atrativas, terá um nível 
inferior de atratividade que foi também verificado neste estudo (LANGLOIS; ROGGMAN, 1990).

Frequentemente os protótipos faciais são julgados com aparências mais jovens e com maior atratividade do que as imagens faciais que lhe deram origem. $O$ aumento na atratividade tem sido atribuído à forma média do composto (LANGLOIS; ROGGMAN, 1990) e um nivelamento ou uma suavização do tom da pele (BENSON; PERRETT, 1991). Tais características, ademais sua atratividade mediana faz dos protótipos bons parâmetros comparativos em estudos com faces com grandes desvios na harmonia.

Este primeiro estudo sobre a atratividade facial deste banco de faces mostrou que, apesar de serem simétricas, pequenas diferenças entre os terços e quintos faciais podem ter comprometido a harmonia facial. Isto pode ter influenciado os julgamentos de atratividade das amostras nas três etnias, consideradas pouco atrativas em média.

$\mathrm{O}$ fato dos julgamentos das faces brancas serem maiores que os julgamentos das pardas pode estar fundamentado não somente na forma física da face (uma vez que as análises físicas faciais destas duas etnias mostraram-se bastante semelhantes em medianas), mas também em outras variáveis, como cor e manchas de pele, cor dos olhos, formatos do nariz e boca, dentre outras. Esta complexidade sempre estará presente em julgamentos estéticos influenciando-os (JONES et al., 2004). Outros estudos devem ser realizados com este banco de faces, com maior rigor no controles de variáveis e tentando correlacionar parâmetros físicos e subjetivos para um melhor entendimento de medidas que subjazem os parâmetros nacionais de análise e estudo facial. 


\section{2) ANÁLISE FACIAL DOS PACIENTES SUBMETIDOS À CIRURGIA ORTOGNÁTICA E} INVESTIGAČ̃̃O DA ATRATIVIDADE DOS MESMOS (EXPERIMENTOS 1 E 2).

\subsection{1) Análise Facial:}

Foram analisadas 23 imagens coloridas, recortadas em molduras ovais, de maneira que os elementos faciais externos (orelhas, pescoço e cabelos) fossem suprimidos. Foram 20 fotografias frontais de 10 pacientes (5 homens e 5 mulheres), com expressão facial neutra, nas fases pré o pós-operatórias, submetidos à cirurgias ortognáticas junto ao CEDEFACE (Centro de Pesquisa e Tratamento das Deformidades Buco-Faciais), localizado na cidade de Araraquara, SP e 3 protótipos faciais da população brasileira (masculinos branco e preto e feminino branco). As etnias e gêneros dos protótipos utilizados corresponderam às etnias e gêneros dos pacientes. Tais protótipos já tinham sido analisados na fase 1 deste estudo, contudo com as alterações da moldura elíptica, foram reanalisados para comparação com as faces dos pacientes.

As idades dos pacientes variaram entre 20 e 40 anos (média de 26,9 anos) e todos assinaram o Termo de Consentimento Livre e Esclarecido que autoriza a manipulação e utilização de suas imagens (Anexo A), aprovado pelo Comitê de Ética da FFCLRP-USP (Anexo B). As análises tiveram seus critérios baseados nas proporções entre os terços, meios e quintos faciais, demonstradas anteriormente, segundo Gregoret et al. (1999).

As faces dos pacientes foram numeradas de 1 a 5, divididas em dois gêneros, feminino (F) e masculino (M) e receberam as letras de identificação (A) para antes e (D) para depois da cirurgia (Figura 29). 

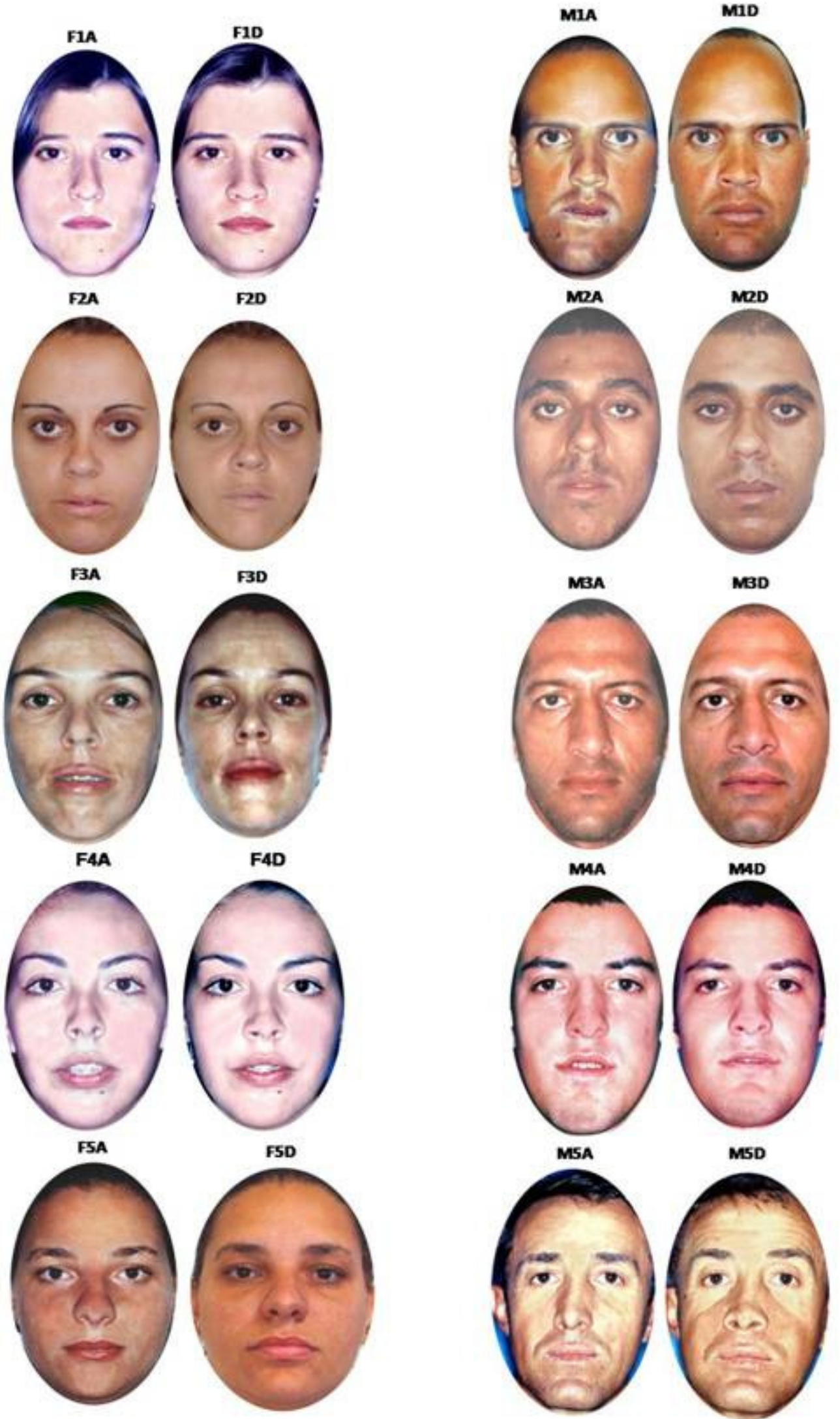

Figura 29. Faces antes (A) e depois (D) da cirurgia dos dez pacientes submetidos à cirurgia ortognática 
Dos 10 pacientes avaliados, com idades entre 20 e 40 anos, $80 \%$ tinham dores na fase pré-cirúrgica, 30\% estalos na ATM (articulação temporomandibular), 100\% dificuldades ao falar e/ou mastigar e/ou respirar e $80 \%$ tinham a queixa estética como ponto importante para a busca da cirurgia. Com relação às deformidades esqueléticas $60 \%$ pertenciam à denominada Classe III, $30 \%$ à Classe II e $10 \%$ à Classe I. Tais deformidades resultaram em $30 \%$ de cirurgias combinadas de maxila, mandíbula e mento, $20 \%$ de cirurgias combinadas de maxila e mandíbula, $20 \%$ de maxila, $20 \%$ de mandíbula e $10 \%$ de maxila e mento como visto nas Tabelas 1 e 2.

Tabela 1- Descrição dos pacientes segundo idade e queixa

\begin{tabular}{|c|c|c|}
\hline Paciente & Idade & Queixa \\
\hline F1 & 20 & Dores: frontal e temporal/ estalos na ATM \\
\hline $\mathrm{F} 2$ & 24 & Dores ATM (D)/ dificuldades ao falar, comer, respirar \\
\hline F3 & 28 & Estética, dores ATM $(\mathrm{D}+) /$ bruxismo/ dificuldades ao respirar \\
\hline $\mathrm{F} 4$ & 20 & $\begin{array}{c}\text { Dificuldades em respirar/ lábios entreabertos/ } \\
\text { estética. }\end{array}$ \\
\hline F5 & 30 & $\begin{array}{c}\text { Estética/ dores na ATM, ao mastigar, cefaleia/ } \\
\text { dificuldades ao respirar }\end{array}$ \\
\hline M1 & 32 & $\begin{array}{l}\text { Dificuldades ao mastigar e respirar/ } \\
\text { dores de estômago/ estalos na ATM/ estética }\end{array}$ \\
\hline M2 & 21 & $\begin{array}{c}\text { Estética/ cefaleia/morde bochechas/ tensão nas costas/dificuldades ao } \\
\text { respirar e falar }\end{array}$ \\
\hline M3 & 32 & Dificuldades ao falar e comer/ sem dores / estética \\
\hline M4 & 22 & Estética/ dores na mandíbula/ bruxismo \\
\hline M5 & 40 & $\begin{array}{l}\text { Estética/ dores de ouvido, na ATM, cefaleia/ } \\
\text { fadiga ao mastigar/dificuldade ao respirar/ estalos bilaterais. }\end{array}$ \\
\hline
\end{tabular}

Tabela 2- Descrição dos pacientes segundo deformidades e cirurgias realizadas

\begin{tabular}{ccc}
\hline Paciente & Deformidade & Cirurgia \\
\hline F1 & $\begin{array}{c}\text { Classe III/ assimetria de } \\
\text { bochechas }(\mathrm{E}+\mathrm{vol}) / \text { mordida } \\
\text { aberta posterior D, mordida } \\
\text { cruzada lateral E }\end{array}$ & $\begin{array}{c}\text { Maxila }(\mathrm{MX}) \text { : avanço } 6 \mathrm{~mm} \\
\text { Mento: recuo 2mm e intrusão de } 4 \mathrm{~mm} \text { com } \\
\text { redução vertical }\end{array}$ \\
F2 & $\begin{array}{c}\text { Classe II / assimetria de } \\
\text { bochechas }(\mathrm{E}+\mathrm{vol})\end{array}$ & $\begin{array}{c}\text { Mandíbula (MD): avanço 4mm com correção } \\
\text { de assimetria }\end{array}$
\end{tabular}


conclusão

Tabela 2- Descrição dos pacientes segundo deformidades e cirurgias realizadas.

\begin{tabular}{|c|c|c|}
\hline $\mathrm{F} 3$ & $\begin{array}{l}\text { Classe I/ protrusão de } \\
\text { mandíbula/ Assimetria de } \\
\text { bochechas ( } \mathrm{D} \text { vol })\end{array}$ & $\begin{array}{l}\text { Combinada: MX: avanço com intrusão de } \\
2 \mathrm{~mm} / \\
\text { MD: avanço anti-horário/ } \\
\text { Mento: redução vertical }\end{array}$ \\
\hline $\mathrm{F} 4$ & $\begin{array}{l}\text { Classe II/ assimetria de } \\
\text { bochechas }(\mathrm{E}+\mathrm{vol})\end{array}$ & $\begin{array}{c}\text { Combinada: MX: avanço de } 3 \mathrm{~mm} \text { com } \\
\text { intrusão de } 6 \mathrm{~mm} / \\
\text { MD: avanço } 8 \mathrm{~mm}\end{array}$ \\
\hline M2 & $\begin{array}{l}\text { Classe III / assimetria de } \\
\text { bochechas, mordida aberta } \\
\text { anterior }\end{array}$ & $\begin{array}{c}\text { Combinada - Mx: avanço } 9 \mathrm{~mm} \text {, } \\
\text { reposicionamento inferior } 2 \mathrm{~mm} / \\
\text { MD: recuo } 6 \mathrm{~mm} \text {, giro anti-horário } 5 \mathrm{~mm} / \\
\text { Mento: enxerto }\end{array}$ \\
\hline M3 & $\begin{array}{l}\text { Classe III / assimetria de } \\
\text { bochechas }(\mathrm{E}+\mathrm{vol}) / \text { mordida } \\
\text { cruzada lateral D, /mandíbula } \\
\text { protrusa e lateralizada para D. }\end{array}$ & Maxila: Avanço 8mm \\
\hline M4 & $\begin{array}{c}\text { Classe III / desvio de } \\
\text { mandíbula na linha média / } \\
\text { assimetria de bochechas } \\
\text { (desvio p/ E) }\end{array}$ & $\begin{array}{l}\text { Combinada: MX: avanço } 5 \mathrm{~mm} \text {, intrusão } \\
1 \mathrm{~mm} / \\
\text { MD: recuo } 2 \mathrm{~mm}+\text { giro anti-horário } 3 \mathrm{~mm}\end{array}$ \\
\hline M5 & $\begin{array}{l}\text { Classe III / assimetria de } \\
\text { bochechas (E+vol; D } \\
\text { hipotônica) }\end{array}$ & Maxila: avanço $9 \mathrm{~mm}$ \\
\hline
\end{tabular}

*Inibição do crescimento da maxila.

As entrevistas realizadas puderam contemplar que o grau de expectativa dos pacientes diante da proximidade da cirurgia foi alto e a maioria deles tinha como certeza a melhoria estética das faces. Grande parte dos pacientes relatou ser a cirurgia um dos eventos mais aguardados e importantes em suas vidas. Também foi verificado que a maioria tinha expectativa realista com relação aos resultados da cirurgia, e consideraram inclusive as possibilidades de intercorrências em sua saúde após as mesmas (como perda da sensibilidade nos lábios e no queixo por um período, dentre outras). 
Todos eles passaram por avaliações psicológicas na fase inicial do tratamento ortodôntico pré-cirúrgico e na fase pré-cirúrgica. Foi relatado que estes encontros com os psicólogos da equipe do CEDEFACE foram muito importantes no preparo dos pacientes, uma vez que, detectado alguma dúvida ou tipo de medo e/ou comorbidades psíquicas mais sérias, havia tempo de um melhor e maior preparo psicológico até a data da cirurgia sendo que a mesma poderia até ser adiada por falta de condições do paciente em lidar com tamanhas mudanças em suas vidas.

Nas entrevistas pós-cirúrgicas foi percebido que quase na totalidade dos casos $(90 \%)$ os resultados estéticos foram aprovados pelos pacientes. Apenas a paciente F2 não ficou satisfeita com os resultados da cirurgia e não faria o procedimento novamente, pois não viu diferença entre o antes e o depois em sua face. O ganho não fora apenas estético, segundo os pacientes satisfeitos, mas também sociais com melhorias nos relacionamentos interpessoais, alguns com possibilidades novas de emprego e/ou novos relacionamentos amorosos.

Todos relataram as dificuldades em lidar com os edemas e inchaços no pós-cirúrgico imediato, alguns ainda apresentavam parestesias (sensações na pele como formigamentos, pressões, calor, frio, dentre outras, vivenciadas espontaneamente, na ausência de estimulação no local) ou falta de sensibilidade nos lábios inferiores e/ou queixo.

Contudo todas as dificuldades relatadas não foram motivo para o arrependimento de ter passado pelo procedimento cirúrgico e fariam tudo novamente. Uma das únicas queixas no pós-cirúrgico unânime aos pacientes foi o longo tempo de tratamento enfrentado por todos. No mínimo três anos de ortodontia pré-cirúrgica e mais um longo período pós-cirúrgico ainda desconhecido no momento das entrevistas.

Com relação às análises físicas das faces, nas Tabelas 3, 4, 5 e 6 são dadas as diferenças entre as medidas faciais das faces pré e pós-cirúrgicas dos pacientes acima descritos, segundo as medidas dos terços, quintos e meios faciais. 
Tabela 3- Diferenças entre as medidas pré e pós-cirúrgicas de terços e quintos faciais das faces femininas

\begin{tabular}{ccccccccc}
\hline Faces & $\begin{array}{c}\mathbf{1 / 3} \\
\text { superior }\end{array}$ & $\begin{array}{c}\mathbf{1 / 3} \\
\text { médio }\end{array}$ & $\begin{array}{c}\mathbf{1 / 3} \\
\text { inferior }\end{array}$ & $\begin{array}{c}\mathbf{1}^{\mathbf{0}} \\
\text { quinto }\end{array}$ & $\begin{array}{c}\mathbf{2}^{\mathbf{0}} \\
\text { quinto }\end{array}$ & $\begin{array}{c}\mathbf{3}^{\mathbf{0}} \\
\text { quinto }\end{array}$ & $\begin{array}{c}\mathbf{4}^{\mathbf{0}} \\
\text { Quinto }\end{array}$ & $\begin{array}{c}\mathbf{5}^{\mathbf{0}} \\
\text { quinto }\end{array}$ \\
\hline F1 & 0.01 & 0.01 & 0.02 & 0.04 & 0.01 & 0.03 & 0.00 & 0.00 \\
$\mathbf{F 2}$ & 0.02 & 0.01 & 0.03 & 0.03 & 0.01 & 0.00 & 0.01 & 0.05 \\
$\mathbf{F 3}$ & 0.00 & 0.00 & 0.00 & 0.02 & 0.01 & 0.01 & 0.01 & 0.01 \\
$\mathbf{F 4}$ & 0.00 & 0.00 & 0.00 & 0.03 & 0.01 & 0.01 & 0.02 & 0.02 \\
F5 & 0.02 & 0.01 & 0.02 & 0.01 & 0.00 & 0.00 & 0.00 & 0.02 \\
\hline
\end{tabular}

Tabela 4- Diferenças entre as medidas pré e pós-cirúrgicas dos meios faciais das faces femininas

\begin{tabular}{ccccccccc}
\hline Face & 1d & 2d & 3d & 4d & 1e & 2e & 3e & 4e \\
\hline F1 & 0.00 & 0.00 & 0.02 & 0.03 & 0.02 & 0.01 & 0.01 & 0.02 \\
F2 & 0.01 & 0.01 & 0.04 & 0.02 & 0.01 & 0.01 & 0.03 & 0.03 \\
F3 & 0.00 & 0.01 & 0.01 & 0.01 & 0.02 & 0.00 & 0.00 & 0.01 \\
F4 & 0.00 & 0.01 & 0.00 & 0.02 & 0.01 & 0.00 & 0.01 & 0.00 \\
F5 & 0.00 & 0.01 & 0.00 & 0.02 & 0.00 & 0.01 & 0.00 & 0.01 \\
\hline
\end{tabular}

Tabela 5- Diferenças entre as medidas pré e pós-cirúrgicas de terços e quintos faciais das faces masculinas

\begin{tabular}{ccccccccc}
\hline Faces & $\begin{array}{c}\mathbf{1 / 3} \\
\text { superior }\end{array}$ & $\begin{array}{c}\mathbf{1 / 3} \\
\text { médio }\end{array}$ & $\begin{array}{c}\mathbf{1 / 3} \\
\text { inferior }\end{array}$ & $\begin{array}{c}\mathbf{1}^{\mathbf{0}} \\
\text { quinto }\end{array}$ & $\begin{array}{c}\mathbf{2}^{\mathbf{0}} \\
\text { quinto }\end{array}$ & $\begin{array}{c}\mathbf{3}^{\mathbf{0}} \\
\text { quinto }\end{array}$ & $\begin{array}{c}\mathbf{4}^{\mathbf{0}} \\
\text { quinto }\end{array}$ & $\begin{array}{c}\mathbf{5}^{\mathbf{0}} \\
\text { quinto }\end{array}$ \\
\hline M1 & 0.05 & 0.01 & 0.06 & 0.01 & 0.02 & 0.00 & 0.00 & 0.01 \\
M2 & 0.00 & 0.00 & 0.01 & 0.02 & 0.01 & 0.01 & 0.00 & 0.01 \\
M3 & 0.00 & 0.03 & 0.03 & 0.01 & 0.01 & 0.01 & 0.00 & 0.00 \\
M4 & 0.02 & 0.02 & 0.00 & 0.01 & 0.01 & 0.00 & 0.02 & 0.02 \\
M5 & 0.01 & 0.00 & 0.01 & 0.00 & 0.00 & 0.01 & 0.00 & 0.00 \\
\hline
\end{tabular}

Tabela 6- Diferenças entre as medidas pré e pós-cirúrgicas dos meios faciais das faces masculinas

\begin{tabular}{ccccccccc}
\hline Faces & 1d & 2d & 3d & 4d & 1e & 2e & 3e & 4e \\
\hline M1 & 0.02 & 0.00 & 0.00 & 0.02 & 0.01 & 0.01 & 0.01 & 0.01 \\
M2 & 0.01 & 0.00 & 0.01 & 0.01 & 0.01 & 0.02 & 0.01 & 0.02 \\
M3 & 0.01 & 0.01 & 0.01 & 0.02 & 0.00 & 0.02 & 0.01 & 0.01 \\
M4 & 0.01 & 0.00 & 0.00 & 0.01 & 0.00 & 0.02 & 0.01 & 0.00 \\
M5 & 0.00 & 0.00 & 0.00 & 0.00 & 0.00 & 0.00 & 0.00 & 0.00 \\
\hline
\end{tabular}




\subsection{2) Experimento I:}

O objetivo deste primeiro experimento foi investigar a atratividade facial de pacientes antes de depois da cirurgia ortognática.

Participantes: 40 voluntários (21 mulheres e 19 homens), com idades entre 20 e 53 anos. Todos assinaram o Termo de Consentimento Livre e Esclarecido para a participação na pesquisa (Anexo C), aprovado pelo Comitê de Ética da FFCLRP-USP. Os voluntários participaram dos dois Experimentos.

Materiais: Os estímulos visuais foram as 20 fotografias frontais de 10 pacientes nas fases pré e pós-operatórias analisadas. Um microcomputador Pentium IV, 992 MB RAM, com placa de vídeo SiS 661FX, true color (24 bits), 1024 x 768 pixels, frequência de atualização da tela 100Hz, acoplado a um monitor LG Flatron ez T910B Plus (19”), com sistema Windows XP Professional ${ }^{\odot}$ versão 2002 e o software Super Lab Pro Experimental Lab, versão 2.0.

Folhas de registros, compostas por 40 linhas, para o julgamento das magnitudes de atratividade de cada fotografia pela escala VAS (Visual Analogue Scale) foram utilizadas. Tal escala consistia em uma linha, de $10 \mathrm{~cm}$ de comprimento, em que a extremidade esquerda significava 'NADA ATRATIVO' e a extremidade direita 'EXTREMAMENTE ATRATIVO'. A distância marcada na linha foi medida por uma régua milimetrada e atribuído um valor numérico correspondente entre 0 e 10.

Procedimento: As 20 fotografias dos pacientes, nas condições pré (10 faces) e pós-cirúrgicas (10 faces), foram apresentadas pareadas na tela do monitor. Cada dupla foi observada e julgada quatro vezes em cada sessão experimental, alternando-se a posição das faces pré e pós-cirúrgicas, direita e esquerda, na tela. As fotografias mediam $12,5 \mathrm{~cm}$ de largura e 18,5cm de altura e a distância entre elas era de $3 \mathrm{~cm}$. 
Após a assinatura do termo de compromisso e a leitura das instruções, as sessões experimentais duraram entre 5 e 15 min e a tarefa do participante era observar a dupla de faces, escolher a face que mais lhe parecia atrativa e estimar o grau de atratividade da face escolhida na VAS. A ordem de apresentação das duplas foi aleatória para cada participante. O tempo de exposição de cada dupla foi livre e a distância entre o centro da tela ao olho do observador foi de aproximadamente $60 \mathrm{~cm}$.

Análise dos dados: Todas as imagens foram medidas com o auxílio de um editor de imagens As medidas reais em cada análise foram transformadas em proporções, depois foram feitas as diferenças entre as proporções das medidas faciais, para terços, quintos e meios, entre as faces pré e pós-cirúrgicas para cada paciente.

Os dados de cada paciente segundo idade, queixas, deformidades dentofaciais e tipos de cirurgias ortognáticas a que foram submetidos também compõe a análise dos dados.

Os escores de atratividade por meio da $V A S$ foram mensurados em relação ao tamanho total da linha, transformados em valores numéricos (entre 0 e 10) e computados para cada imagem julgada. Foram somadas as frequências das escolhas entre faces pré ou pós-cirúrgicas e dos protótipos. Os softwares $S P S S^{\mathcal{O}}$ versão 12.0 e BioEstat 5.0 foram utilizados para análise dos dados.

\section{Resultados}

Os testes de normalidade Shapiro-Wilk e Kolmogorov-Smirnov indicaram que os julgamentos de atratividade das faces dos pacientes não se distribuem em uma curva normal. Portanto para as análises estatísticas de comparações entre os julgamentos de atratividade foram utilizados testes não paramétricos como Friedman para amostras relacionadas 
(DAWSON; TRAPP, 2003), que compara a soma dos postos entre as fases antes e depois da cirurgia.

As análises a partir do teste de Friedman mostraram que faces pós-cirúrgicas foram julgadas como mais atrativas que as faces pré-cirúrgicas $[\mathrm{Q}(1,400)=8,42 ; \mathrm{p}<0,0001]$ nos julgamentos gerais de atratividade para toda a amostra. A mediana para as faces pré-cirúrgicas foi 0,00 (zero; $1^{\circ}$ Quartil: 0,$00 ; 3^{\circ}$ Quartil: 2,24) e para as pós-cirúrgicas foi de 2,13 (1 ${ }^{\circ}$ Quartil: 0,71; $3^{\circ}$ Quartil: 3,54).

Ao separar os gêneros das faces, tanto nas femininas [Q $(1,200)=7,58$; $p<0,01]$ quanto nas masculinas [Q $(1,200)=4,01 ; \mathrm{p}<0,01]$ as faces pós-cirúrgicas foram consideradas mais atrativas que as pré-cirúrgicas. A mediana para as faces pré-cirúrgicas femininas foi de 0,00 (zero; $1^{\circ}$ Quartil: 0,00; $3^{\circ}$ Quartil: 2,34) e masculinas também de 0,00 (zero; $1^{\circ}$ Quartil: 0,00; $3^{\circ}$ Quartil: 1,91). Para as pós-cirúrgicas a mediana para as femininas foi de $2,98\left(1^{\circ}\right.$ Quartil: 1,$51 ; 3^{\circ}$ Quartil: 4,24) e para as masculinas de $1,55\left(1^{\circ}\right.$ Quartil: 1,$91 ; 3^{\circ}$ Quartil: $2,60)$.

Todas as faces tiveram julgamentos medianos inferiores a 5 (cinco), sendo as faces masculinas consideradas menos atrativas que as femininas. Ao analisar separadamente face a face pelo teste de Friedman, foi verificado que para as faces femininas três faces pós-cirúrgicas foram julgadas como mais atrativas que as pré-cirúrgicas, a saber: Face F1 [Q (1, $40)=28,44 ; \mathrm{p}<0,0001]$, Face F3 $[\mathrm{Q}(1,40)=11,11 ; \mathrm{p}<0,0001]$, Face F4 $[\mathrm{Q}(1,40)=28,44$; p<0,0001]. As faces 2 e 5 não tiveram diferenças significativas p>0,05) entre pré e pós-cirúrgicas em seus julgamentos de atratividade, como mostra a Figura 30. 


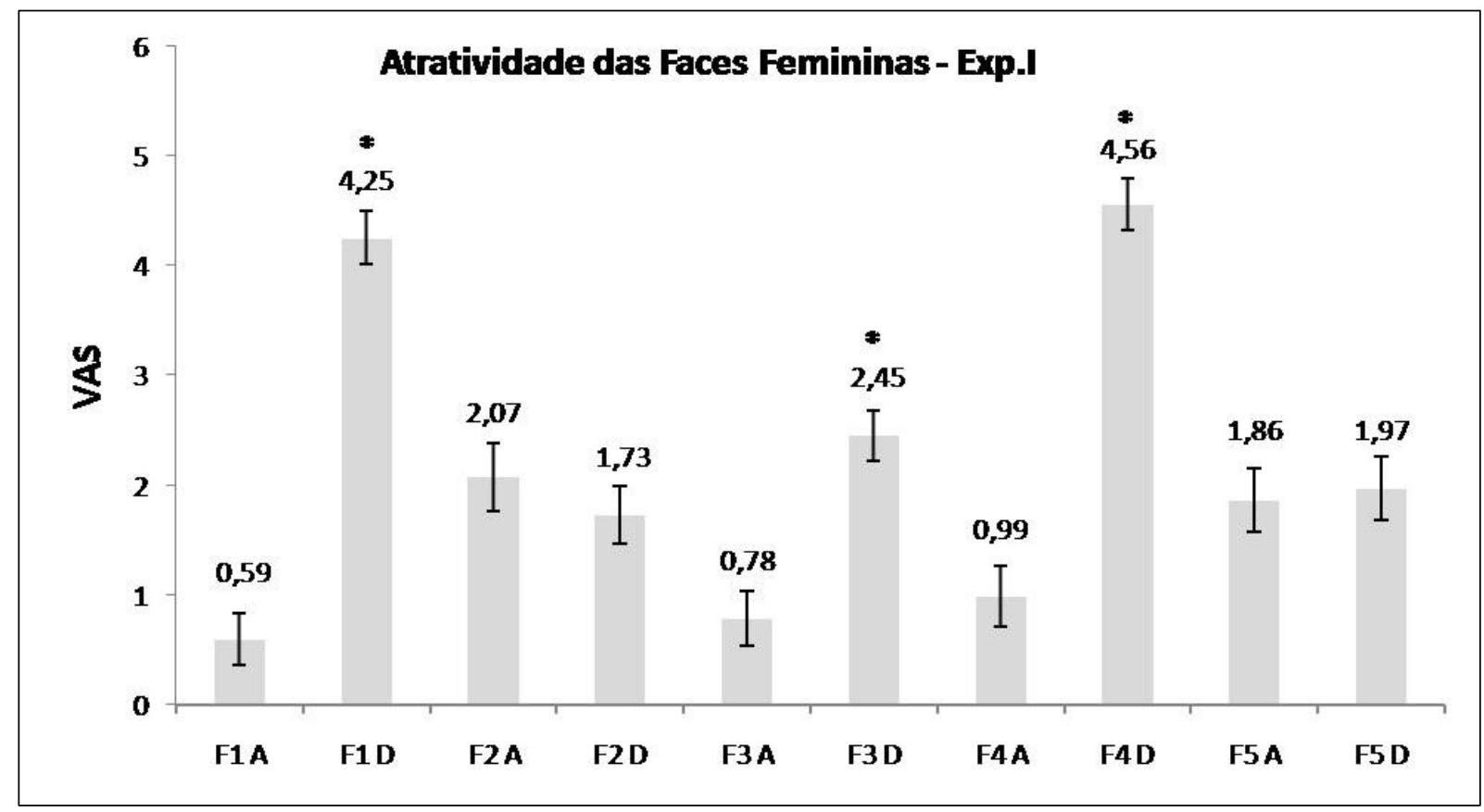

Figura 30. Julgamentos de atratividade das faces de pacientes femininos (F) antes (A) e depois (D) da cirurgia ortognática no Experimento I. Os dados são representados como médias e \pm 1 E.P.M. $\left({ }^{*} \mathrm{p}<0,01\right.$ entre as faces antes e depois)

Para as faces masculinas o teste de Friedman indicou que duas faces pós-cirúrgicas foram julgadas como mais atrativas que as pré-cirúrgicas, a saber: Face M1 [Q $(1,40)=$ 25,66; p<0,0001], Face M4 [Q $(1,40)=30,63 ; \mathrm{p}<0,0001]$. Para a Face M5 a face pré-cirúrgica foi considerada mais atrativa que a pós-cirúrgica [Q $(1,40)=8,10 ; \mathrm{p}<0,0001]$. As medianas de julgamentos de atratividade não se diferiram estatisticamente $(p>0,05)$ entre antes e depois da cirurgia para as faces M2 e M3, como visto na Figura 31. 


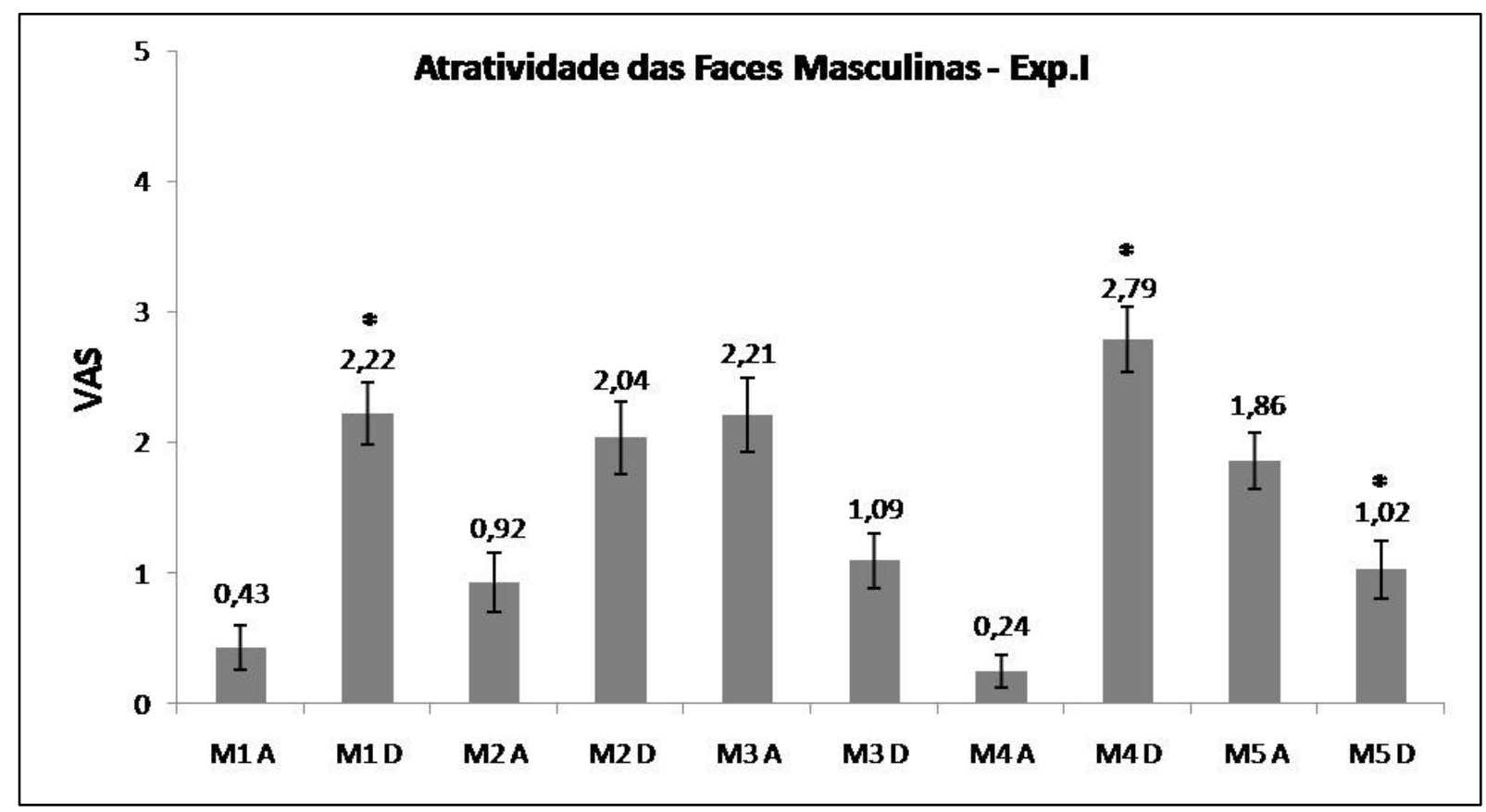

Figura 31. Julgamentos de atratividade das faces de pacientes masculinos (M) antes (A) e depois (D) da cirurgia ortognática no Experimento I. Os dados são representados como médias e \pm E.P.M. (*p<0,01 entre as faces antes e depois)

As Tabelas 7 e 8 mostram as frequências de escolhas para a amostra total das faces femininas e masculinas. As faces F1, F3 e F4 pós-cirúrgicas foram estatisticamente ( $<<0,001)$ escolhidas como mais atrativas que suas correspondentes pré-cirúrgicas. Para as faces F2 e F5 não houve diferenças significativas entre as duas condições. As faces pós-cirúrgicas M1, M2 e M4 foram preferidas às suas correspondentes pós-cirúrgicas, com diferenças estatisticamente significativas $(\mathrm{p}<0,001)$. Para as faces M3 e M5 houve diferenças significativas a $5 \%$ entre as escolhas pré e pós, com preferência para as faces pré-cirúrgicas, nos dois casos.

Tabela 7- Frequências de escolhas das faces femininas pré (A) e pós-cirúrgicas(D)

\begin{tabular}{ccccccccccc}
\hline Escolhas & F1A & F1D & F2A & F2D & F3A & F3D* & F4A & F4D* & F5A & F5D \\
\hline TOTAL & 6 & 154 & 89 & 71 & 27 & 133 & 20 & 140 & 72 & 88 \\
$\%$ & $4 \%$ & $96 \%$ & $56 \%$ & $44 \%$ & $17 \%$ & $83 \%$ & $13 \%$ & $87 \%$ & $45 \%$ & $55 \%$ \\
\hline$*$ p $<0,01$ comparadas com pré $(\mathrm{A})$ & & & & & & &
\end{tabular}


Tabela 8- Frequências de escolhas das faces masculinas pré (A) e pós-cirúrgicas(D)

\begin{tabular}{ccccccccccc}
\hline Escolhas & M1A & M1D* & M2A & M2D $^{*}$ & M3A $^{\#}$ & M3D & M4A & M4D $^{*}$ & M5A $^{\#}$ & M5D \\
\hline TOTAL & 16 & 144 & 46 & 114 & 103 & 57 & 10 & 150 & 107 & 53 \\
$\%$ & $10 \%$ & $90 \%$ & $29 \%$ & $71 \%$ & $64 \%$ & $36 \%$ & $6 \%$ & $94 \%$ & $67 \%$ & $33 \%$ \\
\hline * $<0,01$ comparadas com pré (A); ${ }^{\#}$ p $<0,05$ & comparadas com pós (D)
\end{tabular}

Ao comparar dados dos julgamentos dos participantes femininos e masculinos o teste de Friedman mostrou uma tendência semelhante aos julgamentos da amostra geral para as faces femininas, das quais três pós-cirúrgicas foram julgadas mais atrativas que as pré-cirúrgicas tanto para o gênero feminino: F1 $[\mathrm{Q}(19,21)=4,01 ; \mathrm{p}<0,01]$, F3 [Q $(19,21)=$ $3,67 ; \mathrm{p}<0,01]$, e F4 [Q $(19,21)=3,98 ; \mathrm{p}<0,01]$, quanto para o gênero masculino: F1 [Q (19, $21)=3,70 ; p<0,01], F 3[Q(19,21)=2,70 ; p<0,05]$ e F4[Q $(19,21)=3,70 ; p<0,01]$ (Figura $32)$.

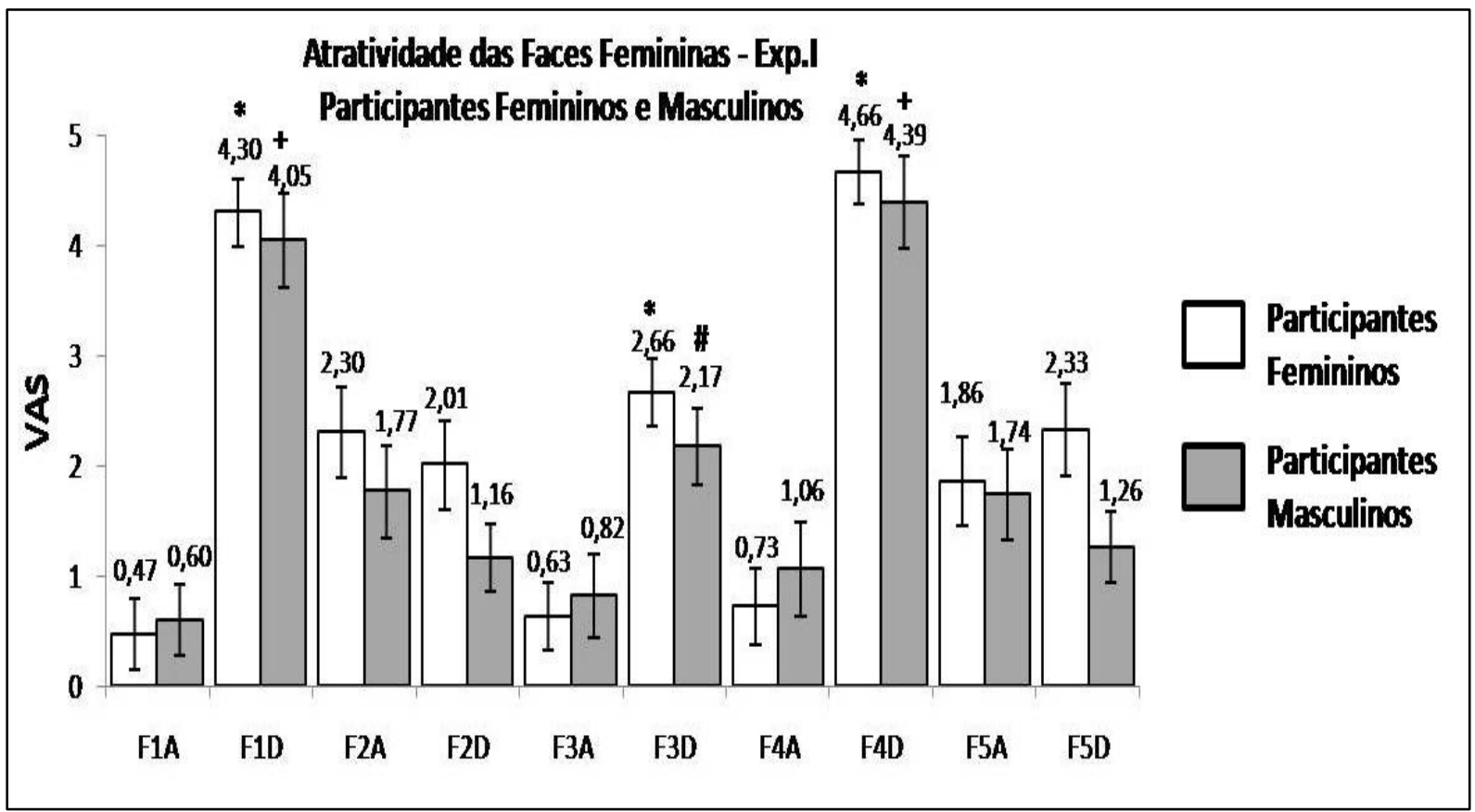

Figura 32. Julgamentos de atratividade das faces de pacientes femininos antes (FA) e depois (FD) da cirurgia ortognática no Experimento I, realizados por participantes femininos e masculinos. Os dados são representados como médias e \pm E.P.M. ( ${ }^{*} \mathrm{p}<0,01$ para participantes femininos; $+\mathrm{p}<0,01$ para particpantes masculinos; $\# \mathrm{p}<0,05$ para participantes masculinos) 
Para as faces masculinas o teste de Friedman mostrou que os julgamentos de participantes femininos e masculinos, separadamente, apresentaram algumas diferenças da amostra geral, com três faces pós-cirúrgicas consideradas mais atrativas que as pré-cirúrgicas: M1, M2 e M4 (na amostra geral foram duas, M1 e M4) e duas faces pré-cirúrgicas consideradas mais atrativas que as pós-cirúrgicas: M3 e M5 (na amostra geral foi apenas uma, M5). As análises estatísticas para os julgamentos femininos foram: M1 $[\mathrm{Q}(19,21)=2,83$; $\mathrm{p}<0,01], \mathrm{M} 3[\mathrm{Q}(19,21)=1,72 ; \mathrm{p}<0,05], \mathrm{M} 4[\mathrm{Q}(19,21)=3,63 ; \mathrm{p}<0,01]$ e M5 [Q $(19,21)=$ 2,69; $\mathrm{p}<0,05]$, e para os masculinos: M1 $[\mathrm{Q}(19,19)=3,57 ; \mathrm{p}<0,01]$, M2 [Q $(19,19)=2,33$; $\mathrm{p}<0,05]$, M4 [Q $(19,19)=3,72 ; \mathrm{p}<0,01]$ (Figura 33).

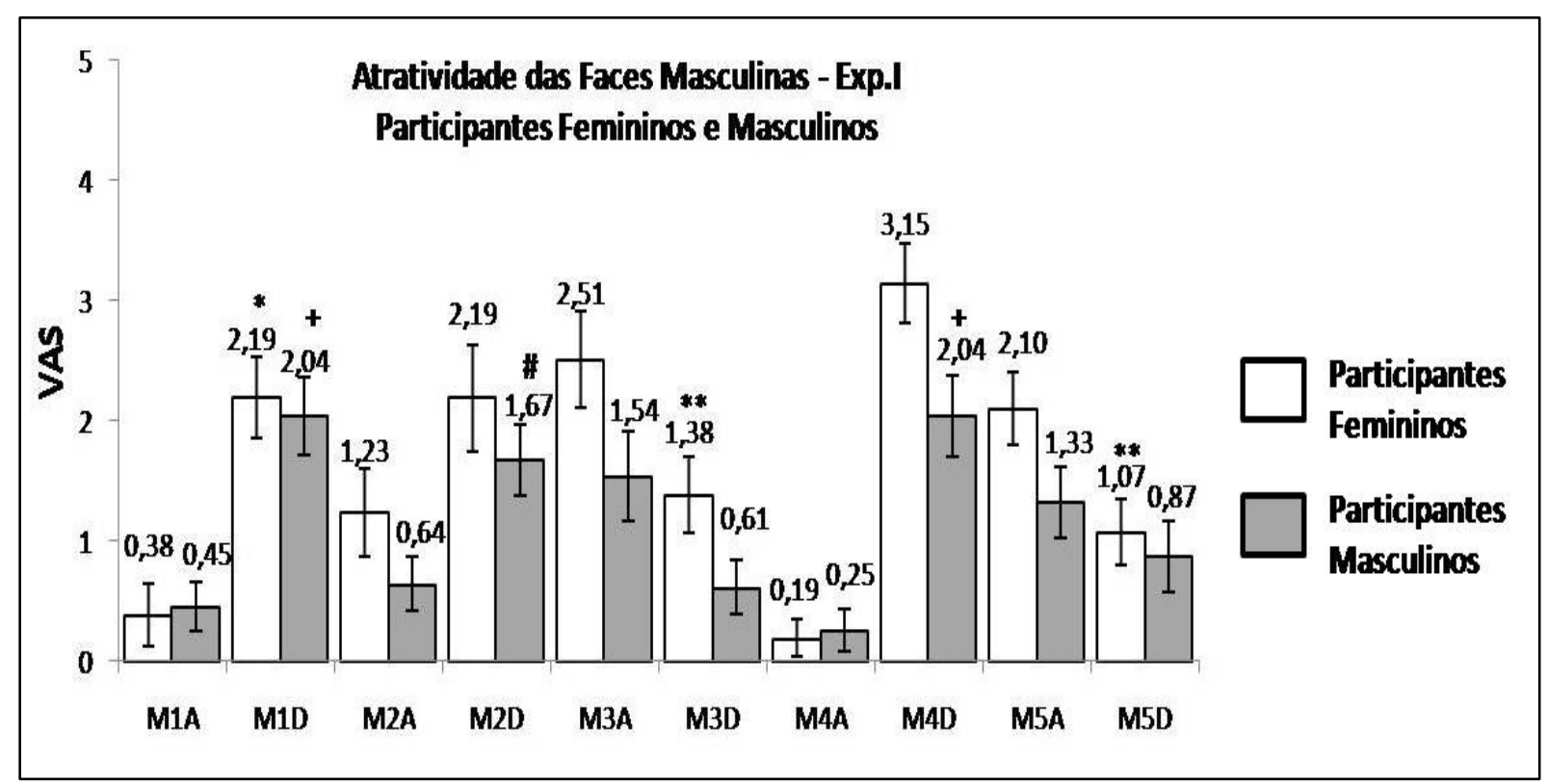

Figura 33. Julgamentos de atratividade das faces de pacientes masculinos antes (A) e depois (D) da cirurgia ortognática no Experimento I, realizados por participantes femininos e masculinos. Os dados são representados como médias e \pm E.P.M. $\left({ }^{*} \mathrm{p}<0,01\right.$ para participantes femininos; $+\mathrm{p}<0,01$ para participantes masculinos; $* * \mathrm{p}<0,05$ para participantes femininos; $\# \mathrm{p}<0,05$ para participantes masculinos) 


\section{Discussão}

Os resultados obtidos mostram que a cirurgia ortognática melhorou a estética facial de pacientes portadores de deformidades dentofaciais uma vez que as faces pós-cirúrgicas foram consideradas mais atrativas que as pré-cirúrgicas de uma maneira geral, corroborando os dados da literatura (KERR; DORTH; O’DONNELL, 1990; ONG, 2004; PHILLIPS; PROFFIT, 2005). Ademais a avaliação dos pacientes foi $90 \%$ positiva com relação aos resultados da mesma, como mostra estudos na área (PHILLIPS; BENNETT, 2000 apud PHILLIPS; PROFFIT, 2005).

No presente Experimento, três faces femininas (F1, F3, F4) e duas faces masculinas (M1 e M4) pós-cirúrgicas foram consideradas mais atrativas que as pré-cirúrgicas. Para uma face masculina (M5) houve um resultado diferente daquele apontado na literatura (KERR; DORTH; O’DONNELL, 1990; ONG, 2004; PHILLIPS; PROFFIT, 2005), pois sua versão pré-cirúrgica foi considerada mais atrativa que a pós-cirúrgica. A análise das escolhas corroborou os dados mostrados pela VAS para as faces femininas e incluiu uma face masculina (M2) pós-cirúrgica no rol das faces pós-cirúrgicas como mais atrativas. Também na análise da preferência a face pré-cirúrgica masculina M5 foi considerada mais atrativa que a pós, acompanhada pela face M3.

As faces pós-cirúrgicas que obtiveram maiores julgamentos de atratividade apresentaram também as maiores diferenças nas medidas das análises faciais de terços, quintos e meios. Faces F1, M1, M2, M3, M4 e M5 apresentaram diferenças nos terços, nos meios e nos quintos faciais. Nas faces F3, F4 foram vistas diferenças nas análises dos meios e dos quintos. A atratividade facial estaria, então, relacionada às diferenças físicas perceptíveis com correções das desarmonias entre os elementos faciais como aponta a literatura (EDLER; ORTH, 2001; ENLOW, 1993; KERR; DORTH; O’DONNELL, 1990; ONG, 2004; SARVER; PROFFIT; ACKERMAN, 2005; SCAVONE JUNIOR et al., 2006). 
Faces F1, M1, M2 apresentaram diferenças nos terços inferiores das faces, o que condiz com os procedimentos cirúrgicos realizados nas mesmas: correções de Classe III esquelética com avanços e reposicionamentos mandibulares, e/ou recuos e giros maxilares e correções de movimentações ou enxertos nos mentos.

Nas faces F1, F3, F4, M1, M2, M4 foram vistas diferenças nas análises dos meios e dos quintos o que pode significar que, apesar da cirurgia ortognática alterar medidas localizadas no terço inferior da face, como avanços, recuos e reposicionamentos de maxilas, mandíbulas e mentos, as alterações podem afetar toda a configuração facial, como preconizam estudos sobre medidas e proporções faciais (ENLOW, 1993; SARVER; PROFFIT; ACKERMAN, 2005).

Contudo nem todas as faces que apresentaram diferenças nas proporções faciais entre antes e depois da cirurgia foram julgadas de maneira diferente, como ocorrido com as faces F2 e F5. Estas diferenças entre o antes e depois da cirurgia também não foram percebidas pela paciente F2, a qual relatou não ter gostado do resultado da cirurgia e até se arrependido de têla feito. Nestes casos pode ser também que outras características faciais como olhos, cor de pele, brilho da fotografia, dentre outras tenham influenciado nos julgamentos e tirado o foco das diferenças físicas como visto nos estudos sobre julgamentos faciais (SILVA, 2005; KERR; DORTH; O’DONNELL, 1990; PROFFIT; SARVER, 2005).

Outro viés a ser considerado é a maneira como os julgamentos de atratividade de são realizados. Os participantes deste estudo não tinham a informação de que deveriam 'procurar' diferenças entre a dupla de faces observadas. Algumas diferenças foram perceptíveis, outras não, sendo que alguns participantes perguntaram se as fotografias eram da mesma pessoa ou não. Talvez os juízes tiveram um olhar menos crítico do que o olhar de um profissional da área que, ao perceber mais as diferenças, julgaria de maneira diferente os mesmos pacientes (KERR; DORTH; O'DONNELL, 1990). 
Algo que pode ter influenciado nos julgamentos foi o fato das fotografias julgadas serem frontais, o que pode fazer com que as deformidades faciais não fiquem tão aparentes, ao ponto de mascarar as desproporções no terço inferior da face. Kerr, Dorth e O’Donnell (1990) mostraram que fotografias frontais de pacientes Classe II e III tiveram julgamento de atratividade maiores que suas fotografias de perfil. As duas faces pré-cirúrgicas masculinas (M3 e M5) consideradas mais atrativas que as pós-cirúrgicas, ambas Classe III, talvez não tiveram as diferenças das análises faciais evidenciadas provavelmente pela posição frontal da cabeça, sendo então julgadas em outros aspectos faciais como os olhos que ganham destaque nesta posição, o que pode desviar a atenção do observador ou compensar a desarmonia no conjunto facial (KERR; DORTH; O’DONNELL, 1990).

A literatura aponta que a grande maioria dos pacientes que buscam cirurgias ortognáticas pertence às Classes II e III esqueléticas (ONG, 2004), como foi visto neste estudo em que 60\% dos pacientes pertenciam à denominada Classe III, 30\% à Classe II e 10\% à Classe I. Tais deformidades resultaram em 30\% de cirurgias combinadas de maxila, mandíbula e mento, $20 \%$ de cirurgias combinadas de maxila e mandíbula, $20 \%$ de maxila, $20 \%$ de mandíbula e $10 \%$ de maxila e mento.

Foi observado que os pacientes submetidos à cirurgia ortognática eram jovens (média 26,9 anos), e $80 \%$ tinham a queixa estética (além das funcionais) como pontos centrais na busca de tratamento cirúrgico para suas deformidades dentofaciais. Estes mesmos resultados foram encontrados na literatura (ONG, 2004) e podem descrever a motivação que pessoas mais jovens têm para realizar uma cirurgia de correção física e vem confirmar o quanto a aparência facial é importante e pode afetar o modo como pessoas são percebidas e julgadas (OMOTE, 1994; CHEN; GERMAN; ZAIDEL, 1996; FAURE; RIEFFE; MALTHA, 2002; PHILLIPS; PROFFIT, 2005). 
Os escores gerais de atratividade facial foram baixos, que pode ter ocorrido devido às faces de pacientes apresentarem desarmonias, desvios da normalidade que podem ter comprometido a atratividade das mesmas (EDLER; ORTH, 2001). Segundo Neger e Newark (1959, apud REIS et al., 2006b) as faces da maioria da população consideradas 'normais', sem grandes desvios, são esteticamente aceitáveis. Contudo aqueles que possuem algum tipo de deformidade a priori (mais comumente indivíduos Classe II e III esquelética) são classificados como esteticamente desagradáveis por apresentarem discrepâncias esqueléticas, as quais necessitam de tratamentos mais invasivos, como as cirurgias ortognáticas. A expectativa do paciente e da equipe que o trata é de que ocorram melhorias estéticas, com a preservação e acentuação das características de agradabilidade do mesmo. Contudo estas faces podem não chegar a um nível de aceitação muito maior que o normal (médio), saindo da zona de não agradabilidade estética para a de aceitação estética (REIS et al., 2006b).

Foi observado que as faces femininas tiveram medianas de julgamentos maiores que as faces masculinas, o que corrobora estudos que mostram que as faces femininas costumam ser avaliadas como mais atrativas que as masculinas (PENTON-VOAK; PERRETT, 2000). Um estudo brasileiro feito com faces em perfil mostrou que faces femininas foram consideradas 6\% esteticamente agradáveis, $90 \%$ esteticamente aceitáveis e $4 \%$ esteticamente desagradáveis, comparando-se com o gênero masculino em que nenhum indivíduo foi classificado como esteticamente agradável na avaliação do perfil, $88 \%$ foram classificados esteticamente aceitáveis e 12\% esteticamente desagradáveis (REIS et al., 2006b).

Os dados deste primeiro experimento levam a crer que a cirurgia ortognática, enquanto tratamento de deformidades dentofaciais, pode trazer melhorias estéticas àqueles que a procuram. Tal melhoria pode ser fundamental na vida de pessoas que sofrem com dificuldades de relacionamento, podem encontrar empecilhos no convívio e na interação 
social, além de dificuldades funcionais e na relação consigo mesmas, devido à suas deformidades.

\subsection{3) Experimento II:}

O objetivo deste segundo experimento foi investigar a relação entre a atratividade de faces de pacientes submetidos à cirurgia ortognática e a atratividade dos protótipos faciais.

Participantes: 40 voluntários (21 mulheres e 19 homens), com idades entre 20 e 53 anos. Todos assinaram o Termo de Consentimento Livre e Esclarecido para a participação na pesquisa (Anexo C), aprovado pelo Comitê de Ética da FFCLRP-USP. Os voluntários participaram dos dois Experimentos.

Materiais: Os estímulos visuais foram as 23 imagens analisadas, sendo 20 fotografias frontais de 10 pacientes nas fases pré o pós-operatórias e os 3 protótipos faciais da população brasileira. Um microcomputador Pentium IV, 992 MB RAM, com placa de vídeo SiS 661FX, true color (24 bits), 1024 x 768 pixels, frequência de atualização da tela $100 \mathrm{~Hz}$, acoplado a um monitor LG Flatron ez T910B Plus (19”), com sistema Windows XP Professional ${ }^{\circledR}$ versão 2002 e o software Super Lab Pro - Experimental Lab, versão 2.0.

Folhas de registros, compostas por 40 linhas, para o julgamento das magnitudes de atratividade de cada fotografia pela escala VAS (Visual Analogue Scale) foram utilizadas. Tal escala consistia em uma linha, de $10 \mathrm{~cm}$ de comprimento, em que a extremidade esquerda significava 'NADA ATRATIVO' e a extremidade direita 'EXTREMAMENTE ATRATIVO'. A distância marcada na linha foi medida por uma régua milimetrada e atribuído um valor numérico correspondente entre 0 e 10.

As 20 fotografias dos pacientes, nas condições pré e pós-cirúrgicas, foram pareadas aos três protótipos faciais correspondentes a cada cor de pele e gênero da face: masculinos branco e preto e feminino branco. Assim sendo 4 faces ( 8 fotografias) de pacientes 
masculinos brancos foram pareados ao protótipo masculino branco; 5 faces (10 fotografias) femininas brancas pareadas ao protótipo feminino branco; e uma face (duas fotografias) masculina preta foi pareada ao protótipo masculino preto.

Antes de iniciar a sessão experimental era explicada, sucintamente, a cada participante a teoria de atratividade dos protótipos faciais. Tal teoria diz que um protótipo facial, sendo uma imagem representativa de uma dada população, tende a ter julgamentos de atratividade medianos (LANGLOIS; ROGGMAN, 1990). Durante a explicação eram mostrados os protótipos faciais representativos da população brasileira branca na tela do computador, os quais foram testados em experimentos prévios e possuem graus de atratividade medianos. $\mathrm{O}$ participante observava as duas faces pareadas, o protótipo e a face do paciente (já familiarizada no Experimento I), sua tarefa era julgar a face do paciente, na $V A S$ e considerar que o protótipo tivesse atratividade mediana. Em cada $V A S$ na folha de respostas havia uma indicação, no meio da linha, escrito 'MÉDIA', que representava o julgamento dos protótipos. Esta indicação serviu de ancoragem para o julgamento das outras faces, ao compará-las aos protótipos correspondentes.

As sessões experimentais duraram entre 4 e 9 min. Cada dupla foi observada duas vezes em cada sessão experimental, se alternado o lado da posição das faces na tela, ora no lado direito, ora no esquerdo dos protótipos. As imagens tiveram as mesmas medidas do Experimento I, também a ordem de apresentação dos estímulos foi aleatória e o tempo de exposição livre.

Análise dos dados: Todas as 23 imagens foram medidas com o auxílio de um editor de imagens As medidas reais em cada análise foram transformadas em proporções, depois foram feitas as diferenças entre as proporções das medidas faciais, para terços, quintos e meios, entre as faces pré e pós-cirúrgicas para cada paciente. 
Os dados de cada paciente segundo idade, queixas, deformidades dentofaciais e tipos de cirurgias ortognáticas a que foram submetidos também compõe a análise dos dados.

Os escores de atratividade por meio da $V A S$ foram mensurados em relação ao tamanho total da linha, transformados em valores numéricos (entre 0 e 10) e computados para cada imagem julgada. Foram somadas as frequências das escolhas entre faces pré ou pós-cirúrgicas e dos protótipos. Os softwares $\operatorname{SPSS}^{\mathcal{O}}$ versão 12.0 e BioEstat 5.0 foram utilizados para análise dos dados.

\section{Resultados}

Os testes de normalidade Shapiro-Wilk e Kolmogorov-Smirnov indicaram que os dados de atratividade das faces dos pacientes não se distribuem em uma curva normal. Portanto, como no Exp.I, as análises estatísticas de comparações entre os julgamentos de atratividade foram feitas com testes não paramétricos como Friedman, que comparou a soma dos postos entre os julgamentos das faces antes e depois da cirurgia e também entre os Exp.I e II. Os julgamentos de atratividade das faces pré e pós-cirúrgicas e dos protótipos foram comparados pelo teste de Wilcoxon (DAWSON; TRAPP, 2003).

O Experimento II também mostrou que faces pós-cirúrgicas foram julgadas como mais atrativas que as faces pré-cirúrgicas no geral $[\mathrm{Q}(1,400)=7,80 ; \mathrm{p}<0,01]$, com medianas de 1,70 (1 Quartil: 0,95; $3^{\circ}$ Quartil: 2,75) para as pré-cirúrgicas e de 2,05 (1ºuartil: 1,10; $3^{\circ}$ Quartil: 2,98) para as pós-cirúrgicas.

A análise dos gêneros separadamente mostrou que também para as faces femininas [Q $(1,200)=5,52 ; \mathrm{p}<0,01]$ e masculinas $[\mathrm{Q}(1,200)=5,50 ; \mathrm{p}<0,01]$, as pós-cirúrgicas foram consideradas mais atrativas, com medianas de 2,18 ( $1^{\circ}$ Quartil: 1,$18 ; 3^{\circ}$ Quartil: 3,39$)$ para as femininas pré-cirúrgicas e de 2,54 (1 ${ }^{\circ}$ Quartil: 1,$31 ; 3^{\circ}$ Quartil: 3,66) e medianas para as 
masculinas de 1,35 (1 $1^{\circ}$ Quartil: 0,$73 ; 3^{\circ}$ Quartil: 2,18$)$ para as pré-cirúrgicas e de $1,85\left(1^{\circ}\right.$ Quartil: 0,95; $3^{\circ}$ Quartil: 2,45) para as pós-cirúrgicas, como mostra a Figura 34.

Na comparação entre faces pré e pós-cirúrgicas e os protótipos faciais foi observado na amostra total que todas as faces, masculinas e femininas, tiveram medianas de atratividade significativamente menores que $5[\mathrm{Q}(20,40)=412,92 ; \mathrm{p}<0,01]$, o qual foi o julgamento ancorado para a atratividade dos protótipos durante o experimento (Figura 35).

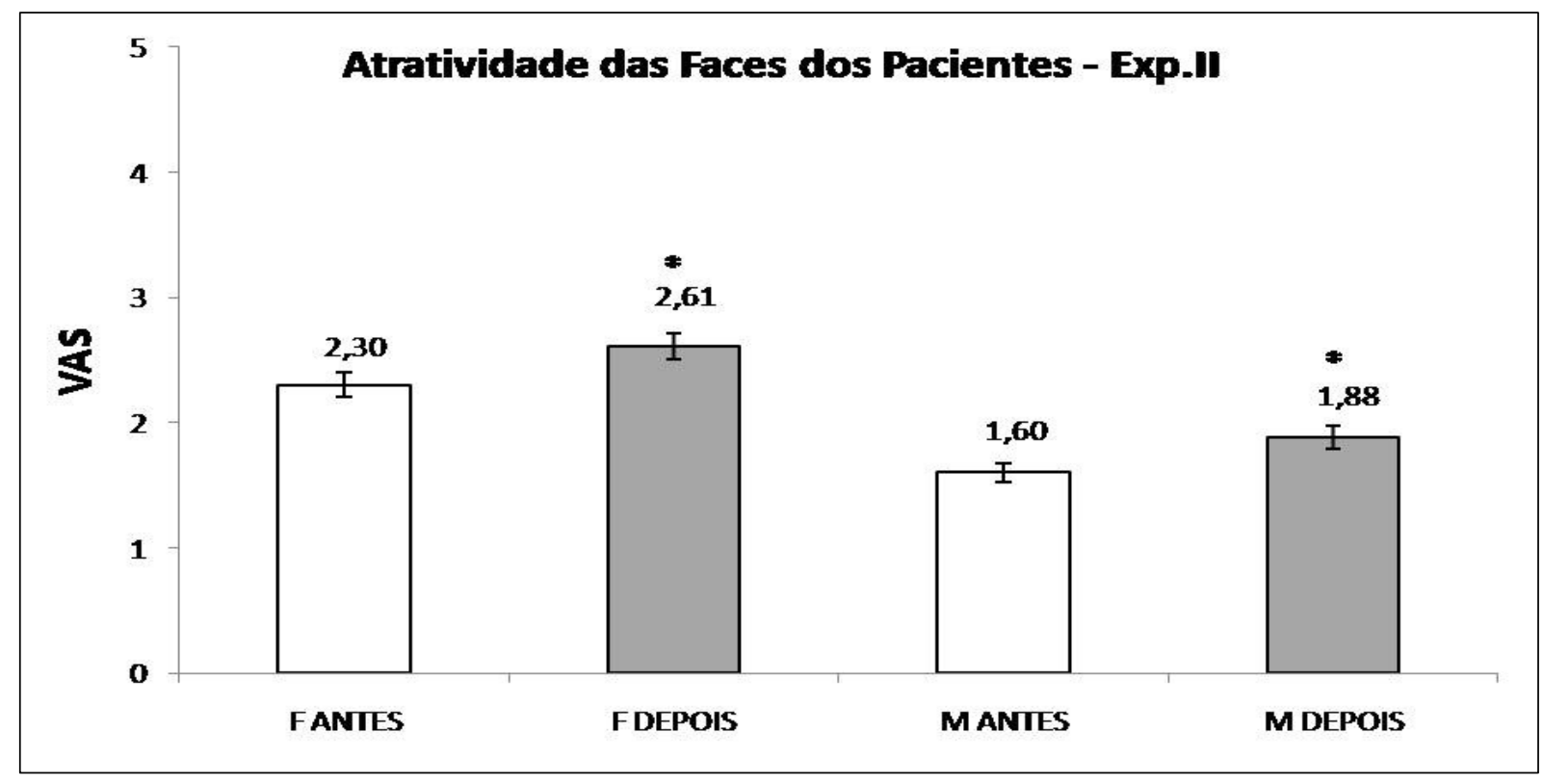

Figura 34. Julgamentos de atratividade das faces de pacientes femininos (F) e masculinos (M) antes (A) e depois (D) da cirurgia ortognática no Experimento II. Os dados são representados como médias e \pm E.P.M. $(* \mathrm{p}<0,01$ entre as faces antes e depois)

Ao comparar os julgamentos de atratividade das faces entre os Experimentos I e II o teste de Friedman apontou diferenças significativas para os julgamentos gerais $[\mathrm{Q}(39,40)=$ 649,62; $\mathrm{p}<0,01]$ em que as faces pós-cirúrgicas obtiveram maiores escores de julgamentos no Exp.I e as faces pré-cirúrgicas maiores escores no Exp.II. Para o Exp. I a mediana para as pré-cirúrgicas foi de 0,00 ( $1^{\circ}$ Quartil: 0,00; $3^{\circ}$ Quartil: 2,24) e pós-cirúrgicas de 2,13 ( $1^{\circ}$ Quartil: 
0,71; $3^{\circ}$ Quartil: 3,54), quanto no Exp.II, a mediana para as pré-cirúrgicas foi de $1,70\left(1^{\circ}\right.$ Quartil: 0,95; $3^{\circ}$ Quartil: 1,10) e pós-cirúrgicas de 2,05 (1ºuartil: 2,75; $3^{\circ}$ Quartil: 2,98).

Ao comparar, pelo teste de Wilcoxon, as medianas dos julgamentos dos sexos das faces separadamente notou-se que para as femininas houve diferenças significativas entre os julgamentos do Exp.I e Exp.II, nas faces pré-cirúrgicas $[Q(7,196)=6,64 ;$ p<0,01] e pós-cirúrgicas $[\mathrm{Q}(7,200)=6,09 ; \mathrm{p}<0,01]$. Para as faces masculinas o teste mostrou diferenças entre os dois Experimentos apenas para as faces pré-cirúrgicas $[\mathrm{Q} F(7,196)=4,62 ; \mathrm{p}<0,01]$, como mostra a Tabela 9.

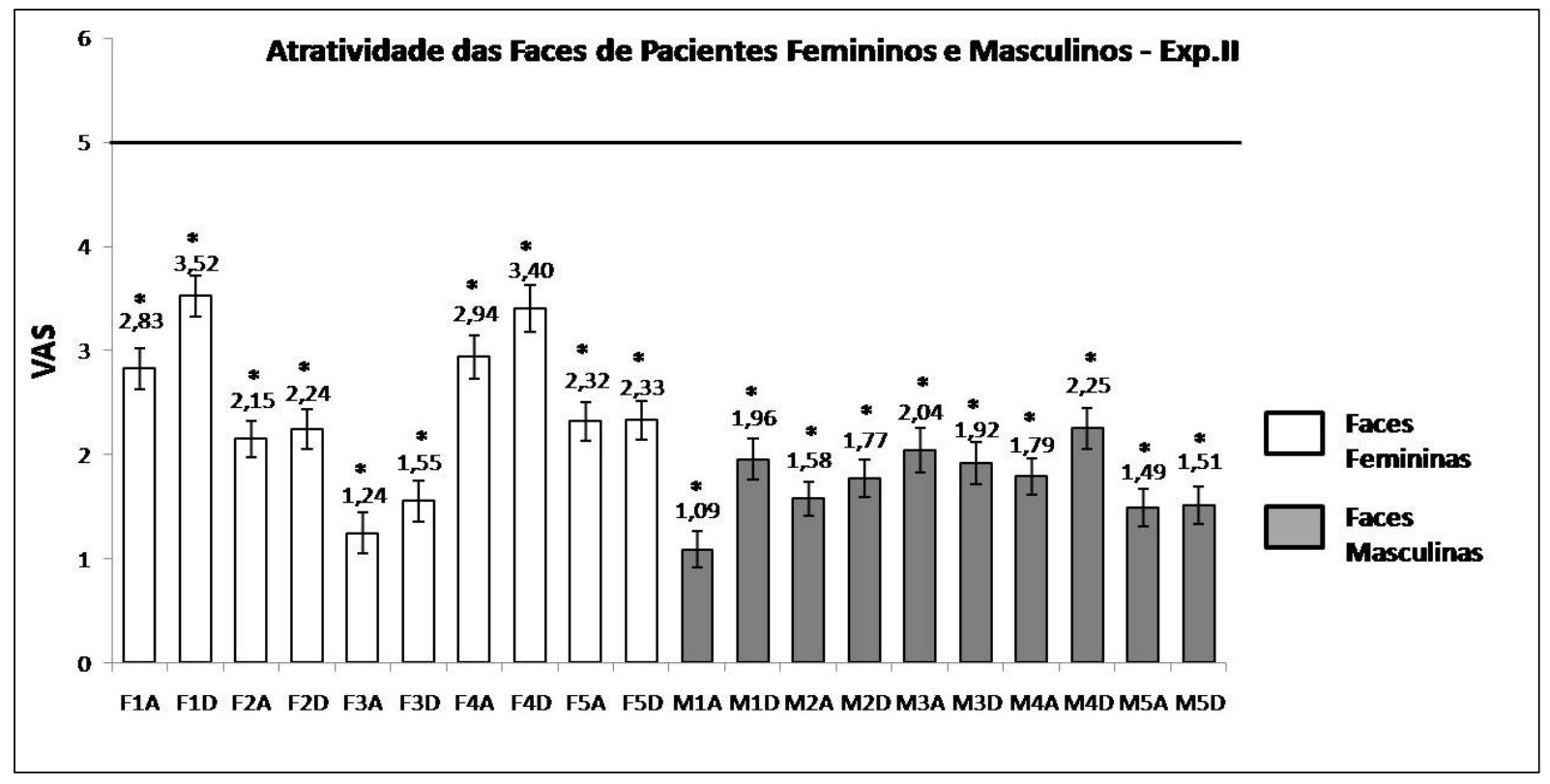

Figura 35. Julgamentos de atratividade das faces de pacientes femininos (F) e masculinos (M) antes (A) e depois (D) da cirurgia ortognática no Experimento II. A linha destacada representa o julgamento predeterminado dos protótipos faciais. Os dados são representados como médias e \pm E.P.M. ( $*$ p $<0,01$, comparado com os julgamentos dos protótipos faciais) 
Tabela 9- Diferenças entre as medianas de julgamentos das faces femininas e masculinas nos Experimentos I e II

\begin{tabular}{ccccccccc}
\hline & Femininas & Femininas & Femininas & Femininas & Masculinas & Masculinas & Masculinas & Masculinas \\
& Antes & Antes & Depois & Depois & Antes & Antes & Depois & Depois \\
& Exp.I & Exp.II & Exp.I & Exp.II & Exp.I & Exp.II & Exp.I & Exp.II \\
\hline MED & 0,00 & $2,18^{*}$ & 2,98 & $2,54^{*}$ & 0,00 & $1,35^{*}$ & 1,55 & 1,82 \\
$1^{\circ}$ Quartil & 0,00 & 1,18 & 1,50 & 1,31 & 0,00 & 0,73 & 0,00 & 0,95 \\
$3^{\circ}$ Quartil & 2,34 & 3,39 & 4,24 & 3,66 & 1,91 & 2,18 & 2,60 & 2,45 \\
\hline
\end{tabular}

(* $\mathrm{p}<0,01$, comparado com Exp.I).

Para as faces femininas os julgamentos das faces pré-cirúrgicas foram maiores no Exp.II, diferente das pós-cirúrgicas, que foram maiores no Exp.I. Para as faces masculinas pré-cirúrgicas houve maiores medianas no Exp.II e, apesar de não haver diferenças significativas entre as pós-cirúrgicas, houve uma tendência das medianas serem maiores também no Exp.II. Os protótipos faciais parecem ter influenciado de maneira diferente os julgamentos dos dois sexos das faces.

\section{Discussão}

Os resultados obtidos também neste segundo Experimento mostram que a cirurgia ortognática melhorou a estética facial de pacientes portadores de deformidades dentofaciais, corroborando mais uma vez os dados da literatura (KERR; DORTH; O'DONNELL, 1990; ONG, 2004; PHILLIPS; PROFFIT, 2005).

Nos dois Experimentos realizados os escores de atratividade facial foram baixos, ocorrido provavelmente devido às desarmonias faciais dos pacientes, que comprometem a atratividade das mesmas (EDLER; ORTH, 2001; NEGER; NEWARK, 1959, apud REIS et al., 2006b). Mesmo quando há a melhora estética com a cirurgia as faces provavelmente 
continuaram como estímulos fora do padrão normativo, distante da média matemática das faces da população a que pertencem, menos atrativas (O'TOOLE et al., 1999; RHODES; TREMEWAN, 1996; RHODES; SIMMONS; PETTERS, 2005; RHODES; SUMICH; BYATT, 1999).

Assim como mostrado na literatura por Penton-Voak e Perrett (2000) e Reis et al. (2006b) em que as faces femininas costumam ser avaliadas como mais atrativas que as masculinas, também foi observado nos dois Experimentos deste estudo; as faces femininas tiveram medianas de julgamentos maiores que as faces masculinas.

Os julgamentos de participantes femininos tiveram a tendência de serem maiores que os masculinos corroborando dados da literatura (PENTON-VOAK; PERRETT, 2000; PERRETT; MAY; YOSHIKAWA, 1994; PERRETT et al., 1998). Estudos mostram que a avaliação da atratividade facial depende de fatores biológicos que direcionam os julgamentos a potenciais parceiros reprodutivos (LITTLE et al. 2008; THORNHILL; GANGESTAD, 1999). Também foi demonstrado, por meio de estudos com fMRI com pessoas hetero e homossexuais, que as ativações neurais durante julgamentos de atratividade facial estão relacionados ao sistema de recompensa, sendo moduladas pela preferência sexual, mesmo quando não está diretamente relacionada a fins reprodutivos (ISHAI, 2007; KRANZ; ISHAI, 2006).

A tendência das diferenças entre os julgamentos dos participantes masculinos e femininos pode demonstrar haver distinções de sexo nos julgamentos de atratividade facial como mostra a literatura (ISHAI, 2007; KRANZ; ISHAI, 2006; LITTLE et al. 2008; PENTON-VOAK; PERRETT, 2000; PERRETT; MAY; YOSHIKAWA, 1994; PERRETT et al., 1998; THORNHILL; GANGESTAD, 1999). Parece ser mais fácil para as mulheres julgarem faces como atrativas, independente do sexo da face, do que para os homens. Tal fato pode passar pelo crivo social da explicitação e aceitação da beleza para homens e mulheres. 
No Experimento II as faces dos pacientes foram consideradas significativamente menos atrativas que as dos protótipos faciais, as quais tinham valores 5,00 de atratividade. Frequentemente os protótipos faciais são julgados com aparências mais jovens e com maior atratividade do que as imagens faciais que lhe deram origem. O aumento na atratividade tem sido atribuído à forma média do composto (Langlois; Roggman 1990) e um nivelamento ou uma suavização do tom da pele (BENSON; PERRETT 1991; JONES et al., 2004). Quanto mais próxima for a aparência da face do protótipo de sua raça, maior será seu nível de atratividade (LANGLOIS; ROGGMAN, 1990; RHODES; SUMICH; BYATT, 1999), além do que resultados de testes de atratividade mostram que os protótipos têm médias de julgamentos superiores às médias de julgamento das faces que os compuseram.

As faces pré-cirúrgicas, femininas e masculinas, tiveram escores de atratividade maiores no Experimento II comparado ao Experimento I. Contudo, para as faces pós-cirúrgicas, houve decréscimo na atratividade das faces femininas, sem diferenças significativas para as masculinas. Os protótipos faciais interferiram de maneira diferenciada nos julgamentos dos dois gêneros de faces.

Protótipos faciais, sendo então representantes das formas físicas faciais de um determinado grupo, podem ser utilizados como parâmetros físicos em cirurgias de correção faciais (BASHOUR, 2006) e garantir bons resultados estéticos.

Os dados deste segundo Experimento também levam a compreender que a cirurgia ortognática pode trazer melhorias estéticas àqueles que a procuram, na medida em que os julgamentos de atratividade facial devem estar condicionados às regras de proporcionalidade, harmonização e aspectos medianos da face humana, dentre outros aspectos como subjetividade, cultura, etnia.

Desde a antiguidade clássica a humanidade tenta descrever relações matemáticas que correspondam a um ideal de beleza e estética corporal e facial. Estudos como este corroboram 
a tese de que, apesar da beleza estar nos olhos de quem vê, existem elementos físicos que podem ser manipulados para melhorias estéticas faciais.

Faz-se importante este tipo de estudo no sentido de auxiliar os profissionais da área de cirurgia ortognática em predizer quais parâmetros podem estar mais ou menos correlacionados à melhoria da estética facial, principalmente na utilização de protótipos faciais oriundos da população atendida. Muitas regras utilizadas no Brasil provêm de normatizações internacionais, dados que podem não traduzir os parâmetros faciais aqui encontrados. O estudo das características da população brasileira em seus aspectos físicos e perceptivos, bem como o de seus protótipos, aumenta as possibilidades de pesquisas e normatização em cirurgias ortognáticas e de correção estética. 
3.3) INVESTIGAÇÃO DA QUALIDAdE DE VIDA, ANSIEDADE E AUTOESTIMA DOS PACIENTES SUBMETIDOS À CIRURGIA ORTOGNÁTICA.

Esta fase consistiu na aplicação de quatro instrumentos de avaliação nos pacientes submetidos à cirurgia ortognática (cujas faces foram analisadas na fase 2) a fim de verificar se as alterações faciais no pós-cirúrgico afetaram sua qualidade de vida, sua ansiedade e autoestima. As entrevistas para coleta de dados também avaliaram o grau de expectativa antes da cirurgia e o grau de satisfação dos pacientes diante dos resultados obtidos.

As escalas foram aplicadas nos 10 pacientes nos contatos pré-cirúrgico (dias antes da cirurgia) e pós-cirúrgico (após seis meses ou mais) no momento anterior à coleta das fotografias. O período de seis meses no pós-cirúrgico foi respeitado, pois após este período a face apresenta-se sem edemas e inchaços, o paciente já tem noção exata de como sua aparência permanecerá e a avaliação emocional sobre as alterações decorrentes da cirurgia podem estar mais consolidada.

As escalas utilizadas foram:

I) Instrumento de Avaliação de Qualidade de Vida da Organização Mundial da Saúde, versão breve e em português: WHOQOL-bref (OMS, 1998, Anexo D). Esta escala é uma versão abreviada do WHOQOL-100 (que consta de 100 questões que avaliam 6 domínios: Físico, Psicológico, Nível de Independência, Relações Sociais, Meioambiente e Espiritualidade/Crenças Pessoais), composta pelas 26 questões que obtiveram os melhores desempenhos psicométricos extraídas da versão original. Esta versão abreviada é composta por 4 domínios: Físico, Psicológico, Relações Sociais e Meio Ambiente e foi desenvolvida com a colaboração de 15 centros simultaneamente em diferentes culturas, pela necessidade de elaboração de instrumentos curtos que demandem pouco tempo para seu preenchimento, mas com características psicométricas satisfatórias (FLECK et al., 1999). 
A definição de qualidade de vida pelo ' Grupo de Qualidade de Vida' da divisão de Saúde Mental da OMS baseia-se nos pressupostos de que qualidade de vida é um constructo subjetivo e multidimensional e composto por dimensões positivas e negativas. Esta versão breve do instrumento abrange tais questões tanto na forma psicométrica quanto conceitual e preserva o caráter abrangente do instrumento original (FLECK et al., 2000).

A versão em português dos instrumentos WHOQOL foi desenvolvida no Centro WHOQOL para o Brasil, no Departamento de Psiquiatria e Medicina Legal da Universidade Federal do Rio Grande do Sul sob a coordenação do Dr. Marcelo Pio de Almeida Fleck. Foi realizada segundo a metodologia indicada para a versão do instrumento, preenchendo os critérios das características psicométricas exigidas de consistência interna, validade discriminante, validade convergente, validade de critério, fidedignidade de teste e reteste (FLECK et al., 2000).

Os participantes devem responder às 26 questões e pontuar entre 1 a 5, de acordo com uma escala tipo Likert, que varia de Nada (1) até Extremamente (5). O inventário pode ser auto-aplicado ou auxiliado pelo avaliador e sua cotação é feita ao transformar os pontos das questões em escalas de 0 a 100 para cada domínio estudado e para as questões 1 e 2 separadamente (as quais dizem respeito à qualidade de vida e saúde em geral), através de uma sintaxe no software estatístico $S P S S^{\odot}$. Quanto maior a pontuação, melhor o nível de qualidade de vida do sujeito nos referidos domínios.

II) Inventário de Ansiedade Traço - Estado, (IDATE) (Spielberg; Gorsuch; Lushene, 1979). O Inventário de Ansiedade Traço-Estado (IDATE) é um dos instrumentos mais utilizados para o estudo da ansiedade nas pesquisas sobre o tema. Desenvolvido nos EUA na Universidade de Vanderbilt, por Spielberger em 1970 (Spildber et al., 1979) originalmente foi planejado para investigar fenômenos de ansiedade em adultos sem perturbações psiquiátricas, também se mostrou útil ao medir ansiedade em estudantes de $1^{\circ}$ e $2^{\circ}$ graus, em pacientes 
neuropsiquiátricos, cirúrgicos e de clínica média. Foi traduzido e adaptado para o Brasil por Biaggio (1979, apud SPIELBERGER; GORSUCH; LUSHENE, 1979) e é editado e distribuído pelo CEPA - Centro Editor de Psicologia Aplicada Ltda.

A aplicação do IDATE é simples. O teste é composto por duas escalas de autorrelatório, impressas em cadernos separados e elaboradas a partir de dois conceitos de ansiedade: o estado de ansiedade ('Ansiedade- Estado’) e o traço de ansiedade ('AnsiedadeTraço'). São escalas com variação de respostas entre 1 e 4.

A primeira, 'Ansiedade-Estado' (A-estado), refere-se a um estado emocional transitório que se caracteriza por sentimentos subjetivos de tensão que podem variar de intensidade de acordo com o contexto. Ela é composta de 20 afirmações que questionam como os participantes se sentem num determinado momento. As respostas possíveis são: 1) Absolutamente Não; 2) Um Pouco; 3) Bastante; 4) Muitíssimo (Anexo E).

A escala 'Ansiedade-Traço' (A-traço), também composta por 20 afirmações, refere-se a diferenças individuais relativamente estáveis na tendência a reagir a situações percebidas como ameaçadoras. Os participantes devem responder como geralmente se sentem diante das situações cotidianas. As respostas possíveis são: 1) Quase Nunca; 2) Às Vezes; 3) Frequentemente; 4) Quase Sempre (Anexo F).

Além dos diversos usos do IDATE como em pesquisas que selecionam indivíduos com diferentes graus de reação às pressões psicológicas, ou ainda que determinam níveis de intensidade de estados de ansiedade em situações experimentais, o inventário também se mostra útil no trabalho clínico. A escala A-estado pode indicar níveis de ansiedade transitória em pacientes em psicoterapia ou pacientes pré-cirúrgicos e pode também medir mudanças na intensidade deste tipo de ansiedade no decorrer destas situações. Em contrapartida a A-traço pode indicar os níveis de ansiedade que acometem geralmente aqueles indivíduos estudados 
ao avaliar o grau de perturbação que a ansiedade gera em seu cotidiano (SPIELBERGER; GORSUCH; LUSHENE, 1979).

A cotação do IDATE é feita pela soma dos pontos assinalados, considerando alguns itens invertidos tanto na escala A-Estado quanto na A-Traço. Quanto maior os escores, maiores os níveis de ansiedade do participante.

III) Escala Analógica de Humor (EAH) (NORRIS, 1971, versão traduzida por ZUARDI; KARNIOL, 1981, Anexo G). Esta escala foi proposta originalmente por Norris (1971) com o nome de "Visual Analogue Mood Scale" (VAMS), no estudo dos efeitos de drogas sobre a ansiedade induzida experimentalmente em voluntários e tem sido bastante aplicada no Brasil. É uma escala analógica, de autoavaliação, na qual a pessoa deve assinalar seu estado subjetivo em uma linha reta contínua que supostamente representa toda a gama de uma situação. A escala é constituída por 16 itens, cada um composto de uma linha reta de 10 cm que liga dois adjetivos de sentidos opostos (Guimarães, 2000). Os 16 itens foram agrupados por Zuardi et al. (1993) em quatro fatores, de acordo com a nomenclatura original: Ansiedade (itens 2, 8 e 10), Sedação Física (itens 3, 4, 5, 6, 9, 12, 16), Sedação Mental (itens 1 e 11) e Outros Sentimentos e Atitudes (itens 7, 13, 14 e 15).

Os participantes assinalam sua resposta no continuum com um traço vertical na linha. Os escores são obtidos ao medir as linhas com uma régua milimetrada ou um paquímetro e estas medidas representam os valores em uma escala de 0 a 100. Quanto maior o valor obtido em cada item na escala, maior o grau de ansiedade do participante. Metade dos itens é direta com adjetivos positivos na extremidade direita da linha e a outra metade é composta de itens invertidos, ou seja, tem na extremidade direita da linha um adjetivo negativo. A transformação destes últimos em escala de 0 a 100 deve ser feita ao subtrair o valor mensurado de 100 . 
Este tipo de escalas, comparadas às de natureza discreta (usualmente mais empregadas), apresentam vantagens em relação à sensibilidade de discriminação de sensações, facilidade de preenchimento e maior possibilidade de uso de estatística paramétrica no tratamento dos dados (GUIMARÃES, 2000).

IV) Escala de Auto-Estima de Rosenberg (Souza; Ferreira, 2005, Anexo H). Esse instrumento é uma escala de autorrelato de sete pontos, que variam de Discordo Totalmente (1) a Concordo Totalmente (7). É composta por dez itens que investigam aspectos globais da autoestima; cinco itens que avaliam sentimentos positivos do indivíduo sobre si mesmo, e outros cinco itens que avaliam sentimentos negativos. Os participantes devem indicar o grau de concordância com o item descrito. Para a pontuação das respostas os cinco itens que expressam sentimentos negativos têm valores invertidos, e então, estes valores são somados aos dos outros itens positivos, totalizando um valor único para a escala, correspondente às respostas dos 10 itens. Os valores podem variar de 10 a 70 e quanto maior o escore obtido, maior a autoestima do participante (VARGAS, DANTAS; GOIS, 2005).

Esta escala é um dos instrumentos mais utilizados para a avaliação da autoestima global e no Brasil tem sido amplamente utilizada em pesquisas em saúde. O conceito de autoestima, segundo Rosenberg (1965, apud ROMANO; NEGREIROS; MARTINS, 2007), refere-se à avaliação que a pessoa efetua e geralmente mantém em relação a si própria, o que implica um sentimento de valor que engloba um componente afetivo, expressa numa atitude de aprovação/desaprovação em relação a si mesma.

Os instrumentos foram cotados e os resultados foram analisados de acordo com os critérios de cada um e posteriormente os resultados obtidos antes e depois da cirurgia foram comparados com testes estatísticos, com auxílio dos softwares $\operatorname{SPSS}^{\mathcal{O}}$ versão 12.0 e BioEstat 5.0 para verificar possíveis alterações emocionais entre as duas condições de análise, antes e após da cirurgia ortognática. 


\section{Resultados}

Os resultados dos instrumentos de avaliação aplicados nos pacientes antes e após a cirurgia ortognática serão apresentados separadamente:

I) WHOQOL- bref: Os dados coletados a partir do "Instrumento de Avaliação de Qualidade de Vida" da Organização Mundial da Saúde, "WHOQOL-bref" (OMS, 1998) foram cotados, transformados em escalas de 0 a 100 para cada domínio: 1) Físico, 2) Psicológico, 3) Relações Sociais e 4) Meio Ambiente) e para as questões 1 e 2 separadamente (relacionadas à qualidade de vida e de saúde em geral). Os dados das escalas foram comparados para as situações pré e pós-cirúrgicas dos 10 pacientes analisados através do Teste T pareado (considerando $\mathrm{p}<0,01$ ).

Como visto nas Tabelas 10 e 11 os resultados mostraram que, apesar de todos os domínios terem médias maiores na condição pós-cirúrgica, o teste estatístico apontou diferença significativa $[\mathrm{T}(9,10)=3,74 ; \mathrm{p}<0,01]$ apenas para o domínio 'Psicológico', com maiores escores para a situação pós-cirúrgica.

Tabela 10- Escores obtidos nos domínios Físico, Psicológico e Relações Sociais no Whoqolbref, com respectivas médias e desvios padrões

\begin{tabular}{ccccccc}
\hline & \multicolumn{2}{c}{ Domínio Físico } & \multicolumn{2}{c}{ Domínio Psicológico } & \multicolumn{2}{c}{ Domínio Relações Sociais } \\
Pacientes & Pré & Pós & Pré & Pós & Pré & Pós \\
\hline F1 & 67,86 & 78,57 & 66,67 & 87,50 & 66,67 & 66,67 \\
F2 & 42,86 & 46,43 & 33,33 & 33,33 & 66,67 & 58,33 \\
F3 & 100,00 & 92,86 & 75,00 & 79,17 & 91,67 & 100,00 \\
F5 & 75,00 & 78,57 & 66,67 & 83,33 & 58,33 & 83,33 \\
& 100,00 & 96,43 & 91,67 & 87,50 & 91,67 & 75,00 \\
& & & & & & \\
\end{tabular}




\section{conclusão}

Tabela 10- Escores obtidos nos domínios Físico, Psicológico e Relações Sociais no Whoqolbref, com respectivas médias e desvios padrões

\begin{tabular}{ccccccc}
\hline M1 & 53,57 & 78,57 & 54,17 & 83,33 & 66,67 & 58,33 \\
M2 & 96,43 & 85,71 & 66,67 & 95,83 & 50,00 & 66,67 \\
M3 & 92,86 & 100,00 & 79,17 & 87,50 & 75,00 & 83,33 \\
M4 & 82,14 & 92,86 & 79,17 & 91,67 & 83,33 & 91,67 \\
M5 & 78,57 & 85,71 & 66,67 & 91,67 & 58,33 & 66,67 \\
Média & $\mathbf{7 8 , 9 3}$ & $\mathbf{8 3 , 5 7}$ & $\mathbf{6 7 , 9 2}$ & $\mathbf{8 2 , 0 8 *}$ & $\mathbf{7 0 , 8 3}$ & $\mathbf{7 5 , 0 0}$ \\
& & & & & \\
Desvio & $\mathbf{1 9 , 6 7}$ & $\mathbf{1 5 , 1 7}$ & $\mathbf{1 5 , 8 4}$ & $\mathbf{1 7 , 7 9}$ & $\mathbf{1 4 , 3 0}$ & $\mathbf{1 4 , 1 6}$ \\
Padrão & & & & & \\
\hline
\end{tabular}

Tabela 11- Escores obtidos nos domínio Meio Ambiente e nas Questões 1 e 2 no Whoqolbref, com respectivas médias e desvios padrões

\begin{tabular}{|c|c|c|c|c|c|c|}
\hline \multirow[b]{2}{*}{ Pacientes } & \multicolumn{2}{|c|}{$\begin{array}{c}\text { Domínio Meio } \\
\text { Ambiente }\end{array}$} & \multicolumn{2}{|c|}{ Questão 1} & \multicolumn{2}{|c|}{ Questão 2} \\
\hline & Pré & Pré & Pré & Pós & Pré & Pós \\
\hline F1 & 56,25 & 71,88 & 12,50 & 18,75 & 18,75 & 18,75 \\
\hline F2 & 40,63 & 50,00 & 12,50 & 12,50 & 12,50 & 12,50 \\
\hline F3 & 75,00 & 71,88 & 18,75 & 18,75 & 12,50 & 18,75 \\
\hline F4 & 65,63 & 71,88 & 18,75 & 18,75 & 25,00 & 18,75 \\
\hline F5 & 75,00 & 78,13 & 25,00 & 18,75 & 18,75 & 18,75 \\
\hline
\end{tabular}


conclusão

Tabela 11- Escores obtidos nos domínio Meio Ambiente e nas Questões 1 e 2 no Whoqolbref, com respectivas médias e desvios padrões

\begin{tabular}{ccccccc}
\hline M1 & 71,88 & 71,88 & 12,50 & 18,75 & 18,75 & 25,00 \\
M2 & 62,50 & 59,38 & 25,00 & 25,00 & 18,75 & 18,75 \\
M3 & 50,00 & 71,88 & 18,75 & 18,75 & 25,00 & 25,00 \\
M4 & 62,50 & 75,00 & 18,75 & 25,00 & 18,75 & 25,00 \\
M5 & 68,75 & 62,50 & 25,00 & 18,75 & 18,75 & 18,75 \\
& & & & & & \\
Média & $\mathbf{6 2 , 8 1}$ & $\mathbf{6 8 , 4 4}$ & $\mathbf{1 8 , 7 5}$ & $\mathbf{1 9 , 3 8}$ & $\mathbf{1 8 , 7 5}$ & $\mathbf{2 0 , 0 0}$ \\
& & & & & & \\
Desvio & $\mathbf{1 1 , 1 7}$ & $\mathbf{8 , 5 2}$ & $\mathbf{5 , 1 0}$ & $\mathbf{3 , 5 5}$ & $\mathbf{4 , 1 7}$ & $\mathbf{3 , 9 5}$ \\
Padrão & & & & & & \\
\hline
\end{tabular}

II) Inventário de Ansiedade Traço-Estado: Os escores coletados a partir do "Inventário de Ansiedade Traço-Estado" (IDATE) (SPIELBERGER; GORSUCH; LUSHENE, 1979) foram comparados entre as duas situações pré e pós-cirúrgicas através de um teste não paramétrico (Wilcoxon), por ser esta uma escala de categorias. Os resultados são mostrados na Tabela 12. Não foram encontradas diferenças significativas $(p>0,01)$ entre as medianas dos escores nas duas condições de análise, apesar de haver uma tendência das medianas serem maiores na condição pré-cirúrgica para a Ansiedade-Estado e o inverso na escala A-Traço. 
Tabela 12- Escores obtidos no IDATE (A-Estado e A-Traço), com respectivas medianas e desvios padrões

\begin{tabular}{|c|c|c|c|c|}
\hline \multirow[b]{2}{*}{ Pacientes } & \multicolumn{2}{|c|}{ Ansiedade-Estado } & \multicolumn{2}{|c|}{ Ansiedade-Traço } \\
\hline & Pré & Pós & Pré & Pós \\
\hline F1 & 30,00 & 31,00 & 45,00 & 45,00 \\
\hline F2 & 50,00 & 49,00 & 52,00 & 67,00 \\
\hline F3 & 36,00 & 35,00 & 30,00 & 30,00 \\
\hline F4 & 37,00 & 38,00 & 42,00 & 41,00 \\
\hline F5 & 20,00 & 30,00 & 29,00 & 35,00 \\
\hline M1 & 25,00 & 30,00 & 47,00 & 35,00 \\
\hline M2 & 52,00 & 26,00 & 62,00 & 36,00 \\
\hline M3 & 40,00 & 28,00 & 31,00 & 27,00 \\
\hline M4 & 35,00 & 30,00 & 41,00 & 34,00 \\
\hline M5 & 35,00 & 29,00 & 42,00 & 32,00 \\
\hline Mediana & $\mathbf{3 5 , 5 0}$ & 30,00 & 42,00 & 35,00 \\
\hline $1^{\circ}$ Quartil & 31,25 & 29,25 & 33,50 & 32,50 \\
\hline $3^{\circ}$ Quartil & 39,25 & 33,75 & 45,75 & 35,75 \\
\hline
\end{tabular}

III) Escala Analógica de Humor (Norris, 1971, versão traduzida por ZUARDI; KARNIOL, 1981): Os escores de cada item da "Escala Analógica de Humor" foram mensurados e transformados em escala de 0 a 100 . Os itens invertidos foram tiveram seus escores subtraídos de 100 e foram somados aos itens diretos. Os 16 itens foram agrupados, de 
acordo com Zuardi et al. (1993), em quatro fatores: Ansiedade (itens 2, 8 e 10), Sedação Física (itens 3, 4, 5, 6, 9, 12, 16), Sedação Mental (itens 1 e 11) e Outros Sentimentos e Atitudes (itens 7, 13, 14 e 15).

As médias dos escores para os quatro fatores nas condições pré e pós-cirúrgicas foram comparadas pelo teste paramétrico de comparação de médias, Teste t, devido à sua natureza contínua. Foi verificada diferença significativa para o fator 'Ansiedade' entre as médias das duas condições $[\mathrm{t}(29,30)=2,84 ; \mathrm{p}<0,01]$, com maior a ansiedade na condição pré-cirúrgica. Os demais fatores não apresentaram diferenças significativas entre as médias das duas condições analisadas ( $\mathrm{p}>0,01)$. Os resultados estão na Tabela 13.

Tabela 13- Escores obtidos na Escala Analógica de Humor (EAH), com respectivas medianas e desvios padrões

\begin{tabular}{cccccccccc}
\hline & \multicolumn{2}{c}{$\begin{array}{c}\text { Fator } \\
\text { Ansiedade }\end{array}$} & \multicolumn{2}{c}{\begin{tabular}{c}
\multicolumn{2}{c}{ Fator Sedação } \\
Física
\end{tabular}} & \multicolumn{2}{c}{$\begin{array}{c}\text { Fator Sedação } \\
\text { Mental }\end{array}$} & \multicolumn{2}{c}{$\begin{array}{c}\text { Fator Outros } \\
\text { Sentimentos e } \\
\text { Atitudes }\end{array}$} \\
\hline Condição & Pré & Pós & Pré & Pós & Pré & Pré & Pré & Pós \\
Média & $32,51^{*}$ & 17,57 & 24,18 & 25,12 & 15,53 & 8,89 & 19,88 & 24,24 \\
Desvio Padrão & 32,89 & 23,04 & 24,85 & 24,42 & 19,77 & 11,21 & 24,90 & 24,97 \\
\hline
\end{tabular}

* $\mathrm{p}<0,01$ comparado com pós-cirúrgico.

IV) Escala de Auto-Estima de Rosenberg (SOUZA; FERREIRA, 2005): Os escores da “Escala de Auto-Estima de Rosenberg” estão descritos na Tabela 14. As comparações entre as medianas foram feitas com o teste de Wilcoxon, pela natureza ordinal da escala e não foram encontradas diferenças significativas $(\mathrm{p}>0,01)$ entre as condições pré e pós-cirúrgicas, apesar da mediana da condição pós-cirúrgica ser um pouco maior que na condição pré-cirúrgica. 
Tabela 14- Escores obtidos na Escala de Auto-Estima de Rosenberg, com respectivas medianas e desvios padrões

\begin{tabular}{|c|c|c|}
\hline \multirow[b]{2}{*}{ Paciente } & \multicolumn{2}{|c|}{ Auto Estima } \\
\hline & Pré & Pós \\
\hline F1 & 51,00 & 54,00 \\
\hline F2 & 32,00 & 38,00 \\
\hline F3 & 65,00 & 65,00 \\
\hline F4 & 50,00 & 58,00 \\
\hline F5 & 57,00 & 37,00 \\
\hline M1 & 43,00 & 63,00 \\
\hline M2 & 50,00 & 66,00 \\
\hline M3 & 65,00 & 70,00 \\
\hline M4 & 53,00 & 58,00 \\
\hline M5 & 53,00 & 56,00 \\
\hline Mediana & 52,00 & 58,00 \\
\hline $1^{\circ}$ Quartil & $\mathbf{5 0 , 0 0}$ & 54,50 \\
\hline $3^{\circ}$ Quartil & 56,00 & 64,50 \\
\hline
\end{tabular}

A aplicação de quatro instrumentos de avaliação foi realizada a fim de verificar se os pacientes submetidos à cirurgia ortognática sofreram algum tipo de alterações emocionais no pós-cirúrgico nos quesitos qualidade de vida, ansiedade e autoestima no período de seis meses após a cirurgia. Tais avaliações foram importantes para verificar o quanto este tipo de cirurgia afetou o cotidiano destes pacientes. 


\section{Discussão}

Os resultados do Instrumento de Avaliação de Qualidade de Vida da Organização Mundial da Saúde, WHOQOL-bref (OMS, 1998) apontaram diferenças significativas para o "Domínio Psicológico", com maiores medianas no pós-cirúrgico, o que indica que houve melhoria neste quesito na qualidade de vida dos pacientes. Tal dado é importante, pois uma vez que a cirurgia altera fisicamente e perceptivamente a face do paciente há uma possível alteração emocional que acompanha este fato. Pessoas que têm suas faces alteradas podem não mais se reconhecer ao espelho ou ainda não serem mais reconhecidas por pessoas de seu convívio social. Ademais o fato dos ganhos estéticos na face, com mudanças para melhor como visto nos Experimentos, o nível de satisfação emocional aumenta, aumentando também a qualidade de vida psíquica dos indivíduos. Melhorias nos relacionamentos interpessoais foram relatadas pelos indivíduos durante nas entrevistas o que pode também explicar os ganhos positivos para o domínio psicológico.

Os outros três domínios (Físico, Relações Sociais e Meio Ambiente) mais as questões 1 e 2 (relacionadas à qualidade de vida e de saúde em geral) tiveram maiores pontuações em medianas para o pós-cirúrgico, apesar de não apresentarem diferenças estatísticas com relação ao pré-cirúrgico. Tais dados levam a crer que os resultados satisfatórios provenientes da cirurgia ortognática podem ter influenciado na qualidade de vida geral destes pacientes, aumentando-a nos diferentes âmbitos do cotidiano. Cirurgias deste tipo podem, então, ser enquadradas no paradigma da qualidade de vida, com melhorias no dia-a-dia destes indivíduos. Estudos mostram que a grande maioria dos pacientes norteamericanos (82\%) está feliz com os resultados do tratamento entre 4 e 6 semanas após a cirurgia e este número sobe para 90\% após dois anos (PHILLIPS; BENNETT, 2000 apud PHILLIPS; PROFFIT, 2005).

Com relação à investigação sobre a ansiedade dos pacientes nos momentos pré e pós-cirúrgicos foi demonstrado que pelo Inventário de Ansiedade Traço - Estado, (IDATE) 
(SPIELBERGER; GORSUCH; LUSHENE, 1979) não houve diferenças significativas entre as medidas dos dois tipos de situações, apesar de haver uma tendência das medianas na condição pré-cirúrgica para a Ansiedade-Estado serem maiores e para a escala A-Traço serem maiores na pós-cirúrgica. Contudo na Escala Analógica de Humor (EAH) (Norris, 1971, versão traduzida por ZUARDI; KARNIOL, 1981) houve diminuição da ansiedade na fase pós-cirúrgica de avaliação. Tal divergência de resultados pode se apoiar no fato da EAH ser uma escala que apresenta vantagem em relação à sensibilidade de discriminação de sensações, facilidade de preenchimento e maior possibilidade de uso de estatística paramétrica no tratamento dos dados (GUIMARÃES, 2000), o que leva a índices de ansiedade mais fidedignos e seguros.

Foi verificado durante as entrevistas pré-cirúrgicas um alto grau de expectativa nos pacientes pela iminência da cirurgia (o evento tão aguardado pela maioria deles), o que pode ter afetado o nível de ansiedade dos pacientes nesta fase, que envolve expectativas e medos sobre o procedimento cirúrgico e suas intercorrências.

A diminuição da ansiedade na fase pós-cirúrgica pode demonstrar tanto uma situação de maior relaxamento pela familiaridade com o pesquisador e/ou instrumento ou também um decréscimo de angústia cotidiana, com melhorias nas relações pessoais consigo e com terceiros, corroborados pelo alto grau de satisfação dos pacientes observado nas entrevistas.

Estudos norteamericanos mostraram que até metade dos pacientes com deformidades maxilomandibulares apresentam nível elevado de angústia, o que prediz problemas de relacionamento interpessoal (PHILLIPS; BENNETT; BRODER, 1998). Tal fato deve ser levado em consideração pelos profissionais que se dispõem a tratar pacientes com estes problemas, o que reforça a necessidade da presença de um psicólogo no acompanhamento de casos em tratamentos ortognáticos (Nardi et al., 2003; NEWELL; MARKS, 2000). E quando não há a possibilidade de muitos profissionais trabalharem em equipe, há necessidade dos 
ortodontistas e cirurgiões ficarem atentos aos sintomas psicológicos de angústia e aflição, ou a qualquer outra dificuldade emocional muito comuns nestes tipos de pacientes (PHILLIPS; BENNETT; BRODER, 1998).

As ansiedades relacionadas às deformidades dentárias parecem ser influenciadas pela visão do paciente e pelas reações de terceiros. $\mathrm{O}$ sentimento de inferioridade aparece como primeiro e principal efeito psicológico da deformidade dentofacial; e tal sentimento é um estado emocional complexo e doloroso, e caracterizado por sensações de incompetência, inadequação e depressão em vários âmbitos (HUNGERFORD, 2000, apud MORI, 2003). A reversão destas deformidades resgata sentimentos positivos no indivíduo e pode até diminuir a ansiedade em sua vida cotidiana. Tal impacto positivo reflete em suas atitudes pessoais, sociais e comportamentais (NARDI et al., 2003).

Com relação à análise da autoestima alguns estudos apontam que pessoas com problemas estéticos dentários têm tendência a baixa autoestima (com comportamentos de cobrir a boca quando falam, ou moverem os lábios de forma artificial, ou ainda não gostar de tirar fotografias, falar ou trabalhar com grande público) muitas vezes até com sintomas de fobia social (NEWELL; MARKS, 2000). Contudo, Lazaridou-Terzoudi et al. (2003) não encontraram diferenças significativas na autoestima e na imagem corporal entre grupos de pacientes e não pacientes ortognáticos.

No presente estudo não foram verificadas alterações na autoestima entre as fases pré e pós-cirúrgicas pela Escala de Auto-Estima de Rosenberg (SOUZA; FERREIRA, 2005). Tais dados corroboram os resultados de Cunningham, Hunt e Feinmann (1996) que, ao utilizar o mesmo instrumento, mostraram não haver diferença na autoestima nos pacientes nas fases antes e depois da cirurgia, apesar do alto grau de satisfação dos mesmos diante dos bons resultados da cirurgia ortognática. 
Embora os resultados não tenham demonstrado diferenças estatisticamente diferentes, a fase pós-cirúrgica teve uma inclinação para maior mediana de autoestima. Nicodemo, Pereira e Ferreira (2008) mostraram em um estudo com pacientes nas mesmas condições e coma utilização da mesma escala de autoestima, que houve aumento da autoestima para os pacientes femininos, mas não para os masculinos.

O conceito de autoestima, segundo Rosenberg (1965 apud ROMANO; NEGREIROS; MARTINS, 2007), refere-se à avaliação que a pessoa efetua e geralmente mantém em relação a si própria, o que implica um sentimento de valor que engloba um componente afetivo, expressa numa atitude de aprovação/desaprovação em relação a si mesma. A falta de segurança e baixa autoestima podem afetar a obtenção ou não de sucesso de muitas pessoas, incluindo aquelas com deformidades dentofaciais. Tal depreciação pode atingir os aspectos intelectuais e psicológicos, diminuir a autoestima, interferir na inserção da pessoa no mercado de trabalho e dificultar relações pessoais e profissionais (NEWELL; MARKS, 2000; OMOTE, 1994; PROFFIT; WHITE JUNIOR, 2005).

Quando a estética pode ser restabelecida em uma face deformada, tornando-a mais harmônica, aproximando o aspecto físico dos resultados esperados pelos pacientes, muitos ganhos psíquicos, emocionais e relacionais são obtidos pelos indivíduos. O que pode tornar suas relações mais tranquilas, seu cotidiano menos doloroso e sua vida mais feliz. Tais consequências parecem ser muito importantes para pacientes que se submetem a cirurgias ortognáticas do ponto de vista emocional e social. 


\section{4) Discussão Geral}

As análises faciais de amostras de imagens faciais de voluntários da cidade de Ribeirão Preto, SP e seus respectivos protótipos mostraram resultados interessantes. A que diz respeito aos aspectos físicos das faces, parâmetros diferentes daqueles apontados na literatura foram observados nas três etnias, principalmente na análise dos terços e quintos faciais. Os protótipos tiveram a mesma tendência nas medidas das amostras. Tais resultados apontam para uma forte importância de estudos nacionais sobre parâmetros de análises faciais, tão importantes nos planejamentos de tratamentos ortocirúrgicos para fins de melhorias estéticas e correções funcionais.

Apesar de a amostra nacional apresentar-se simétrica, as diferenças entre os terços e quintos faciais podem ter comprometido os julgamentos de atratividade das faces, consideradas pouco atrativas na média geral (ARRAIS, 2007). Tal resultado corrobora o que Reis et al. (2006b) discutem sobre a Análise Facial Subjetiva ao dizerem faces esteticamente agradáveis são exceções. Os protótipos tiveram médias de atratividade maiores que das faces que o compuseram, apesar destas serem medianas, o que corrobora dados da literatura.

Apesar dos protótipos apresentarem praticamente as mesmas medidas das faces que os deram origem, eles foram considerados mais atrativos que elas. Este aumento na atratividade tem sido atribuído à forma deste estímulo, composto pela média matemática dos valores dos traços da amostra que os compuseram (LANGLOIS; ROGGMAN 1990; RHODES, 2006) com suavizações de imperfeições e tons de pele (BENSON; PERRETT, 1991).

Estes resultados podem apontar que, mesmo com a mesma tendência de medidas, as imagens tiveram julgamentos de atratividade diferenciados: menores para as amostras e maiores para os protótipos, dados concordantes com a literatura da área. 
Os protótipos, sendo representantes das faces da população brasileira, podem ser utilizados em comparações com faces de pacientes que apresentam deformidades e desvios de medidas faciais, sendo mais atrativos que esta amostra.

As faces analisadas mostraram-se simétricas assim como seus protótipos e passíveis de serem utilizados como parâmetros de comparação com faces de pessoas que apresentam grandes desvios de simetria, como é o caso de pacientes que necessitam de cirurgias ortognáticas corretivas, estética ou funcional.

Foi visto também neste estudo que diferenças físicas faciais geram como consequência alterações na percepção da atratividade, bem como alterações emocionais na vida de quem as sofrem. Tantas mudanças importantes na vida dos pacientes devem ser acompanhadas de perto por profissionais psicólogos de preferência nos dois momentos: antes da cirurgia (na preparação dos pacientes para as mudanças físicas e emocionais) e após as mesmas (no suporte de possíveis frustrações por expectativas não alcançadas e até mesmo ao dividir as alegrias e poder aprender a lidar com boas novidades).

A estética facial tem uma importância muito grande na vida pessoal e profissional de quem sofre com deformidades e deve ser um dos pontos cruciais em se considerar no momento de diagnóstico e planejamento de cirurgias ortognáticas. As modificações podem ser grandes ou pequenas, mas sempre estarão presentes e marcarão para sempre a vida destas pessoas.

Os dados deste estudo levam a crer que a cirurgia ortognática, enquanto tratamento de deformidades dentofaciais, pode trazer melhorias estéticas a aqueles que a procuram. Tal melhoria pode ser fundamental na vida de pessoas que sofrem com dificuldades de relacionamento e que encontram empecilhos no convívio e na interação social, além de dificuldades funcionais e na relação consigo mesma, devido à suas deformidades. 
Isto leva a compreender que os julgamentos de atratividade facial devem estar condicionados às regras de proporcionalidade, harmonização e aspectos medianos da face humana, dentre outros aspectos como subjetividade, cultura, etnia.

Desde a antiguidade clássica a humanidade tenta descrever relações matemáticas que correspondam a um ideal de beleza e estética corporal e facial. Estudos como este corroboram com a tese de que, apesar da beleza estar nos olhos de quem vê, existem elementos físicos que podem ser manipulados para melhorias de estéticas faciais. E tais melhorias podem trazer muitos benefícios físicos, funcionais e emocionais à vida de muitas pessoas que sofrem com problemas de deformidades dentofaciais.

Faz-se importante este tipo de estudo no sentido de auxiliar os profissionais da área de cirurgia ortognática em predizer parâmetros que podem estar mais ou menos correlacionados à melhoria da estética facial, principalmente utilizando-se de medidas e proporções oriundas da população atendida. Muitas regras utilizadas no Brasil provêm de normatizações internacionais, dados que podem não traduzir os parâmetros faciais aqui encontrados. O estudo das características da população brasileira em seus aspectos físicos e perceptivos, bem como o de seus protótipos, aumenta as possibilidades de pesquisas e normatização em cirurgias ortognáticas e de correção estética no Brasil. 
Referências

ANDRADE, L.; GORENSTEIN, C. Aspectos gerais das escalas de avaliação de ansiedade. In: GORENSTEIN, C.; ANDRADE, L.; ZUARDI, A. Escalas de avaliação clínica em psiquiatria e psicofarmacologia. São Paulo: Lemos Editorial, 2000. cap. 15, p. 139-144.

ARNETT, G. W.; MCLAUGHLIN, R. P. Exame clínico facial - vista frontal. In: Planejamento facial e dentário para ortodontistas e cirurgiões bucomaxilofaciais. Porto Alegre: Artes Médicas, 2004. cap. 2. p. 51-63.

ARRAIS, K. C. Construção de faces prototípicas brasileiras. Ribeirão Preto: FFCLRPUSP, 2007. (Mimeografado).

BASHOUR, M. M. D. History and current concepts in the analysis of facial attractiveness. Plastic and Reconstructive Surgery, v. 1, p. 741-756, 2006.

BENNETT, M. E.; PHILLIPS, C. L. Assessment of health-related quality of life for patients with severe skeletal disharmony: a review of the issues. International Journal Adult Orthodon Orthognathic Surgery, v. 14, n. 1, p. 65-75, 1999.

BENSON, P. J.; PERRETT, D. I. Extracting prototypical facial images from exemplars. Perception, v. 22, p. 257-262, 1991.

BRUCE, V.; YOUNG, A. The mating game: attractiveness and the sociobiology of faces. In: BRUCE, V.; YOUNG, A. (Eds.). In the eye of the beholder. Oxford: Oxford University Press, 1998. p. 119-149.

CHEN, A. C.; GERMAN, C.; ZAIDEL, D. W. Brain asymmetry and facial attractiveness: Facial beauty is not simply in the eye of the beholder. Neuropsychologia, v. 35, p. 471-476, 1996.

CHOE, K. S.; SClAFANI, A. P.; LITNER, J. A.; YU, G. P.; ROMO III, T. The Korean American woman's face. Anthropometric measurements and quantitative analysis of facial aesthetics. Archives Facial Plastic Surgery, v. 6, p. 244-252, Jul./Ago. 2004.

CUNNINGHAM, S. J.; HUNT, N. P.; FEINMANN, C. Perceptions of outcome following orthognathic surgery. British Journal Oral Maxillofacial Surgery, v. 34, n. 3, p. 210-213, Jun. 1996.

DA SILVA, J. A.; RIBEIRO-FILHO, N. P. Avaliação e mensuração de dor: pesquisa, teoria e prática. Ribeirão Preto: Funpec, 2006. 
DAWSON, B.; TRAPP, R. G. Bioestatística básica e clínica. 3. ed. São Paulo: McGrawHill, 2003. (Coleção Lange Medical Book).

ECO, U. História da beleza. Tradução Eliana Aguiar. Rio de Janeiro: Record, 2004.

EDLER, R. J.; ORTH, M. Background considerations to facial aesthetics. British Orthodontic Society, v. 28, n. 2, p. 159-167, 2001.

ENLOW, D. H. Crescimento facial. Porto Alegre: Artes Médicas, 1993.

ENQUIST, M.; GHIRLANDA, S.; LUNDQVIST, D.; WACHTMEISTER, C. A. An ethological theory of attractiveness. In: RHODES, G.; ZEBROWITZ, L. A. Facial attractiveness: evolutionary, cognitive, and social perspectives. London: Ablex, 2002. p. 127-151.

EPKER, B. N.; STELLA, J. P.; FISH, L. C. Systematic patient evaluation. In:

Dentofacial deformities. Integrated Orthodontic and Surgical Correction. 2nd ed. St Louis: Mosby, 1994. v. 1, cap. 1. p. 3-71.

FAURE, J. C.; RIEFFE, C.; MALTHA, J. C. The influence of different facial components on facial aesthetics. European Journal of Orthodontics, v. 24, p. 1-7, 2002.

FINK, B.; PENTON-VOAK, I. Evolutionary psychology of facial attractiveness. Current Directions in Psychological Science, v. 11, n. 5, p. 154-158, 2002.

FINLAY, P. M.; ATKINSON, J. M.; MOOS, K. F. Orthognathic surgery: patients expectations; psychological profile and satisfaction with outcome. British Journal Oral Maxillofacial Surgery, v. 33, n. 1, p. 9-14, 1995.

FLECK, M. P. A. O instrumento de avaliação de qualidade de vida da Organização Mundial da Saúde (WHOQOL-100): características e perspectivas. Ciência \& Saúde Coletiva, v. 5, n. 1, p. 33-38, 2000.

FLECK, M. P. A.; LEAL, O. F.; LOUZADA, S.; XAVIER, M.; CHACHAMOVICH, E.; VIEIRA, G.; SANTOS, L.; PINZON, V. Desenvolvimento da versão em português do instrumento de avaliação de qualidade de vida da OMS (WHOQOL-100). Revista Brasileira de Psiquiatria, v. 21, n. 1, p. 19-28, 1999. 
FREITAS, S.; GORENSTEIN, C.; APPOLINARIO, J. C. Instrumentos para a avaliação dos transtornos alimentares. Revista Brasileira de Psiquiatria, v. 24, n. 3, p. 34-38, 2002.

FRIEDENBERG, J. Lateral feature displacement and perceived facial attractiveness. Psychological Reports, v. 88, p. 295-305, 2001.

GREGORET, J.; TUBER, E.; ESCOBAR P. L. H.; FONSECA, A. M. Exame da face. In: Ortodontia e cirurgia ortognática: diagnóstico e planejamento. São Paulo: Ed. Santos, 1999. cap. 1, p. 17-22.

GUIMARÃES, F. S. Escalas analógicas visuais na avaliação de estados subjetivos. In: GORENSTEIN, C.; ANDRADE, L.; ZUARDI, A. Escalas de avaliação clínica em psiquiatria e psicofarmacologia. Sao Paulo: Lemos Editorial, 2000. cap. 3, p. 29-33.

HABBEMA, L. Facial esthetics and patient selection. Clinics in Dermatology, v. 22, p. 14$17,2004$.

HENDERSON, J. J. A.; ANGLIN, J. M. Facial attractiveness predicts longevity. Evolution and Human Behavior, v. 24, p. 351-356, 2003.

HUSKISSON, E. C. Visual analogue scales. In: MELZACK, R. (Ed.). Pain measurement and assessment. New York: Raven Press, 1983. p. 33-37.

INSTITUTO BRASILEIRO DE GEOGRAFIA E ESTATÍSTICA - IBGE. Ministério do Planejamento, Orçamento e Gestão. Censo Demográfico. Rio de Janeiro: IBGE, p. 1-232. 2000 .

ISHAI, A. Sex, beauty and the orbitofrontal cortex. International Journal of Psychophysiology, v. 63, p. 181-185, 2007.

JONES, B.; LITTLE, A. C.; BURT, D. M.; PERRETT, D. I. When facial attractiveness is only skin deep. Perception, v. 33, p. 569-576, 2004.

KERR, W. J. S.; DORTH, F. D. S.; O'DONNELL, J. M. Panel perception of facial attractiveness. British Journal of Orthodontics, v. 17, p. 299-304, 1990.

KRANZ, F.; ISHAI, A. Face perception is modulated by sexual preference. Current Biology, v. 16, p. 63-68, 2006. 
LANGlOIS, J. H.; ROGGMAN, L. A. Attractive faces are only average. Psychological Science, v. 1, p. 115-121, 1990.

LAUREANO FILHO, J. R.; CYPRIANO, R. V.; MORAES, R. P. A.; FREITAS, M. Q. Avanço maxilar: descrição da técnica e relato de caso clínico. Revista de Cirurgia e Traumatologia Buco-Maxilo-Facial, v. 3, n. 2, p. 25-31, 2003.

LAZARIDOU-TERZOUDI, T.; KIYAK, H. A.; MORRE, R.; ATHANASIOU, A. E.; MELSEN, B. Long-term assessment of psychologic outcomes of orthognathic surgery. Journal Oral Maxillofacial Surgery, v. 61, n. 5, p. 545-552, May 2003.

LITTLE, A.C.; JONES, B.C.; WAITT, C.; TIDDEMAN, B.P.; FEINBERG, D.R.; PERRETT, D.I.; APICELLA, C.L.; MARLOWE, F.W. Symmetry Is Related to Sexual Dimorphism in Faces: Data Across Culture and Species. PLoS ONE, v. 3, n. 5 e2106, p. 1-8, May 2008.

MEALEY, L.; BRIGSTOCK, R.; TOWSEND, G. C. Symmetry and perceived facial attractiveness: a monozygotic co-twin comparison. Journal of Personality and Social Psychology, v. 76, p. 151-158, 1999.

MILLER, G. F. A mente seletiva: como a escolha sexual influenciou a evolução da natureza humana. Tradução Dayse Batista. Rio de Janeiro: Campus, 2000.

MORI, A. T. Expectativas com relação aos resultados estéticos dos tratamentos odontológicos. 2003. 155 f. Dissertação (Mestrado) - Faculdade de Odontologia, Universidade de São Paulo, São Paulo, 2003.

NARDI, P.; ACOCELLA, A.; TEDESCO, A.; RISPOLI, A.; GIACOMELLI, E. Psychological aspects in orthoganathic surgery. Body image and quality of life in postsurgical assessment. Minerva Stomatologica, v. 52, n. 4, p. 145-152, Apr. 2003.

NEWEL, R.; MARKS, I. Phobic nature of social difficulty in facially disfigured people. British Journal of Psychiatry, v. 176, p. 177-181, 2000.

NICODEMO, D.; PEREIRA, M. D.; FERREIRA, L. M. Self-esteem and depression in patients presenting angle class III malocclusion submitted for orthognathic surgery. Medicina Oral Patología Oral y Cirurgía Bucal, Valencia, v. 13, n. 1, p. E48-51, Jan. 2008.

OMOTE, S. Efeitos da atratividade física facial de crianças sobre a percepção de outras qualidades delas. Psicologia: Teoria e Pesquisa, v. 7, n. 3, p. 295-302, 1991. 
OMOTE, S. Fidedignidade na percepção da atratividade física facial. Psicologia: Teoria e Pesquisa, v. 10, n. 2, p. 143-157, 1994.

ONG, M. A. H. Spectrum of dentofacial deformities: a retrospective survey. Annals Academy of Medicine, v. 33, n. 2, p. 239-242, 2004.

ORGANIZAÇÃO MUNDIAL DA SAÚDE. Divisão de Saúde Mental. Grupo WHOQOL. Versão em português dos Instrumentos de Avaliação de Qualidade de Vida (WHOQOL). OMS, 1998.

O'TOOLE, A. J.; PRICE, T.; VETTER, T.; BARTLETT, J. C.; BLANZ, V. 3D shape and 2D surface textures of human faces: the role of "averages" in attractiveness and age. Image and Vision Computing, v. 18, p. 9-19, 1999.

PANOFSKY, E. A história da teoria das proporções humanas como reflexo da história dos estilos. In: O significado nas artes visuais. São Paulo: Perspectiva, 1976. cap. 2, p. 89-148.

PASQUALI, L. Psicometria: teoria dos testes na psicologia e na educação. Petrópolis: Vozes, 2003.

PENTON-VOAK, I. S.; PERRETT, D. I. Consistency and individual differences in facial attractiveness judgments - an evolutionary perspective. Social Research, v. 67, p. 219-245, 2000 .

PERRETT, D. I.; MAY, K.; YOSHIKAWA, S. Attractive characteristics of female faces: preferences for non-average shape. Nature, v. 368, p. 239-242, 1994.

PERRETT, D. I.; LEE, K. J.; PENTON-VOAK, I.; ROWLAND, D.; YOSHIKAWA, S.; BURT, D. M.; HENZI, S. P.; CASTLES, D. L.; AKAMATSU, S. Effects of sexual dimorphism on facial attractiveness. Nature, v. 394, p. 884-887, 1998.

PERRETT, D. I.; BURT, D. M.; PENTON-VOAK, I. S.; LEE, K. J.; ROWLAND, D. A.; EDWARDS, R. Symmetry and human facial attractiveness. Evolution and Human Behavior, v. 20, p. 295-307, 1999.

PHILLIPS, P.; BENNETT, M. E.; BRODER, H. Dentofacial disharmony: psychological status of patients seeking treatment consultation. Angle Orthodontist, v. 68, n. 6, p. 547-556, 1998. 
PHILLIPS, C.; PROFFIT, W. R. Aspectos psicossociais das deformidades dentofaciais e de seu tratamento. In: PROFFIT, W. R.; WHITE JUNIOR, R. P.; SARVER, D. M. (Orgs.). Tratamento contemporâneo das deformidades dentofaciais. Porto Alegre: Artmed, 2005. cap. 3, p. 80-101.

PROFFIT, W. R.; SARVER, D. M. Diagnóstico: coleta e organização de informações adequadas. In: PROFFIT, W. R.; WHITE JUNIOR, R. P.; SARVER, D. M. (Orgs.). Tratamento contemporâneo das deformidades dentofaciais. Porto Alegre: Artmed, 2005. cap. 5. p. 140-187.

PROFFIT, W. R.; TURVEY, T. A. Assimetria dentofacial. In: PROFFIT, W. R.; WHITE JUNIOR, R. P.; SARVER, D. M. (Orgs.). Tratamento contemporâneo das deformidades dentofaciais. Porto Alegre: Artmed, 2005. cap. 7. p. 609-681.

PROFFIT, W. R.; WHITE JUNIOR, R. P. Problemas dentofaciais: predominância e necessidade de tratamento. In: PROFFIT, W. R.; WHITE JUNIOR, R. P.; SARVER, D. M. (Orgs.). Tratamento contemporâneo das deformidades dentofaciais. Porto Alegre: Artmed, 2005. cap. 1, p. 12-38.

PROFFIT, W. R.; WHITE JUNIOR, R. P.; SARVER, D. M. Problemas de face longa. In: PROFFIT, W. R.; WHITE JUNIOR, R. P.; SARVER, D. M. (Orgs.). Tratamento contemporâneo das deformidades dentofaciais. Porto Alegre: Artmed, 2005. cap. 15, p. 496-540.

PORTER, J. P.; OLSON, K. L. Anthropometric facial analysis of the African American woman. Archives Facial Plastic Surgery, v. 3, p. 191-197, Jul./Sep. 2001.

REIS, S. A. B.; ABRÃO, J.; CAPELOZZA FILHO, L.; ClARO, C. A. A. Análise facial numérica do perfil de brasileiros Padrão I. Revista Dental Press de Ortodontia e Ortopedia Facial, Maringá, v. 11, n. 6, p. 24-34, nov./dez. 2006a.

REIS, S. A. B.; ABRÃO, J.; CAPELOZZA FILHO, L.; CLARO, C. A. A. Análise facial subjetiva. Revista Dental Press de Ortodontia e Ortopedia Facial, Maringá, v. 11, n. 5, p. 159-172, set./out. $2006 b$.

RHODES, G. The evolutionary psychology of facial beauty. Annual Review Psychology, v. 57, p. 199-226, 2006.

RHODES, G.; TREMEWAN, T. Averageness, exaggeration, and facial attractiveness Psychological Science, v. 7, p. 105-110, 1996. 
RHODES, G.; SIMMONS, L.; PETERS, M. Attractiveness and sexual behaviour: does attractiveness enhance mating success? Evolution and Human Behavior, v. 26, p. 186-201, 2005.

RHODES, G.; SUMICH, A.; BYATT, G. Are average facial configurations attractive only because of their symmetry? Psychological Science, v. 10, p. 52-58, 1999.

RHODES, G.; PROFFIT, F.; GRADY, J. M.; SUMICH, A. Facial symmetry and the perception of beauty. Psychonomic Bulletin \& Review, v. 5, p. 659-669, 1998.

RHODES, G.; YOSHIKAWA, S.; CLARK, A.; LEE, K.; MCKAY, R.; AKAMATSU, S. Attractiveness of facial averageness and symmetry in non-Wertern cultures: insearch of biologically based standards of beauty. Perception, v. 30, n. 5, p. 611-625, 2001.

ROMANO, A.; NEGREIROS, J.; MARTINS, T. Contributos para a validação da escala de auto-estima de Rosenberg numa amostra de adolescentes da região interior norte do país. Psicologia, Saúde e Doenças, v. 8, n. 1, p. 109-116, 2007.

SAMUELS, C. A.; BUTTERWOTH, G.; ROBERTS, T.; GRAUPNER, L.; HOLE, G. Facial aesthetics: babies prefer attractiveness to symmetry. Perception, v. 23, p. 823-831, 1994.

SARVER, D. M.; PROFFIT, W. R.; ACKERMAN, J. L. Avaliação dos tecidos moles da face. In: PROFFIT, W. R.; WHITE JUNIOR, R. P.; SARVER, D. M. (Orgs.). Tratamento contemporâneo das deformidades dentofaciais. Porto Alegre: Artmed, 2005. cap. 4, p. 104139.

SCAVONE JUNIOR, H.; TREVISAN JUNIOR, H.; GARIB, D. G.; FERREIRA, F. V. Facial profile evaluation in Japanese-Brazilian adults with normal occlusions and well-balanced faces. American Journal of Orthodontics and Dentofacial Orthopedics, v. 721, p. e1721.e5, 2006.

SILVA, L. M. Simetria e atratividade facial. 2005. 108 f. Dissertação (Mestrado) Faculdade de Filosofia Ciências e Letras de Ribeirão Preto, Universidade de São Paulo, Ribeirão Preto, 2005.

SILVA, L. M.; ALVES, N. T.; FUKUSIMA, S. S. Effect of facial symmetry on human attractiveness. In: ANNUAL MEETING OF THE INTERNATIONAL SOCIETY FOR PSYCHOPHYSICS, 20., 2004, Coimbra. Proceedings... Coimbra: University of Coimbra, 2004. p. 536-540. 
SOUZA, D. B. L.; FERREIRA, M. C. Auto-estima pessoal e coletiva em mães e não-mães.

Psicologia em Estudo, Maringá, v. 10, n. 1, p. 19-25, 2005.

SPIELBERGER, C. D.; GORSUCH, R. L.; LUSHENE, R. E. Inventário de Ansiedade

Traço-Estado (IDATE). Tradução e Adaptação de Ângela M. B. Biaggio e Luiz

Natalício.Rio de Janeiro: CEPA, 1979.

SUGUINO, R.; RAMOS, A. L.; TERADA, H. H.; FURQUIM, L. Z.; MAEDA, L.; SILVA FILHO, O. G. Análise facial. Revista Dental Press de Ortodontia e Ortopedia Maxilar, Maringá, v. 1, n. 1, p. 86-107, 1996.

SWADDLE, J. P.; CUTHILL, I. C. Asymmetry and human facial attractiveness: symmetry may not always be beautiful. Proceedings of the Royal Society of London, Series B: Biological Science, London, v. 261, n. 1360, p. 111-116, 1995.

THORNHILL, R.; GANGESTAD, S. W. Facial attractiveness. Trends in Cognitive Sciences, v. 3, n. 12, p. 452-460, 1999.

VARGAS, T. V. P.; DANTAS, R. A. S.; GOIS, C. F. L. A auto-estima de indivíduos que foram submetidos à cirurgia de revascularização do miocárdio. Revista da Escola de Enfermagem, São Paulo, v. 39, n. 1, p. 20-27, 2005.

VILLELA, O. V. Manual de cefalometria. Rio de Janeiro: Guanabara Koogan, 1998.

ZUARDI, A. W.; KARNIOL, I. G. Estudo transcultural de uma escala de auto-avaliação para estados subjetivos. Jornal Brasileiro de Psiquiatria, v. 31, p. 403-496, 1981.

ZUARDI, A. W.; COSME, R. A.; GRAEFF, R. G.; GUIMARÃES, F. S. Effects of ipsapirone and cannabidiol on human experimental anxiety. Journal of Psychopharmacology, v. 7, p. 82-88, 1993. 
ANEXOS 


\section{TERMO DE CONSENTIMENTO LIVRE E ESCLARECIDO}

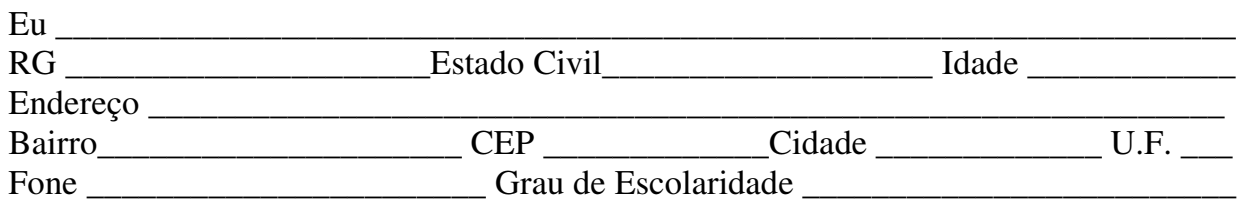

CONCORDO EM AUTORIZAR O USO DE QUALQUER INFORMAÇÃO OU IMAGEM RELACIONADA AO TRATAMENTO DA DEFORMIDADE DENTOFACIAL, A SER REALIZADO NO CEDEFACE, QUE SEJAM NECESSÁRIOS NO ESTUDO "AVALIAÇÃO DA ATRATIVIDADE FACIAL, QUALIDADE DE VIDA, ANSIEDADE E AUTO-ESTIMA EM PACIENTES SUBMETIDOS À CIRURGIA ORTOGNÁTICA". ESTES DADOS SERÃO UTILIZADOS PARA DESENVOLVIMENTO DE TESE DE DOUTORADO NO PROGRAMA DE PÓS-GRADUAÇÃO EM PSICOBIOLOGIA DA FFCLRP-USP PELA PESQUISADORA LUCIANA MARIA DA SILVA (RG 24163667-X).

Declaro ter sido esclarecido pela pesquisadora a respeito dos seguintes aspectos:

1) Meu nome será mantido em sigilo, assegurando assim, minha privacidade e se desejar deverei ser informado sobre o uso dos dados relacionados ao meu tratamento.

2) Poderei me recusar ou mesmo retirar meu consentimento a qualquer momento do tratamento sem que haja qualquer penalidade ou prejuízo.

3) Responderei a quatro escalas, de caráter psicológico, alguns dias antes da cirurgia e alguns meses depois da cirurgia.

4) Não sofrerei nenhum prejuízo pessoal, moral ou social ao participar deste estudo e nem mesmo correrei riscos físicos ou mentais.

5) A pesquisadora compromete-se em vir ao CEDEFACE, na cidade de Araraquara, nos dias em que eu estiver presente neste centro para o levantamento dos dados, sem que eu seja prejudicado em meus atendimentos corriqueiros e nem tenha gastos financeiros extras.

6) Tenho consciência que, ao autorizar o uso de informações relacionadas ao tratamento, estarei contribuindo para o aperfeiçoamento das diversas etapas do tratamento ortodôntico-cirúrgico.

7) Declaro ter compreendido todas as informações citadas acima e que autorizo a utilização dos dados referentes ao meu tratamento ortodôntico-cirúrgico realizado nesta instituição, para uso acadêmico e científico, bem como para a publicação em revistas especializadas.

Diante dos esclarecimentos prestados, concordo sem restrições sobre as informações descritas acima.

Araraquara, de de 
Of.CEtP/FFCLRP-063/2006-03.10.06

Senhor(a) Pesquisador(a):

Comunicamos a V. Sa. que o trabalho intitulado "Avaliação da Atratividade Facial, Qualidade de vida, ansiedade e auto-estima em pacientes submetidos à cirurgia ortognática" foi analisado pelo Comitê de Ética em Pesquisa da FFCLRP-USP, em sua 55a Reunião Ordinária realizada em 28/09/2006, e enquadrado na categoria: APROVADO, de acordo com o Processo CEP-FFCLRP no 271/2006 2006.1.1387.59.3

Aproveitamos a oportunidade para apresentar nossos protestos de estima e consideração.

Atenciosamente,

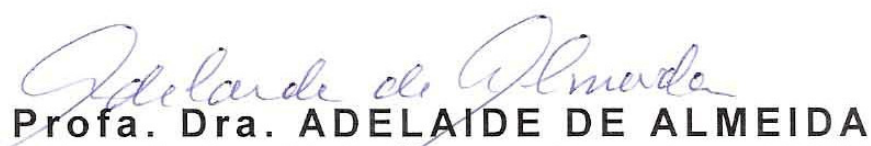

Coordenadora do Comitê de Ética em Pesquisa - FFCLRP-USP

llustríssimo(a) Senhor(a)

LUCIANA MARIA DA SILVA

Docente do Departamento de Psicologia e Educação

Desta FFCLRP-USP

c/c.: Prof. Dr. SÉRGIO SHEIJI FUKUSIMA

CEP-FFCLRP-USP - Fone: (016) 602-3653 - Fax: (016) 633-5015

Avenida Bandeirantes, 3900 - Bloco A - 14040-901 - Ribeirão Preto - SP - Brasil 


\section{TERMO DE CONSENTIMENTO LIVRE E ESCLARECIDO}

Esta pesquisa tem por objetivo investigar a atratividade facial em humanos. Os requisitos para você participar desta pesquisa são: ter boa acuidade visual, ter instrução mínima secundária e que sua participação seja voluntária.

A tarefa a ser realizada será estimar quão atrativas são algumas faces mostradas na tela de um computador, atribuindo-lhes valores em duas escalas.

O experimento não apresenta riscos à integridade da sua saúde física e mental e durará entre 15 e 30 minutos aproximadamente.

É importante que você finalize a sessão experimental, porém, caso você deseje interrompê-la ou encerrá-la, assim poderá proceder em qualquer momento.

Os dados gerados por esta pesquisa serão divulgados em reuniões e publicações científicas e as identidades dos participantes serão mantidas em sigilo.

Declaro que estou ciente das informações acima e concordo participar da pesquisa.

\section{Local e data:}

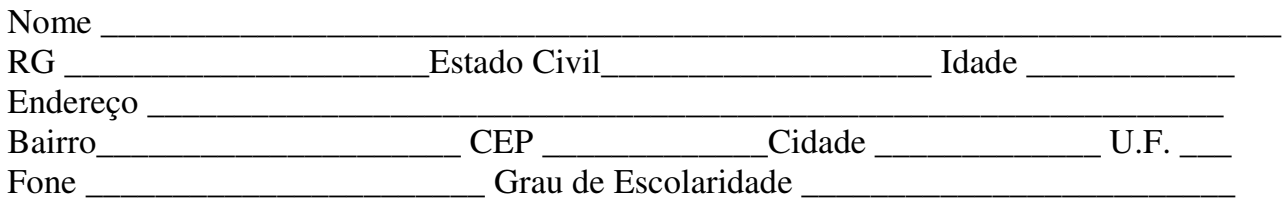

\section{Assinatura do voluntário}

Pesquisadora: Luciana Maria da Silva, RG: 24163667-X, Av. dos Bandeirantes, 3900,

Departamento de Psicologia e Educação, Laboratório de Percepção e Psicofísica - FFCLRP- USP; Fone: 36024448.

Orientador: Prof. Dr. Sérgio S. Fukusima.

\section{Luciana Maria da Silva}

Pesquisadora 


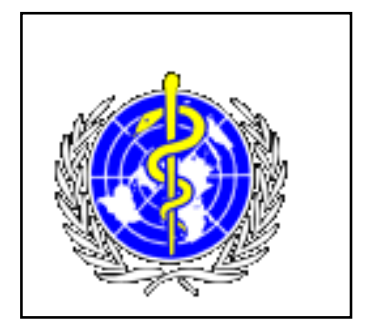

\author{
ORGANIZAÇÃO MUNDIAL DE SAÚDE \\ DIVISÃO DE SAÚDE MENTAL \\ GRUPO WHOQOL
}

VERSÃO EM PORTUGUÊS DOS INSTRUMENTOS DE

AVALIAÇÃO DE QUALIDADE DE VIDA (WHOQOL)

1998

\title{
FICHA DE INFORMAÇÕES SOBRE O RESPONDENTE
}
SEXO
Masculino
(1)
Feminino
(2)
IDADE (em anos completos)

DATA DE NASCIMENTO

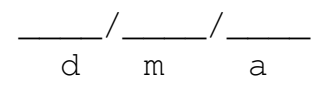

RENDIMENTO salários mínimos

NÍVEL EDUCACIONAL

Analfabeto
I grau incompleto
I grau completo
II grau incompleto
II grau completo
III grau incompleto
III grau completo
Pós-Graduação incompleto
Pós-Graduação completo

ESTADO CIVIL

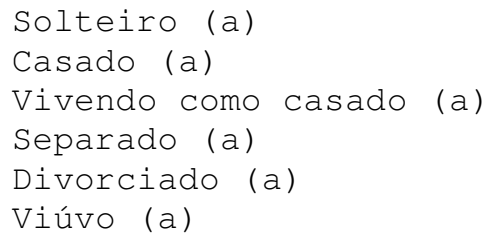

COMO ESTÁ A SUA SAÚDE

muito ruim (1)

fraca (2)

nem ruim nem boa (3)

boa (4)

muito boa (5)

FORMA DE ADMINISTRAÇÃO DO QUESTIONÁRIO

Auto-administrado

Assistido pelo entrevistador

Administrado pelo entrevistador

PROBLEMA DE SAÚDE ATUAL/CONDIÇÃO PRESENTE (marcar somente uma, que é a mais relevante para a presente busca de um serviço de saúde) 
Nenhum problema

Problema de coração

Pressão alta

Artrite ou reumatismo

Câncer

Enfisema ou bronquite

Diabetes

Catarata

Derrame

Osso quebrado ou fraturado
00 Problema nervoso crônico

01 ou emocional

02 Problema crônico de pé

03 (joanete, unha encravada)

04 Hemorróidas ou sangramento

05 No ânus

06 Doença de Parkinson-n

07 Gravidez 14

08 Depressão 15

09 Doença de pele 16

Queimaduras $\quad 17$

Problema de álcool ou drogas 18

Outros (especificar)..........

DIAGNóSTICO (CID-10) (preenchido pelo entrevistador)

\section{REGIME DE CUIDADOS DE SAÚDE}

Sem tratamento (1)

Ambulatório (2)

Internação (3) 
ESCALA DE QUALIDADE DE VIDA - OMS (WHOQoL-bref)

Nome: Data:

\section{Instruções}

Este questionário é sobre como você se sente a respeito da sua qualidade de vida, saúde e outras áreas de sua vida. Por favor responda a todas as questões. Se você não tem certeza sobre que resposta dar em uma questão, por favor, escolha entre as alternativas a que lhe parece mais apropriada. Esta, muitas vezes, poderá ser sua primeira escolha.

Por favor, tenha em mente seus valores, aspirações, prazeres e preocupações. Nós estamos perguntando o que você acha de sua vida, tomando como referência as duas últimas semanas. Por exemplo, pensando nas últimas duas semanas, uma questão poderia ser:

\begin{tabular}{|l|c|c|c|c|c|}
\cline { 2 - 6 } \multicolumn{1}{c|}{} & nada & Muito pouco & Médio & Muito & Completamente \\
\hline Você recebe dos outros o apoio de que necessita? & 1 & 2 & 3 & 4 & 5 \\
\hline
\end{tabular}

Você deve circular o número que melhor corresponde ao quanto você recebe dos outros o apoio de que necessita nestas últimas duas semanas. Portanto, você deve circular o número 4 se você recebeu "muito" apoio como abaixo.

\begin{tabular}{|l|c|c|c|c|c|}
\cline { 2 - 6 } \multicolumn{1}{c|}{} & Nada & Muito pouco & Médio & Muito & Completamente \\
\hline Você recebe dos outros o apoio de que necessita? & 1 & 2 & 3 & & 5 \\
\hline
\end{tabular}

Você deve circular o número 1 se você não recebeu "nada" de apoio. 
Por favor, leia cada questão, veja o que você acha e circule no número que lhe parece a melhor resposta.

\begin{tabular}{|c|c|c|c|c|c|c|}
\hline & & Muito ruim & Ruim & $\begin{array}{l}\text { Nem ruim } \\
\text { Nem boa }\end{array}$ & Boa & Muito boa \\
\hline $\begin{array}{l}1 \\
(\mathrm{G} 1)\end{array}$ & $\begin{array}{l}\text { Como você avaliaria sua qualidade } \\
\text { de vida? }\end{array}$ & 1 & 2 & 3 & 4 & 5 \\
\hline
\end{tabular}

\begin{tabular}{|l|l|c|c|c|c|c|}
\cline { 3 - 6 } \multicolumn{2}{l|}{} & $\begin{array}{l}\text { Muito } \\
\text { insatisfeito }\end{array}$ & Insatisfeito & $\begin{array}{l}\text { Nem satisfeito } \\
\text { Nem insatisfeito }\end{array}$ & Satisfeito & $\begin{array}{l}\text { Muito } \\
\text { Satisfeito }\end{array}$ \\
\hline $\begin{array}{l}2 \\
\text { (G4) }\end{array}$ & $\begin{array}{l}\text { Quão satisfeito(a) você está } \\
\text { com a sua saúde? }\end{array}$ & 1 & 2 & 3 & 4 & 5 \\
\hline
\end{tabular}

As questões seguintes são sobre o quanto você tem sentido algumas coisas nas últimas duas semanas.

\begin{tabular}{|l|l|c|c|c|c|c|}
\cline { 3 - 6 } \multicolumn{2}{l|}{} & Nada & $\begin{array}{l}\text { Muito } \\
\text { pouco }\end{array}$ & $\begin{array}{l}\text { Mais ou } \\
\text { menos }\end{array}$ & Bastante & Extremamente \\
\hline $\begin{array}{l}3 \\
\text { F1.4 })\end{array}$ & $\begin{array}{l}\text { Em que medida você acha que sua } \\
\text { dor(física) impede você de fazer o que } \\
\text { você precisa? }\end{array}$ & 1 & 2 & 3 & 4 & 5 \\
\hline $\begin{array}{l}4 \\
(\text { F11..3 })\end{array}$ & $\begin{array}{l}\text { O quanto você precisa de algum } \\
\text { tratamento médico para levar sua vida } \\
\text { diária? }\end{array}$ & 1 & 2 & 3 & 4 & 5 \\
\hline $\begin{array}{l}5 \\
(\text { F4.1 })\end{array}$ & O quanto você aproveita a sua vida? & 1 & 2 & 3 & 4 & 5 \\
\hline $\begin{array}{l}6 \\
(\text { F24.2) }\end{array}$ & $\begin{array}{l}\text { Em que medida você acha que sua vida } \\
\text { tem sentido? }\end{array}$ & 1 & 2 & 3 & 4 & 5 \\
\hline $\begin{array}{l}\text { (F5.3) } \\
\text { O quanto você consegue se } \\
\text { concentrar? }\end{array}$ & $\begin{array}{l}\text { Quão seguro(a) você se sente em sua } \\
\text { vida diária? }\end{array}$ & 1 & 2 & 3 & 4 & 5 \\
\hline $\begin{array}{l}\text { F16.1) } \\
(\text { F22.1) }\end{array}$ & $\begin{array}{l}\text { Quão saudável é o seu ambiente físico } \\
\text { (clima, barulho, poluição, atrativos?) }\end{array}$ & 1 & 2 & 3 & 4 & 5 \\
\hline
\end{tabular}

As questões seguintes perguntam sobre quão completamente você tem sentido ou é capaz de fazer certas coisas nestas últimas duas semanas.

\begin{tabular}{|c|c|c|c|c|c|c|}
\hline & \multirow{3}{*}{\begin{tabular}{|r|} 
Nada \\
1
\end{tabular}} & \multirow{3}{*}{\begin{tabular}{|l|}
$\begin{array}{l}\text { Muito } \\
\text { pouco }\end{array}$ \\
2
\end{tabular}} & \multirow{3}{*}{\begin{tabular}{|c|} 
Médio \\
3
\end{tabular}} & \multirow{3}{*}{\begin{tabular}{|c|} 
Muito \\
4
\end{tabular}} & \multirow{3}{*}{\begin{tabular}{|c|} 
Completamente \\
5
\end{tabular}} \\
\hline & & & & & & \\
\hline \begin{tabular}{|l|l|}
10 \\
$(\mathrm{~F} 2.1)$
\end{tabular} & $\begin{array}{l}\text { Você tem energia suficiente para seu } \\
\text { dia-a-dia? }\end{array}$ & & & & & \\
\hline $\begin{array}{l}11(\mathrm{~F} 7.1) \\
(\mathrm{F} 11 . .3)\end{array}$ & $\begin{array}{l}\text { Você é capaz de aceitar sua aparência } \\
\text { física? }\end{array}$ & 1 & 2 & 3 & 4 & 5 \\
\hline $\begin{array}{ll}12 \\
(\mathrm{~F} 18.1)\end{array}$ & $\begin{array}{l}\text { Você tem dinheiro suficiente para } \\
\text { satisfazer suas necessidades? }\end{array}$ & 1 & 2 & 3 & 4 & 5 \\
\hline $\begin{array}{l}13 \\
(\mathrm{~F} 20.1)\end{array}$ & $\begin{array}{l}\text { Quão disponíveis para você estão as } \\
\text { informações que precisa no seu dia-a- } \\
\text { dia? }\end{array}$ & 1 & 2 & 3 & 4 & 5 \\
\hline $\begin{array}{ll}14 \\
(\mathrm{~F} 21.1)\end{array}$ & $\begin{array}{l}\text { Em que medida você tem oportunidade } \\
\text { de lazer? }\end{array}$ & 1 & 2 & 3 & 4 & 5 \\
\hline
\end{tabular}

As questões seguintes perguntam sobre quão bem ou satisfeito você se sentiu a respeito de vários aspectos de sua vida nas últimas duas semanas. 


\begin{tabular}{|l|l|c|c|c|c|c|}
\cline { 3 - 6 } \multicolumn{2}{l|}{} & Muito ruim & Ruim & $\begin{array}{l}\text { Nem ruim } \\
\text { Nem bom }\end{array}$ & Bom & Muito bom \\
\hline F9.1 & $\begin{array}{l}\text { Quão bem você é capaz de se } \\
\text { locomover? }\end{array}$ & 1 & 2 & 3 & 4 & 5 \\
\hline
\end{tabular}

\begin{tabular}{|c|c|c|c|c|c|c|}
\hline & & \begin{tabular}{|l|} 
Muito \\
insatisfeito \\
\end{tabular} & Insatisfeito & \begin{tabular}{|l|} 
Nem satisfeito \\
Nem insatisfeito \\
\end{tabular} & Satisfeito & \begin{tabular}{|l|} 
Muito \\
Satisfeito \\
\end{tabular} \\
\hline $\begin{array}{l}16 \\
(\mathrm{~F} 3.3)\end{array}$ & $\begin{array}{l}\text { Quão satisfeito(a) você está com o } \\
\text { seu sono }\end{array}$ & 1 & 2 & 3 & 4 & 5 \\
\hline $\begin{array}{l}17 \\
(\mathrm{~F} 10.3)\end{array}$ & $\begin{array}{l}\text { Quão satisfeito(a) você está com a } \\
\text { sua capacidade de desempenhar as } \\
\text { atividades do seu dia-a-dia? }\end{array}$ & 1 & 2 & 3 & 4 & 5 \\
\hline $\begin{array}{l}18 \\
(\mathrm{~F} 12.4)\end{array}$ & $\begin{array}{l}\text { Quão satisfeito(a) você está com } \\
\text { sua capacidade para o trabalho? }\end{array}$ & 1 & 2 & 3 & 4 & 5 \\
\hline $\begin{array}{l}19 \\
(\mathrm{~F} 6.3)\end{array}$ & $\begin{array}{l}\text { Quão satisfeito(a) você está } \\
\text { consigo mesmo }\end{array}$ & 1 & 2 & 3 & 4 & 5 \\
\hline $\begin{array}{l}20 \\
(\mathrm{~F} 13.3)\end{array}$ & $\begin{array}{l}\text { Quão satisfeito(a) você está com } \\
\text { suas relações pessoais (amigos, } \\
\text { parentes, conhecidos, colegas)? }\end{array}$ & 1 & 2 & 3 & 4 & 5 \\
\hline $\begin{array}{l}21 \\
(\mathrm{~F} 15.3)\end{array}$ & $\begin{array}{l}\text { Quão satisfeito(a) você está com } \\
\text { sua vida sexual? }\end{array}$ & 1 & 2 & 3 & 4 & 5 \\
\hline $\begin{array}{ll}22 \\
(\mathrm{~F} 14.3)\end{array}$ & $\begin{array}{l}\text { Quão satisfeito(a) você está com o } \\
\text { apoio que recebe dos amigos? }\end{array}$ & 1 & 2 & 3 & 4 & 5 \\
\hline $\begin{array}{l}23 \\
(\mathrm{~F} 17.3)\end{array}$ & $\begin{array}{l}\text { Quão satisfeito(a) você está com } \\
\text { as condições do local onde mora? }\end{array}$ & 1 & 2 & 3 & 4 & 5 \\
\hline $\begin{array}{ll}24 \\
(\mathrm{~F} 19.3)\end{array}$ & $\begin{array}{l}\text { Quão satisfeito(a) você está com o } \\
\text { seu acesso aos serviços de saúde? }\end{array}$ & 1 & 2 & 3 & 4 & 5 \\
\hline $\begin{array}{l}25 \\
(\mathrm{~F} 23.3)\end{array}$ & $\begin{array}{l}\text { Quão satisfeito(a) você está com o } \\
\text { seu meio de transporte? }\end{array}$ & 1 & 2 & 3 & 4 & 5 \\
\hline
\end{tabular}

As questões seguintes referem-se a com que freqüência você se sentiu ou experimentou certas coisas nas últimas duas semanas.

\begin{tabular}{|l|l|c|c|c|c|c|}
\cline { 3 - 6 } \multicolumn{2}{l|}{} & Nunca & Algumas vezes & Freqüentemente & $\begin{array}{l}\text { Muito } \\
\text { freqüentemente }\end{array}$ & Sempre \\
\hline (F8.1) & $\begin{array}{l}\text { Com que freqüência você } \\
\text { tem sentimentos negativos } \\
\text { tais como mau humor, } \\
\text { desespero, ansiedade, } \\
\text { depressão }\end{array}$ & 1 & 2 & 3 & 4 & 5 \\
\hline
\end{tabular}

Alguém lhe ajudou a preencher este questionário?

Quanto tempo você levou para preencher este questionário? 


\section{IDATE - Parte I}

\section{Nome:}

Data:

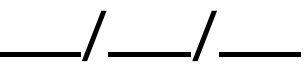

Instruções: A seguir são dadas algumas afirmações que têm sido usadas para descrever sentimentos pessoais. Leia cada uma e faça um círculo ao redor do número à direita da afirmação, que melhor lhe indicar como você se sente agora, neste momento. Não há repostas certas ou erradas, não gaste muito tempo numa única resposta, mas tente dar uma afirmação que mais se aproxime de como se sente no momento.

\begin{tabular}{|c|c|}
\hline MUITÍSSIMO .......... 4 & UM POUCO \\
\hline BASTANTE ............. 3 & ABSOLUTAMENTE NÃO ........ 1 \\
\hline
\end{tabular}

\begin{tabular}{|c|c|c|c|}
\hline 01. Sinto-me calmo (a) & 1 & 2 & 3 \\
\hline 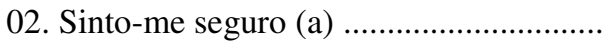 & 1 & 2 & 3 \\
\hline 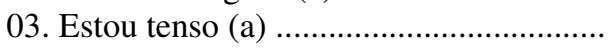 & 1 & 2 & 3 \\
\hline 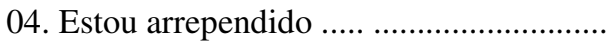 & 1 & 2 & 3 \\
\hline 05. Sinto-me à vontade (a) ........................... & 1 & 2 & 3 \\
\hline 06. Sinto-me perturbado (a) ............. & 1 & 2 & 3 \\
\hline 07. Estou preocupado (a) & & & \\
\hline com possíveis infortúnios.... & 1 & 2 & 3 \\
\hline 08. Sinto-me descansado (a) & 1 & 2 & 3 \\
\hline 09. Sinto-me ansioso (a) .............................. & 1 & 2 & 3 \\
\hline 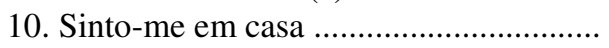 & 1 & 2 & 3 \\
\hline 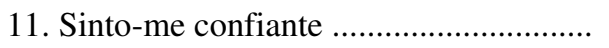 & 1 & 2 & 3 \\
\hline 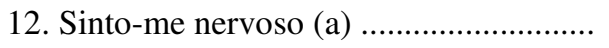 & 1 & 2 & 3 \\
\hline 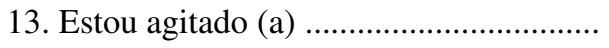 & 1 & 2 & 3 \\
\hline 14. Sinto-me uma pilha de nervos .............. & 1 & 2 & 3 \\
\hline 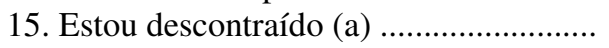 & 1 & 2 & 3 \\
\hline 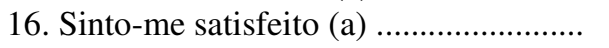 & 1 & 2 & 3 \\
\hline $\begin{array}{l}\text { 17. Estou preocupado (a) .............................. } \\
\text { 18. Sinto-me super-excitado (a) }\end{array}$ & 1 & 2 & 3 \\
\hline 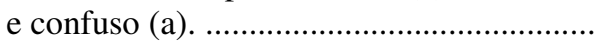 & 1 & 2 & 3 \\
\hline 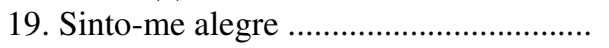 & 1 & 2 & 3 \\
\hline 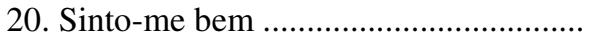 & 1 & 2 & 3 \\
\hline
\end{tabular}




\section{IDATE - Parte II}

\section{Nome:}

Data:

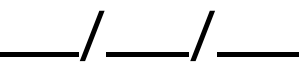

Instruções: A seguir são dadas algumas afirmações que têm sido usadas para descrever sentimentos pessoais. Leia cada uma e faça um círculo ao redor do número à direita, que melhor lhe indicar como você geralmente se sente. Não há repostas certas ou erradas, não gaste muito tempo numa única afirmação, mas tente dar a resposta que mais se aproximar de como se sente geralmente.

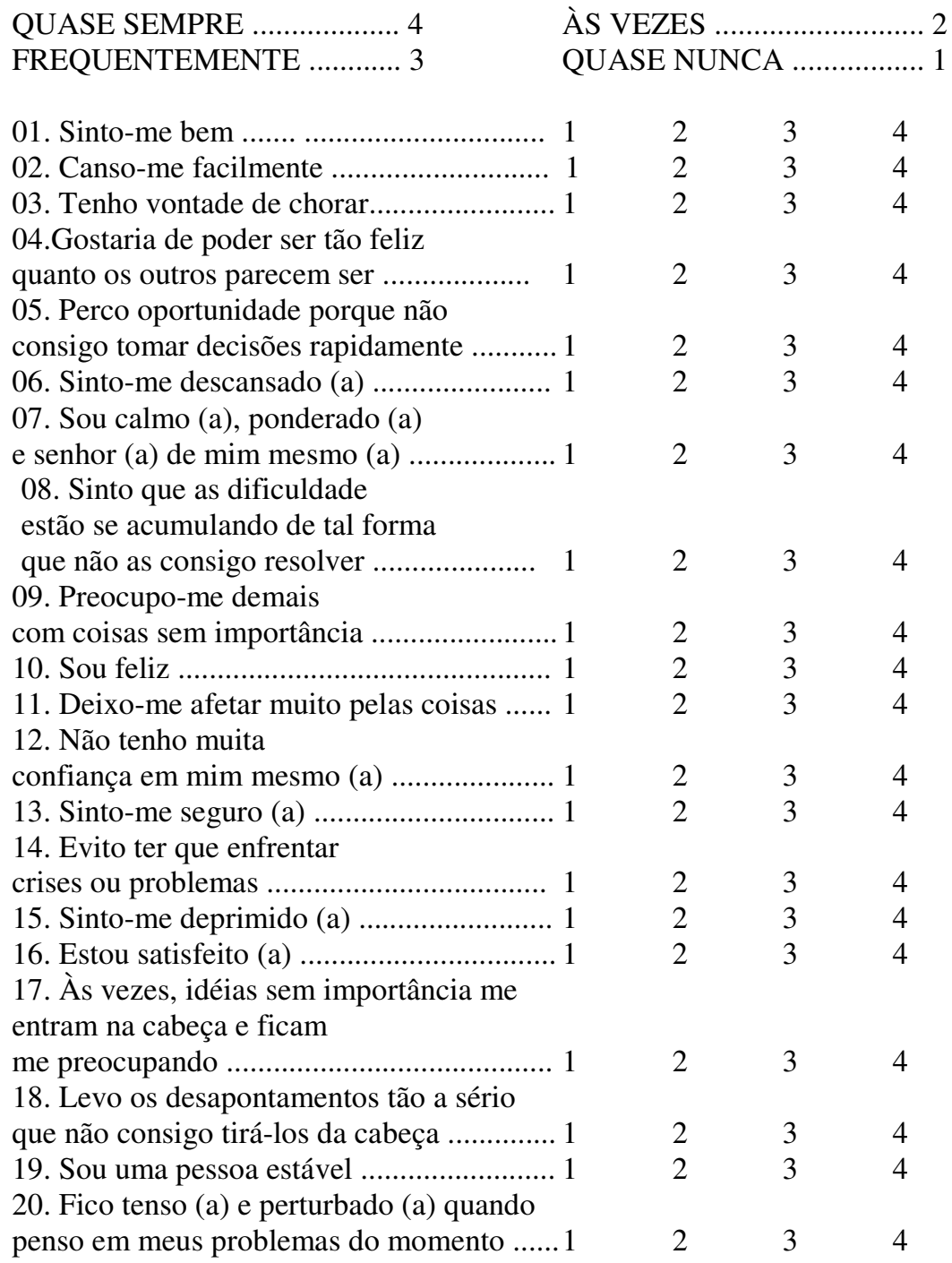




\section{EsCALA ANALÓGica de Humor}

Visual Analogue Mood Scale (Norris, 1971) - versão traduzida por Zuardi e Karniol (1981)

\section{ESTADO PSÍQUICO ATUAL}

INSTRUÇŌES - Avalie como você se sente agora em relação aos itens abaixo. Considere cada linha como representando a gama completa de cada dimensāo, isto é, as extremidades indicam os máximos de cada condiçāo. Marque claramente cada linha com um: traço vertical.

Alerta

Sonolento

Calmo

Agitado

Forte

Fraco

Confuso

Com idéias claras

Ágil

Desajeitado

Apático

Dinâmico

Satisfeito

Insatisfeito

Preocupado

Tranqüillo

Raciocínio difícil

Perspicaz

Tenso

Relaxado

Atento

Distraido

Incompetente

Competente

Alegre

Triste

Hostil

Amistoso

Interessado

Desinteressado

Retraido

Sociável 


\section{ESCALA DE AUTO-ESTIMA DE ROSEMBERG}

Analise cada uma das afirmativas que se seguem segundo a escala abaixo e responda-as de acordo com a sua opinião sobre cada uma.

\begin{tabular}{|c|c|c|c|c|c|c|}
\hline 1 & 2 & 3 & 4 & 5 & 6 & 7 \\
\hline Discordo & Discordo & $\begin{array}{c}\text { Discordo em } \\
\text { parte }\end{array}$ & $\begin{array}{c}\text { Não tenho } \\
\text { Opinião }\end{array}$ & $\begin{array}{c}\text { Concordo em } \\
\text { parte }\end{array}$ & Concordo & $\begin{array}{c}\text { Concordo } \\
\text { Totalmente }\end{array}$ \\
\hline
\end{tabular}

Eu sinto que sou uma pessoa de valor, no mínimo tanto quanto as outras pessoas

Eu acho que eu tenho várias boas qualidades

Levando tudo em conta, eu penso que eu sou um fracasso

Eu acho que sou capaz de fazer as coisas tão bem quanto a maioria das pessoas

Eu acho que eu não tenho muito do que me orgulhar

Eu tenho uma atitude positiva com relação a mim mesmo

No conjunto, eu estou satisfeito comigo

Eu gostaria de poder ter mais respeito por mim mesmo

Às vezes eu me sinto inútil

Às vezes eu acho que não presto para nada 